Portland State University

PDXScholar

\title{
Cross-cultural Training of Chinese Managers and Workers by U.S. Companies: a Comparative Cultural Analysis of the Problems Reported by U.S. Trainers
}

Linda Vick

Portland State University

Follow this and additional works at: https://pdxscholar.library.pdx.edu/open_access_etds

Part of the International Business Commons, Speech and Rhetorical Studies Commons, and the Training and Development Commons

Let us know how access to this document benefits you.

\section{Recommended Citation}

Vick, Linda, "Cross-cultural Training of Chinese Managers and Workers by U.S. Companies: a Comparative Cultural Analysis of the Problems Reported by U.S. Trainers" (1993). Dissertations and Theses. Paper 4632.

https://doi.org/10.15760/etd.6516

This Thesis is brought to you for free and open access. It has been accepted for inclusion in Dissertations and Theses by an authorized administrator of PDXScholar. Please contact us if we can make this document more accessible: pdxscholar@pdx.edu. 
AN ABSTRACT OF THE THESIS OF Linda Vick for the Master of Science in Speech Communication presented March 5, 1993.

Title: Cross-Cultural Training Of Chinese Managers And Workers By U. S. Companies: A Comparative Cultural Analysis Of The Problems Reported By U. S. Trainers.

APPROVED BY THE MEMBERS OF THE THESIS COMMITTEE:

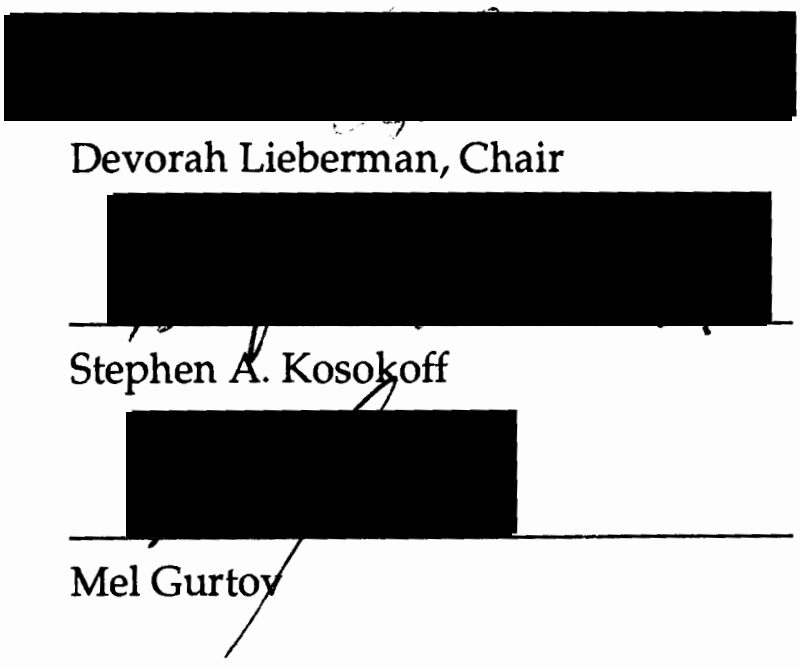

As Western business increases in China and China acquires more technology from the West, the need to effectively train the Chinese workforce becomes more important. Identifying and understanding the perceived problems that Western corporate trainers encounter when they train Chinese may lead to more effective and efficient training programs. This study examines the experiences of trainers, working for American companies, who 
have designed and implemented training programs for Chinese from the People's Republic of China. The purpose of the study is to identify perceived problems the trainers encounter and to determine whether differences between Chinese and American cultures may account for these problems. Hofstede's Value Dimensions of Cultural Difference and Hall's Low-High Context Communication Schema are used to analyze the dimensions of cultural difference operating between the trainers and students of these training programs. Hofstede's and Hall's rating of U.S. culture as an individualist, moderately low power-distance, moderately weak uncertainty-avoidance, low context culture contrasts with the collectivist, moderately high power-distance, moderately strong uncertainty-avoidance, high context Chinese culture. Hofstede suggests that when a trainer from a culture with the American configuration trains students from a culture with a Chinese configuration several problems are likely to occur. Specific examples are included in the text. In-depth interviews, lasting between two and three hours, were conducted with nine trainers working for eight American companies. The data were analyzed using an ongoing constant comparative method which produced evolving problem categories and themes. In the final analysis of the data, three major problem categories, each with several subcategories, emerged. The major problem category, Power and Authority includes problems dealing with, Bureaucratic Maze, Decision-making, Getting Things Done, Communication, and the Chinese system of Connections. The second major problem category, Training and Learning Problems describes problems pertaining to Language, Training and Learning Processes, Problem-solving, Technical Sophistication, and Selection of Trainees. The third major problem category, Work Attitudes and Behavior addresses problems relating to Motivation, Responsibility, and 
Work Habits. Using Hofstede's Dimensions of Cultural Differences and Hall's Low-High Context Communication Schema, a sample of the most salient problems are analyzed for cultural differences between Chinese and American culture.

Hofstede's and Hall's theories identify various dimensions of cultural differences between China and the U.S. which potentially lead to problems in a training context. The research revealed several perceived problems common to trainers of Western companies in training Chinese from the People's Republic. This study concludes that many of these problems can be explained in terms of the cultural differences identified by Hofstede and Hall.

Finally, recommendations are made concerning both design and implementation of more effective training for Chinese. Possibilities for future study are suggested. 
CROSS-CULTURAL TRAINING OF CHINESE MANAGERS AND WORKERS BY U. S. COMPANIES:

A COMPARATIVE CULTURAL ANALYSIS OF THE PROBLEMS REPORTED BY U. S. TRAINERS

\author{
by \\ LINDA VICK
}

A thesis submitted in partial fulfillment of the requirements for the degree of

\author{
MASTER of SCIENCE \\ in \\ SPEECH COMMUNICATION
}

Portland State University

1993 
TO THE OFFICE OF GRADUATE STUDIES:

The members of the Committee approve the thesis of Linda Vick presented March 5, 1993.



\section{APPROVED:}

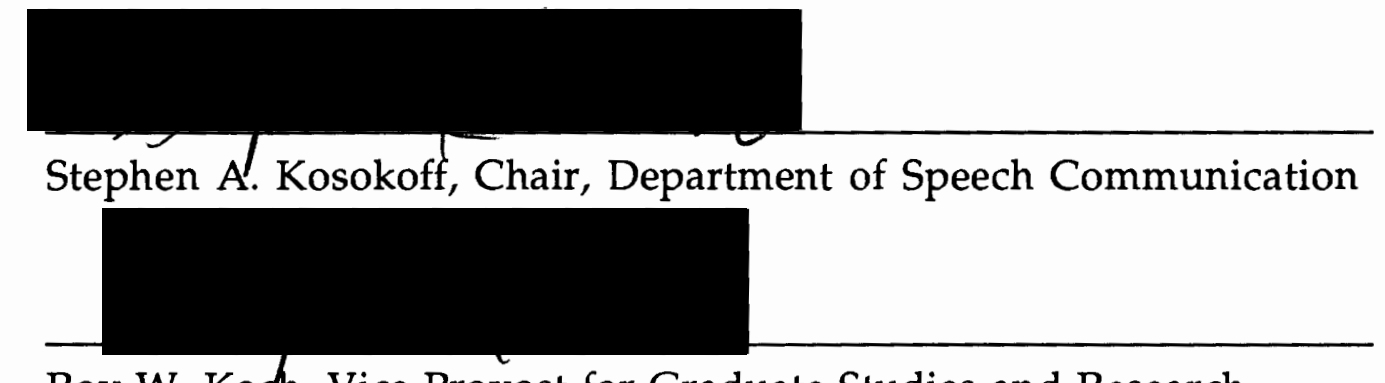

Roy W. Ko hh, Vice Provost for Graduate Studies and Research 


\section{ACKNOWLEDGEMENTS}

I can say in all honesty this thesis would never have been completed without the help and support from my husband Jack Bennett. Not only was his computer expertise invaluable, but his unfailing faith in my ability to complete this project kept me going when I had lost faith in myself and couldn't produce a sensible sentence. Jack was my sounding board, my editor and spell-checker, my cheerleader and my loving friend throughout the year it took me to write this thesis. And so, in gratitude and love I dedicate this thesis to Jack.

There are many other people I am deeply grateful to for their support, interest and willingness to listen to me talk about this thesis for such a long time. I know you are as glad as I am that it is done. My friends Terry Heffernan, Berkeley Merchant, Gail Gallaher and my sister Bev Vonfeld have been my core support group. Thank you all for your generous help, ideas, contacts and encouragement. You've been wonderful friends and true lifesavers at times.

A special thanks goes to my dear friend Qiu Lu Liang. Going through graduate school together is a cherished memory. Our many hours of conversation in our office at Portland State, over coffee and now long distance telephone calls have enriched my knowledge and understanding of Chinese culture, my own culture and myself. Thank you for your willingness to endure my questions, for your insight and suggestions, and for your support. Your friendship is precious to me. 
I would like to thank the members of my committee Devorah Lieberman, Steve Kosokoff, and Mel Gurtov for your support and interest in my work. I particularly want to thank Devorah Lieberman. You have truly been a mentor to me. Your continuous encouragement and belief in my abilities has meant more than you can imagine. You picked me up when I had fallen hard, brushed me off and got me going again. Thank you for your careful attention to my work. Your probing questions helped me to clarify my thinking and communicate more precisely. Your suggestions always made my work better. Your willingness to discuss issues of cultural differences with me without judgement reflects the true spirit of academic exploration. Thank you Devorah for your support and friendship.

I would also like to thank Milton Bennett and Janet Bennett. I am indebted to you both for pointing me in the direction of intercultural communication. I appreciate having had the opportunity to study with both of you through classes at Portland State University, the Intercultural Communication Workshops and the Summer Institute for Intercultural Communication. Milton I learned a lot from you, thank you.

Finally I would like to thank the respondents who gave so generously of their time and experience for my research. I enjoyed meeting and talking with each of you. I appreciate your openness and willingness to share, so forthrightly, your experiences and impressions of the problems of training Chinese. I feel honored that you trusted me with your stories. 
TABLE OF CONTENTS

PAGE

ACKNOWLEDGEMENTS .iii

\section{CHAPTER}

I INTRODUCTION 1

An American In China - The Foundation

Of This Study ...................................................

The Need For Training.............................................5

The Need For Cultural Awareness In

Training ........................................................10

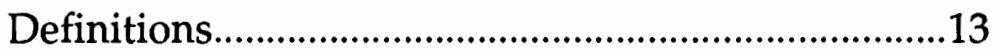

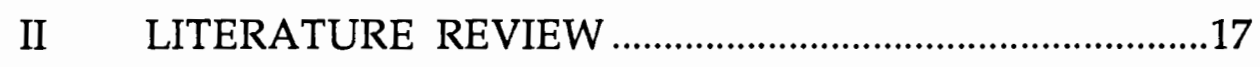

Culture Defined ......................................................17

Cultural Differences And Communication

Problems ...........................................................19

Dimensions Of Cultural Comparison......................22

Models Of Cultural Variability ................................36

China And United States Compared ........................49



Meta-Theoretical Considerations: The

Social Construction Of Reality And

Phenomenology ...............................................94

Qualitative Research Methods...............................97 
Procedures .105

IV DATA DESCRIPTION. .111

Overview Of Categories..............................................113

General Observations..............................................117

Overview Of Companies............................................119

Problems And Issues..................................................130

V ANALYSIS AND DISCUSSION ........................................193

Analysis Of Cultural Differences..............................194

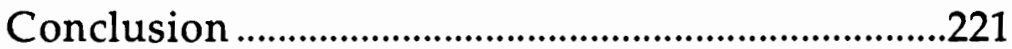

Limitations Of This Study..........................................222

Suggestions For Further Research ............................224

REFERENCES .227

APPENDICES

A LETTER TO PROSPECTIVE RESPONDENT.......................244

B INTERVIEW SCHEDULE PHASE I ..................................246

C INTERVIEW SCHEDULE PHASE II.................................249

D INFORMED CONSENT FORM …......................................254 


\section{CHAPTER I}

\section{INTRODUCTION}

This chapter discusses the motivation for this study, the significance of the research, and presents the specific research questions addressed by the study. Definitions of essential terms are also provided.

\section{AN AMERICAN IN CHINA - THE FOUNDATION OF THIS STUDY}

The stimulus for this study came from my experience teaching in the People's Republic of China in 1984-1985. I taught English language and American culture to Chinese scientists who had been chosen by their institutes as candidates for study or research abroad. At that time I had not had the benefit of training or education in intercultural communication. I knew very little about Chinese teaching methods or for that matter the proper role of the teacher in Chinese culture. But I knew that these students would be leaving soon for American or British universities. I therefore introduced them to American teaching methods and educational expectations in the hopes that they would be somewhat prepared for the new experience.

As my teaching progressed it became apparent that my methods were causing many students much confusion and frustration. And I became aware of the difficulties these men and women would encounter when they 
were transplanted into American or British universities. I began thinking about how I could change my approach to integrate the way the students were used to learning while still preparing them for a totally different foreign environment.

In addition, I met many Americans in China who were working for American companies, living in hotels and struggling to work with and understand their Chinese counterparts. I heard numerous stories of their frustrations with trying to "get things done," "make them understand how we do things in this company" or "teach them technical skills." Most of these Americans had little idea how to negotiate interactions with the Chinese and were mystified with how the Chinese system worked. I began to wonder how anything worked when people from these two cultures tried to interact.

As I pondered what was involved in mutually successful interaction many other questions came to mind regarding American-Chinese business and education: Do other American teachers and trainers of Chinese experience the same problems I did? Do trainers and teachers in successful joint ventures adapt their methods to the Chinese situation? And if so, how is it done? Why are some American businesses successful in China and others not? Perhaps there are certain qualities "successful" Americans share, such as similar communication styles, or knowledge of Chinese language. To begin exploring these broad issues I decided to focus on the experience of Americans who have trained Chinese students.

In general, scholars of intercultural communication view interactions between people from different cultures as containing inherent difficulties. These difficulties arise because individuals socialized in a particular culture 
will percieve events and make attributions for behavior in a different culture based on the values and beliefs of their own culture. Often this filtering of another culture through one's own cultural values and beliefs results in negative judgements made about the behavior and motives of the other culture. As a result of this cultural conditioning, it is very difficult to be completely nonethnocentric when examining a different culture from one's own cultural perspective. One goal of the field of intercultural communication is to explore the ways we can become more skilled at viewing other cultures nonethnocentrically - as if from the point of view of a member of that culture.

This thesis begins from this premise and therefore assumes that a training situation involving Americans and Chinese will contain misunderstandings and problems. Therefore, I decided to assume problems would exist and to concentrate specifically on identifying those problems American trainers experience in training Chinese. This thesis investigates whether there are similarities in the experiences and perceptions of trainers working for American companies training Chinese from the PRC. In addition, this study will identify cultural differences between Americans and Chinese which are influential in a training context.

This study addresses two research questions:

1. What problems do trainers, working for American companies, report they experience in training Chinese students from the People's Republic of China?

2. To what extent do cultural differences between Americans and Chinese account for these problems in a training context? 
Intercultural Communication training serves to raise our awareness of our cultural biases and provides avenues for developing intercultural sensitivity. One step in developing cultural sensitivity is becoming aware of our own cultural values and beliefs and how they influence our perceptions and judgements of another culture. This thesis examines both American cultural values and assumptions and Chinese cultural values and assumptions that may influence a training context. In Chapter $\mathrm{V}$ the analysis of the respondents' problems is an exercise in contextual evaluation. As noted by Bennett (1986) contextual evaluation is

... the ability to analyze and evaluate situations from one or more chosen cultural perspectives. Implied by this ability is both the skill to shift cultural context and the concomitant selfawareness necessary to exercise choice. The outcome of this action is a judgement of relative goodness that is specific to some identified context (p. 59).

This analysis of an intercultural situation allows one to choose a course of action based on what is deemed most appropriate given the goals and the context. As an example, an American training Chinese knows that Chinese students consider it good to help one another in a way that may be construed as cheating in an American classroom. The trainer may devise an assignment that combines both the Chinese and the American evaluations, or may decide to act in concert with only one evaluation. As Bennett says, "... the important point is the consideration of multiple evaluations" (p. 60).

In Chapter V suggestions are offered for Western or American trainers that would allow a shifting of perspectives primarily toward the Chinese evaluation of the situation. It is hoped that, in the end, the reader will be able to empathize with both the Americans and the Chinese and will 
be able to understand the situations described in this study from both cultural perspectives.

\section{THE NEED FOR TRAINING}

In 1979, after years of isolation from the West, China passed the Joint Venture Law as one of the first major steps toward opening the country to foreign investment (Sullivan, 1990). The ambitious goals for modernizing the country were aimed at increasing the per capita GNP from U. S. $\$ 300.00$ to $\$ 800.00$ by the end of the century (Deng, 1984). Seeing one billion people as a lucrative potential market, developed countries quickly responded with investments and joint venture agreements. By June 1989 the United States had become the second largest foreign investor in China with three and a half billion dollars invested (Powell, 1989).

According to the US-China Business Council the June, 1989 crackdown on students in Tiananmen Square by the Chinese government caused many foreign companies to cancel or postpone investments in China and reassess their goals and priorities. The Council notes that while the mood of foreign investors continues to be cautious in 1992, foreign investment continues to be made in China. The Chinese have also reconsidered their priorities and have become more selective in the development projects they approve for foreign involvement (U. S. China Business Council, 1990). While retrenchment and reassessment of goals and priorities is the current business environment, one component in ChinaU.S. business that continues to be of vital importance to both countries is 
the need for the education and training of China's management and workforce.

China is still recovering from the ten chaotic years of the cultural revolution when all education except political study came to a standstill. By the autumn of 1966 universities and high schools were closed and the student Red Guards were involved in factional fighting among themselves, destroying buildings and books and persecuting professors. Many experienced and knowledgeable teachers and an entire generation's education were lost (Hooper, 1985; Spence, 1990).

Many university and high school students of this "lost generation" are now the teachers, managers and administrators of China's modernization effort. In a recent survey of Chinese managers it was found that only 27.6 percent held the equivalent of an undergraduate degree (Hildebrandt \& Liu, 1988).

Foreign business people doing business in China are well aware that their Chinese workforce is badly in need of training in management techniques, engineering and technical skills (Holton, 1990; Kelley, 1984; Walker, 1979; Warner, 1986). Considering that less than $1 \%$ of the labor force have college degrees, foreign businesses contend with a severe shortage of highly trained people. And given that only $2.7 \%$ of all 18 yearolds in 1989 will go on to college, it's clear this shortage will continue. Given the narrow focus on specialization in most college programs in China, even a college degree does not necessarily prepare the graduate to contend with the range of issues involved in modern management. At the Dalian Institute of Technology, an engineering school, a senior student was asked what he was majoring in. His response was "Cranes." The student 
had taken six courses in cranes and nothing else (Holton, 1990). China's approach to training new workers is also highly specialized. An individual worker is generally trained in a single skill to perform one task in production (Warner, 1986).

It is now acknowledged by high level Chinese cadres that training and education are among the highest priorities if China is going to be able to compete in the modern industrialized world. During an interview at the annual, 1986 Davos symposium in Switzerland, vice chairman of the State Economic Commission, Zhu Rongji said

There is a gap in technology with the developed countries but the gap in management is even larger. So in some ways the training of managers is more important than acquiring technology from abroad (Anonymous, 1986, p. 55).

China has responded to this need in several ways. Thousands of students and scholars have been sent abroad for university education and research to bring back to China new knowledge and expertise. According to Zikopoulos (1990) by 1990 there were 39,600 Chinese students from the People's Republic of China studying in American universities. In addition, many management, technical and vocational schools and training centers have been established in China (Warner, 1986). Several of these training centers are cooperative ventures with foreign governments, universities and businesses (Bing, 1984; Keck, 1985; Lee, 1985; Speidel, 1985). In 1980 the U. S. Department of Commerce with China's State Council and Ministry of Education created the National Center for Industrial Science and Technology Management Development in Dalian. Mid-level managers are taught business and management courses by American and Chinese faculty 
with guest lectures by American business people (Bing, 1984). This investment by the U.S. government and businesses indicates a clear commitment to continuing participation in China's educational system. American trainers and teachers involved in this educational exchange need to be aware of the problems they may encounter in Chinese classrooms.

Another way China is working to acquire the training needed for its workforce is by requiring foreign companies which receive approval for manufacturing and joint venture contracts to provide extensive specialized training for Chinese managers and workers. Many foreign companies vying for contracts with China have found that winning the contract increasingly depends on the training they are willing to provide along with the technology (Ondrik, 1984; Sensenbrenner, 1986). Foreign companies interested in oil exploration in China in the early 1980's found that training was mandated by the Chinese government as one of the top three conditions for receiving contracts to develop Chinese oil resources (Burns, 1984). Ondrik (1984, p. 7) concluded from his study of foreign training of Chinese oil industry workers that

... in the future any company with substantial sales will probably face increasing pressure to engage in technology transfer and training... . They [Chinese] expect companies to make front-end commitments to train personnel by offering extensive classroom, on-the-job, and study-abroad programs.

The need for training in China and the need for American companies to provide training for Chinese workers and managers is well recognized. Given the importance that China places on training and the recognition that the pool of workers available to American enterprises in China have limited skills, it behooves American companies to make the quality and 
effectiveness of their training a high priority. The profits that American companies gain from their China joint ventures may depend on how well the Chinese learn to operate the new technology, meet production goals and maintain the company's quality standards. The ability of the Chinese to operate American-made technology appropriately and to maximize its potential within the Chinese context depends in large part on the quality and appropriateness of the training they receive.

Increasingly, reports on corporate training of Chinese are appearing in management and training literature. And the problems foreign companies are experiencing appear to be fairly common. Westerners who have taught or trained Chinese students have most often cited the following as problematic: students' lack of verbal response and interaction, students' inability to analyze and lack of creativity, English language deficiency, inappropriate selection of students, student's low motivation to work hard, inappropriate fit between Western and Chinese reality, poor quality control on the job, lack of resources, low learning transfer and erosion of training skills once on the job, a mysterious Chinese decision-making process, and a variety of logistical issues (Dalton, 1990; Holton, 1990; Ondrik, 1984; Porter, 1990; Sensenbrenner, 1986). Some of these reports provide analysis of these problems in terms of cultural differences and a few offer suggestions for adapting to the Chinese context. It is hoped this study will provide a foundation for future exploration of ways trainers can develop culturallysensitive programs that effectively train Chinese in the use of American technology and management systems. 
THE NEED FOR CULTURAL AWARENESS IN TRAINING

It is becoming increasingly accepted by educators and trainers that training programs are more successful if cultural factors are considered in the design and presentation of the training (Adler \& Kiggundu, 1983; Bourgeois \& Boltvinik, 1981; Seelye \& Wasilewski, 1979; Swanland, 1979; Walker, 1979). It has also been found that the successful transfer of newly learned skills by a trainee to his or her actual work situation is largely dependent upon how well the training program was adapted to the trainee's particular needs, strengths, learning styles and context (Dalton, 1990; Hayes \& Allison, 1988; Honey \& Mumford, 1983; Pusch, Patico, Renwick \& Saltzman, 1981; Swanland, 1979; Wexley \& Latham, 1981). The evidence is growing that for training to be effective, individual and cultural differences of the trainees must be factored into the design and presentation of training programs.

This means that American corporate trainers must develop an understanding of both Chinese and American cultures. They need to become aware of the significant cultural differences that come into play when people from these two cultures interact within an American training context. And they must be able to translate that understanding into designing and presenting culturally-sensitive training programs that meet the needs of their companies and the needs of the Chinese.

According to Harris and Moran (1987), American businesses that don't pay attention to culture stand to lose as the marketplace becomes more competitive with increased globalization. Those who are sensitive to cultural differences and learn to manage with an intercultural perspective 
will be the most successful. This involves awareness of the influence of cultural conditioning on one's own and others' behaviors, values, self image, standards and expectations. Successful intercultural management also requires that one be willing to consider alternative realities and the ability to be empathetic. They conclude, "Such an individual tries to adapt modern principles of administration to the indigenous circumstances ..." (pp. 9-10).

The recognition of the critical role that culture plays in international business has not yet been fully accepted by American business people (Stewart \& Bennett, 1991). In a 1978 videotape, Stewart (1978) points to the financial losses in Iran, growing foreign competition and declining U. S. productivity as evidence of the need for American business people to become interculturally sensitive. He suggests that Iran is a good example of how technological modernization, which depended on foreign expertise and advice, neglected ideology and culture and resulted in national crisis. He says, "The Iranian experience strongly demonstrates that we ignore culture at our financial peril." Stewart goes on to describe the benefits derived from cultural awareness in the business context:

- an understanding of deep culture [e.g.. values, beliefs, patterns of thought] facilitates interpersonal interaction,

- awareness of cultural factors helps us identify cultural resources,

- understanding culture softens culture shock during periods of adjustment to other societies,

- familiarity with cultural differences helps us make objective judgments about the strengths and weaknesses of groups of people we work with ... . By identifying cultural strengths and weaknesses of our foreign partners and integrating them into our own cultural patterns, the results of our interactions can be far more satisfying and productive. 
American business experience with China is still very new; only 20 years have gone by since the first American companies committed to projects in China. But as the experience accumulates, more information and analysis is available on the successes and failures of these projects (Baldinger, 1990; Bing, 1988; Green, 1990; Macleod, 1988; Mann, 1989; Nelson, 1992; Sensenbrenner, 1988). Reports increasingly focus on the necessity of developing intercultural communication skills in order to be successful in international business (Ackerman, 1976; Adler, 1986; Barnes, 1985; Bochner, 1981; Bond, 1986,1990; Dalton, 1990; Fisher, 1980; Harris \& Moran, 1987; Lindsay \& Dempsey, 1985; Schnapper, 1979). McCaffrey and Hafner (1985) reported on a USAID project that involved sending six American consultants to an Asian country to conduct a variety of assignments. All of the consultants had overseas experience but one had extensive crosscultural training. When performance evaluations were carried out by the host government and AID it was found that the consultant receiving the highest evaluation was the one with cross-cultural training.

While several intercultural communication researchers have reported on cross-cultural orientation and training designed to develop intercultural sensitivity and skills (Martin, 1986), there has not been much research that links intercultural communication with individuals training in a different culture. Given the growing evidence of the need for and the effectiveness of intercultural sensitivity in international business, American business people and teachers should gain from knowing more about what happens when Americans train Chinese. 


\section{DEFINITIONS}

\section{Orientation}

In typical orientation programs the goal is to acquaint a person, new to the organization, with the existing situation through a process of socialization. Usually, "This involves learning the attitudes, standards, and patterns of behavior that are expected by the organization and its various subunits" (Wexley \& Latham, 1981, p. 103). The most common strategy for accomplishing the goals of orientation programs is cognitive - the verbal or written transmission of factual information about the company.

Bennett (1986) describes orientation as the "who, what, when and where" while training additionally provides the "how."

\section{Training}

Miller (1979) defines training as

the process of affecting change in an individual human's behavior often applied to the acquisition of limited, job-related skills... . Training supplies the specific skill, knowledge or attitudes needed to meet goals of organization (usually performing specific tasks within specific productivity standards) (p. 3).

According to Wexley and Latham (1981) the overall purpose of training and development is to facilitate the learning of knowledge and skills necessary for successful performance of one's job. Any training program may involve three goals:

1) to improve an individual's level of self-awareness,

2) to increase an individual's skill in one or more areas of expertise, and 
3) to increase an individual's motivation to perform his or her job well (p. 4).

To accomplish these goals, there are three basic training strategies aimed at improving the individual's job performance:

1) engaging cognitions (i. e. thoughts and ideas),

2) influencing and modifying behaviors, and

3) changing the environment in which the person is working (p. 5).

\section{Education}

Education, as distinct from training, adds the "why" perspective to the groundwork provided in orientation and training (Bennett, 1986). The educational perspective provides the theoretical underpinnings of the learners objective. Bennett believes that all training should involve the "why" perspective; therefore she refers to both educators and trainers and trainees and students interchangeably. This will be the approach used in this study.

\section{Learning transfer}

Learning transfer is "the extent to which what was learned during the training is used on the job" (Wexley \& Latham, 1981, p. 74).

\section{Management}

Management embraces a spectrum of organizational process and skills including defining organizational goals and planning, developing and overseeing budgeting, inventory control, resource allocation, performance 
planning and evaluation, supervision, and program evaluation (Redding \& Wong, 1986; Von Glinow \& Teagarden, 1988).

\section{Technology Transfer}

Spencer (1970) defines technology transfer as

... a planned and rational movement of information and technique on how to perform some task, simple or complex. It should be distinguished from diffusion, the historic, unplanned movements of technical or social items from one country to another or from one user to another in the same system... The present-day technology transfer results from carefully considered planning and programming for controlled action, with feedback and monitoring of the success or failure of the results (p. 29).

Historically, China has been concerned with acquiring hardware the equipment, components and raw materials. But it is the transfer of software (the technical know-how to operate the equipment) which requires training and consulting follow up, that allows for independence from foreign expertise (Hawes, 1980; Von Glinow \& Teagarden, 1988).

\section{American}

This author recognizes that America refers to North and South America and is used to identify many different cultures. North American has been suggested as a more appropriate term when referring to people who are citizens of the U.S. but that assumes considerable homogeneity with Canada and Mexico which cannot be assumed. There is also considerable historical precedence for calling citizens of the United States of America, Americans (Stewart \& Bennett, 1991). Therefore, for simplicity 
America, Americans (Stewart \& Bennett, 1991). Therefore, for simplicity and ease in the use of language in this thesis American will be used to refer to the people and culture of the United States of America.

\section{Foreign and Western}

Foreign is used throughout this thesis to refer to all cultures outside mainland China. This term includes Westerners and people from Taiwan, Hong Kong and other Asian cultures. It is a term commonly used in management and training literature to refer to non-mainland China cultures. Western is used to refer to cultures of European origin and cultural tradition. 


\section{CHAPTER II}

\section{LITERATURE REVIEW}

The purpose of this chapter is to examine the existing literature pertaining to the issues of Culture, Chinese culture, American culture and the training and education of Chinese students. A discussion of the dimensions of cultural comparison including a description of Hofstede's Value Dimensions and Hall's High-Low Context Communication Schema is provided along with other theories that have been associated with Hofstede's and Hall's theories. Several potential problems, proposed by Hofstede, that can arise between different cultures in a training context are examined in relation to Chinese and American cultures.

\section{CULTURE DEFINED}

The way a person makes sense of and orders the world derives from the culture in which he or she was raised and his or her unique individual biological traits and life experiences. Culture provides the members' foundational perceptual structures including cognitive processes and communication patterns which are then built upon and modified through personal experience. Frake (cited in Ehrenhaus, 1983) cautions against seeing culture as imposing a cognitive map upon persons, but suggests looking at it as providing a set of principles for map-making and navigation. 
Culture then, provides the structure that organizes reality in a way that allows human beings to interact with each other with some predictability and which allows them to accomplish their goals.

Culture has been defined most simply as "the form or pattern for living" (Porter \& Samovar, 1988, p. 19), as "the learned and shared behavior of a community of interacting human beings" (Useem, Useem \& Donoghue, 1963) and as communication (Hall, 1959). But for the purpose of this thesis the definition Kroeber and Kluckhohn (1952) synthesized from over 150 definitions is the most useful. It provides the basis for an analysis of how culture affects its members' behavior and supports the social construction of reality.

Culture consists of patterns, explicit and implicit, of and for behavior acquired and transmitted by symbols, constituting the distinctive achievements of human groups, including their embodiments in artifacts; the essential core of culture consists of traditional (i.e.., historically derived and selected) ideas and especially their attached value; culture systems may, on the one hand, be considered as products of action, on the other as conditioning elements of further action (p. 180).

This definition does not restrict culture to defined geographical or national groups but can be used to describe any number of groups that identify as a culture. For example, in recent years organizational communication and management theorists have been describing organizational culture or corporate culture and have been using this distinction successfully in diagnosing problems and suggesting change within organizations (Dinges \& Maynard, 1983; Frost, Moore, Louis, Lundberg and Martin, 1985; Pettigrew, 1979; Van Mannen \& Schein, 1979). The roles performed by members of organizations can be compared cross- 
culturally. Role cultures within organizations found in different national cultures can share more similarities than different role cultures within the same national culture. For example, corporate CEO's from the United States and France may share more similarities as a function of their roles than they share with farmers within their own national cultures (Harris \& Moran, 1987; Samovar, Porter \& Jain, 1981). This distinction is useful as this study focuses on trainers in corporate America interacting with workers and managers in industrial China.

\section{CULTURAL DIFFERENCES AND COMMUNICATION PROBLEMS}

Communication is the primary means for the creation, maintenance and objectification of social reality. Culture and communication are linked in a continuous process of mutual creation, modification and expression it is through culture that people learn to communicate (Prosser, 1978;

Samovar, Porter \& Jain, 1981). It is culture which determines

... who talks to whom, about what, and how the communication proceeds, it also helps to determine how people encode messages, the meanings they have for messages, and the conditions and circumstances under which various messages may or may not be sent, noticed, or interpreted. In fact, our entire repertory of communicative behaviors is dependent largely on the culture in which we have been raised. Culture consequently is the foundation of communication. And, when cultures vary, communication practices also vary (Porter \& Samovar, 1988, p. 20).

It has been well established that culture influences a person's world view and behaviors. Within the field of communication it is generally agreed that communication is facilitated between people when their values, 
beliefs, world views, languages and so on are similar (Bell, 1981; Blau \& Schwartz, 1984; Gudykunst, 1983; Lazarfeld \& Merton, 1954, Rogers \& Bhowmik, 1970; Simard, 1981). Similarity in cultures and personal experiences of people trying to communicate increases the probability of shared norms and expectations (Brislin, 1981). Therefore fewer obstacles exist in the sharing of the meaning and intentions of their messages. Finding similarities between oneself and another person is satisfying and is the basis for relationships (Knapp, Ellis \& Williams, 1980). Having one's beliefs and opinions reflected back in conversation is validation that one's sense of reality and self has foundation and is valuable. Communication between people who are similar is easier, with less ambiguity and uncertainty. Predictions about what will happen and what is expected, and the attributions made about each other's behavior will be more accurate (Brislin, 1981).

The pervasive and unconscious nature of culture leads its members to believe that it represents reality and they come to expect the same unstated rules of behavior and communication to be standard for all environments. As a result, communication between people from different cultures with different assumptions, codes, normative behaviors and expectations can be laden with difficulties and misunderstandings. According to Kim and Rubin, "When confronted with situations in which assumptions and premises acquired in childhood are called into question, the communicators experience uncertainty and conflict" (Kim \& Rubin, 1988 , p. 310). This challenge to their expectations of what ought to happen in a given situation causes feelings of anxiety (Stephan \& Stephan, 1985). To resolve these feelings they call upon their familiar categories and stereotypes 
to help explain the other person's behavior and to reduce the uncertainty in the situation (Gudykunst, 1988). When an individual feels the taken-forgranted rules have been broken by another person, he or she often incorrectly attributes a negative explanation for the other's behavior. Instead of an interaction which results in understanding and mutual satisfaction they are both left with negative stereotypes being reinforced.

To become interculturally sensitive a person needs to reframe attitudes and conditioning that regard differences as negative and something to avoid. Rather differences need to be viewed as resources that allow entrance to new and potentially useful ways of looking at the world. This reframing requires first an awareness of one's own cultural assumptions and an understanding of the power of cultural conditioning on one's own behavior. Second, one needs to assume that differences rather than similarities will characterize intercultural encounters and have the willingness to consider alternative realities (Barna, 1982). This opens the person to new interpretations of behavior. Categories that are more appropriate for the intercultural situation can then be formed and used with success. Third and finally, learning about other cultures' value and belief systems and other cultural aspects will provide information that can be used in making appropriate attributions about another person's behavior in an intercultural situation. Brislin (1981) and Triandis (1973) emphasize that the ability to make appropriate attributions when interacting with a person from a different culture is one of the most important skills for becoming interculturally competent.

The cross-cultural training context, where the trainer is a member of one culture and the students are members of another, is rife with potential 
communication problems and mis-attributions. Hofstede (1986, p. 302) points out that all programs dealing with economic development for lowincome nations involve a cross-cultural learning situation in which the teacher is a representative of a richer nation and the students are from the poorer nation. The cultural and economic differences create potential problems for both the teacher and the students. But, he goes on to say, there is very little research or literature that addresses this situation.

It is hoped that this study will contribute to advancing the cultural sensitivity of American trainers of Chinese by raising awareness of the common problems trainers experience and how cultural differences between Chinese and Americans influence the training context.

\section{DIMENSIONS OF CULTURAL COMPARISON}

In order to examine the aspects of culture that have the most influence on the training context, it is important to distinguish between what Stewart and Bennett (1991, p. 2) describe as subjective culture and objective culture. Objective culture is the material and institutional aspects of culture that have been the usual objects of study by social science and the humanities. The arts, crafts, literature, social customs and political and economic systems are examples of objective culture. These aspects of culture tend to reflect the subjective aspects of culture, the psychological or unconscious features of culture. These are the cultural beliefs, attitudes, values, world views and systems of social organization and communication processes that influence perception, thinking, and memory and which are reflected in people's behavior (Samovar, Porter \& Jain, 1981). 
Selected subjective and objective aspects of culture will be examined in order to understand how the problems American trainers experience training Chinese students are influenced by culture. Cultural Values and Assumptions, Cognitive Processes, Social Organization and two models of cultural variability, Hofstede's Value Dimensions and Hall's High-Low Context Communication Schema are used to explore the cultural differences between American and Chinese cultures.

\section{$\underline{\text { Values }}$}

While values per se cannot be seen they are reflected, often symbolically, in people's behavior. Researchers, for example, have identified values through the analysis of verbal and written expressions (Eckhardt and White, 1967; Fallding, 1965; Williams, 1970), social customs and rituals and analysis of people's justifications for their behaviors (Scott, 1965).

Much intercultural communication research has focused on cultural values and the relationship values have with communication (Condon and Yousef, 1975; Sitaram \& Haapanen, 1979). In fact, Sitaram and Haapanen propose that values are the most important variables in intercultural communication (p. 158). According to Sitaram and Cogdell,

Value seems to be the basis of all decisions that a person makes. It tells him how something ought to be and for what his life is worth living, worth fighting, and even worth dying. Since value is so important, it is also necessary to influence others to accept it as the only end state of life. Value thus becomes the standard for a person to judge his own and others' actions (Sitaram \& Cogdell, 1976, p. 163). 
Values are the evaluative, underlying principles of our perceptual systems which "include qualities such as usefulness, goodness, aesthetics, need satisfaction ability, and pleasure production" (Samovar, Porter and Jain, 1981, p. 40). They tell members of a culture what is right and wrong, good and bad, true and false and so on. Values are expressed as normative rules that define what behavior is obligated, prohibited, permitted or preferred by a culture (Shiminoff, 1980). They are usually outside of people's awareness and taken for granted. These guidelines of appropriate and inappropriate behavior produce expectations in a person that others ought to and will behave in a particular way or be considered in violation of these unconscious rules.

Identification and comparisons of cultural values often appear to be statements of absolutes. It must be understood that value statements made about a culture are generalizations that assume some differences in the acceptance and expression of the value within that culture. The acceptance and expression of a value or belief should be perceived as a continuum, with the majority of the members of a culture generally accepting and adhering to the value and associated behavior but with others at the extreme ends of acceptance and rejection. By stating these generalizations as tendencies, this researcher tried to be sensitive to not making absolute statements about Chinese and American values and behaviors.

All discussions of values and value differences must be understood within a context and within relationship with other values, beliefs and expectations. No value is isolated but its power to influence and guide behavior is affected by the situation and by other values that may be relevant. In one situation a particular value may appear as of primary 
importance in guiding behavior while in another it may be subsumed, modified or even contradicted by another primary value.

Several reports on a number of studies of Chinese values were reviewed by Yang (1986). Using Kluckhohn and Strodbeck's (1961) value orientations, traditional Chinese cultural values have been identified as follows: collectivism with a hierarchical emphasis in human relationships, a past orientation to time, a preference for inner development on the activity modality, and submission to nature. These values are expressed in a culture where identity rests in the individual's relationship with the group; tradition is relied upon to guide the present and future and change is slow. Relationships are formal and hierarchical, and there is a sense that people have very little power to affect the world. Research (Lin, 1978; Yang \& Chang, 1975) in Taiwan and Hong Kong indicates a shift away from the traditional values in these cultures, toward values that have been associated with American culture.

American values have been identified on the Kluckhohn and Strodbeck scale as individualism, future orientation, an achievement or doing activity orientation, and mastery over nature (Green, 1979; Nordlie, 1968; Samovar, Porter \& Jain, 1981; Stewart \& Bennett, 1991). In the United States these values have led to a culture where each person is considered to have a separate identity and is worthy of respect in his or her own right. There is a belief that change is good and progress is considered a process of continuous betterment. This has led to a high value of technological development and materialism, and the belief that anyone can better himself or herself if given the opportunity. Work and productivity is the way to gain recognition, material comforts and power. And there is an overriding 
belief that human beings can and should control and exploit nature for the betterment of humanity (Samovar, Porter \& Jain, 1981).

Using a Chinese adaptation of Gordon's Survey of Interpersonal Values, Tarwater (1966) compared results obtained from Chinese in Taiwan and Hong Kong with data on Americans. He found the Chinese higher in the value of conformity and benevolence and lower on interpersonal support, social recognition, and leadership than Americans. Benevolence or Jen is a central Chinese virtue that formed the basis of Confucius' philosophy (see Confucian Tradition and Chinese Collectivism p. 51). In a 1979 study by the Chinese Psychological Association (cited in Bond \& Hwang, 1986) Chinese rated filial duty and respect for parents as the primary value followed by loving and protecting their own nation, cultivating good character and regard for public welfare. Among the least important values were enjoying the present and being independent.

Yang (1981) describes traditional Chinese values as "social orientation," one end of a spectrum, with "individual orientation" at the other end. A member of a socially oriented culture acts according to "external expectations and social norms rather than be guided by internal desires or personal integrity" (p. 161). The socially oriented person must concern him/herself with protecting the social self in order to function as a part of a social network. This focus on the social network results in a number of concerns:

... submission to social expectations, social conformity, worry about external opinions, and non-offensive strategy in an attempt to achieve one or more of the purposes of reward attainment, harmony maintenance, impression management, face protection, social acceptance, and avoidance of 
punishment, embarrassment, conflict, rejection, ridicule, and retaliation in a social situation (Yang, 1986, p. 161).

A study of Chinese values by Argyle, Henderson, Bond, Iizuka, and Contarello (1986) found a number of norms relating to obedience, avoiding loss of face, maintaining harmonious relations in groups and restraining emotional expression. The Chinese tend to believe that showing joy or sadness may disrupt harmony by imposing one's feelings on others.

Therefore they usually avoid emotional expressions (Bond \& Hwang, 1986, p. 231).

\section{Cognitive Processes}

Cognitive processes or patterns of thinking are rooted in the cultural structure of reality. The way a person orders and uses concepts is a reflection of the "map-making" process of category development. Hofstede (1986), citing the findings of Cole, Gay, Glick, \& Sharp (1971), Cole \& Bruner (1971), Scribner \& Cole (1981) and Redding (1980) point out that differences in cognitive development are determined by culture. Each culture guides its members to perform tasks, solve problems, and create new artifacts or ideas in a way that is consistent with its values and beliefs.

There are two dimensions to cognitive style that have been specifically related to learning: mode of abstraction and field articulation (Cohen, 1969). Mode of abstraction refers to the way an individual organizes perceptual information from the external environment and conceptually categorizes it. Field articulation refers to the discernment of figure from ground. Two major styles of conceptual classification have been identified:

1) the descriptive-analytic (also referred to as inferential-categorical by Chiu, 
1972) has been associated with Americans, and 2) the relational-contextual has been associated with Chinese (Cohen, 1969; Kagan, Moss and Sigel, 1963). The descriptive-analytic style is characterized by field independence and an analytical mode of abstraction while relational-contextual style uses a descriptive mode of abstraction and field dependence. Messick's (1976) description of field dependence and field independence can be used as a description of the two cognitive styles identified by Cohen and Kagan et al.

Field independence [analytical] versus field dependence [relational] refers to a consistent mode of approaching the environment in analytical, as opposed to global, terms. It denotes a tendency to articulate figures as discrete from their backgrounds and a facility in differentiating objects from embedding contexts, as opposed to a counter tendency to experience events globally in an undifferentiated fashion. The field-independent pole includes competence in analytical functioning combined with an impersonal orientation, while the field-dependent pole reflects correspondingly less competence in analytical functioning combined with greater social orientation and social skills (p. 14).

Field dependence appears related to strict socialization that encourages obedience and parental authority (Hoosain, 1986). This strict socialization tends to "discourage active searching modes of behavior which are conducive to the testing of hypothesis and experimentation with formal thought" therefore independence of thought and formal operations are less developed in "socially-oriented" cultures (Chiu, 1972, p. 236). Yang (1986, p. 54) points out that in "socially-oriented" cultures "there is less initiative to act independently and less perceived capacity to influence events and therefore less opportunity to exercise the capacity to assess the outcome of such events." 
Cohen's (1969) examination of these cognitive styles, which is supported by Grieve and Davis (1971), leads her to believe that socialization in one style makes it very difficult to use the other style. When teaching and teaching material is presented in a style different from the student's style, learning is more difficult and less successful. Therefore, some researchers suggest that matching teacher-student cognitive styles facilitates learning and effective communication between teacher and student (Witkin, 1976). In a study by Grieve and Davis (1971) it was found that the more field-dependent the student the more effective was the discovery method of instruction. The discovery method involves the student in interaction with the teacher which is a context that suits the social orientation of the field dependent student.

On the other hand Wapner (1976) contends that matching styles between teacher, teaching material and students facilitates subject-matter achievement while mismatching styles, which produces contradiction and obstacles, is necessary to facilitate individual development and creativity. He also proposes that mismatching cognitive styles encourages development of different styles that can be used in different contexts as the need arises.

A number of other characteristics have been associated with cognitive style by researchers. For example, field-dependent people tend to use the social frame of reference to define their attitudes, beliefs, feelings and self image within a social situation (Witkin, 1976, p. 43). Field-dependent persons are also guided by authority figures and peer group. They tend to be better at remembering faces and verbal messages that are more social in context. They use fewer personal pronouns, and make fewer self references. 
They are simply more attuned and sensitive, than field independent persons, to the social environment (Witkin, 1976, p. 44).

Witkin (1976) contends that cognitive style also determines problemsolving behavior. Field-dependent persons, who tend to view items and events as wholes, not separate parts, also tend to approach problem solving in a similar way. Solving a problem by separating elements out from the context and restructuring the problem material so the construct can be used in a different way is the process used by analytic, field-independent individuals.

Chinese have been found to primarily use a relational-contextual cognitive style (Chiu, 1972). This means Chinese prefer to categorize objects and events on the basis of interdependence and relationship. They tend to be field dependent in that they use the environment as the frame of reference and they tend to perceive globally, that is to see things as wholes rather than as parts as Americans tend to do (Chiu, 1972, Hoosain, 1986; Yang, Tsai \& Hwang, 1963, cited in Bond, 1986). The dominant American cognitive style is descriptive-analytic. Americans are trained to perceive objects and events by dissecting them into parts, associating them in cause and effect relationships and finally developing a general principle.

Bond (1991) reports on a study where Taiwanese and American children were asked to pick, from an array of three familiar items, two items that were alike. The Taiwanese children tended to pair objects on the basis of similarities in overall appearance such as 'both people are fat,' and on the basis of an assumed relationship 'the man is married to the woman.' The American children were more analytic in their groupings. They chose items on the basis of some attribute such as 'both animals have fur' or inferential 
such as 'both animals are mammals.' "American children join the objects after decomposing them into parts; Chinese children join the objects after considering them as wholes" (p. 24).

This orientation to holistic perception may reflect the Chinese spirit of harmony (Yang, 1986).

In this spirit, the Chinese will try to synthesize the constituent parts into a whole so that all parts blend into a harmonious relationship at this higher level of perceptual organization. In fact, Chinese people tend to be highly sensitive to outside conflicts and inconsistencies, and they usually manifest a strong tendency to find some way to reconcile the incongruent parts in a higher integrated framework. This powerful holistic approach is widely found not only in the realm of Chinese intellectual activities, but also in the realm of Chinese practical and ethical life. From this perspective, the famous Chinese collectivism may be seen as a special application or case of the Chinese holistic orientation operating in the domain of social life (pp. 147-148).

Samovar et al. (1981) compare the Western and Eastern patterns of thinking as a way of illustrating the differences in cognitive processes, forms of reasoning and problem solving. They point out that in the Western way of thinking there is an objective concrete world out there that can be known by following correct logical processes. Logic, rationality and human activity are highly valued in the solution of problems. However in the Eastern way of thinking, illustrated by Taoist thought, truth is the active agent and will make itself known by one's waiting and allowing the situation to unfold ( $p$. 57). Needless to say this example illustrates the problems that may arise when people from these cultures approach solving a problem together. The question arises as to whether they would agree that a "problem" even exists that needs solving. 
The Chinese have been described as being very practical and as valuing utility and concreteness in their thinking (Nakamura, 1964; Pedersen, 1983). In a 1972 study, Sue and Kirk compared Chinese American and non-Chinese American students on a test of practicality. Chinese students scored higher on Practical Outlook which is a tendency to evaluate ideas on the basis of their immediate practical application.

Researchers assume that the relational-contextual, field dependent cognitive style of the Chinese and their practical approach to problems would limit originality and creativity, and that appears to be the case in creativity tests. Liu and Hsu (1974) tested Chinese in Taiwan on the Torrance test of Creative Thinking and compared the results with data on Americans. On all three measures, idea fluency, originality and flexibility, the Taiwan norms were below the American norms. Liu (1986) reports on studies where Chinese children have scored higher on space conceptualization and lower on verbal ability when compared to Jewish, Black and Puerto Rican American children. Verbal ability has been related to originality and creativity while space conceptualization has been associated with the learning of Chinese characters (pp. 84-85).

In a study by Lesser, Fifer, and Clark (1965) Chinese performed well in space conceptualization and reasoning tests where the tests presented welldefined problems with explicitly stated goals. Liu (1986) provides an explanation for why Chinese perform well on this type of problem and less well on more open-ended problems requiring a number of solutions. He suggests that Chinese children acquire three behavioral rules early in their socialization that tend to influence their subsequent cognitive development. The three rules are these: 
1) If your superiors are present, or indirectly involved, in any situation, then you are to respect and obey them.

2) If the purpose is to acquire the knowledge contained in an article, then the best strategy is to memorize the article.

3 ) If the purpose is to acquire any new cognitive skill, then the best strategy is to practice repeatedly (pp. 78-82).

... Chinese subjects would suffer in solving ill-defined problems that require subjects to generate as many ideas as possible. There are two reasons for this conjecture. First, the 'respect superiors' rule is incompatible with a stimulus condition that calls for generating as many ideas as possible ... [and perhaps] Chinese have acquired, and have performed according to, more behavioural rules than Westerners [and therefore would transfer this behavior to a test situation] ( $p$. 86).

It is argued that higher levels of education and the mastery of certain disciplines requires more than description. Analytical skills that inductively identify less obvious patterns and associations, discover underlying assumptions and themes, and trace the directions of arguments are considered necessary for advanced education in the Western world. Because these are precisely the skills Chinese students are weakest in psychologist Norman (cited in Bond, 1991, p. 26) suggests Chinese students are

ideally suited ... for additive and fine-tuning approaches to learning. Neither adding to a core of existing knowledge nor honing one's established skills challenges what one has already mastered. Instead it 'polishes the jade'. Additive and fine tuning strategies are tailor-made for subjects like physics, chemistry, computer science, and engineering which Chinese graduate students have come increasingly to dominate in many Western universities.

Creative problem solving, where several unique ideas or solutions are produced to solve a problem and/or a problem is reframed in a way that 
allows for new solutions, has been associated with Western scientific investigation and with modern industrialization. American culture values creativity very highly. American technological development, which considers anything new as better, is an outcome of American creativity and the ability to come up with unique solutions and ideas. Very early in school, American children are encouraged to think up new and different ways of doing things or solving a problem. Trial and error is encouraged and one is always prompted to learn from one's mistakes and to try again. According to Bond, "Teachers guide students to look for the basic, underlying principle; to look beneath the surface of things to see the relationships among the elements of a problem" (Bond, 1991, p. 24).

Several conditions have been identified as necessary for creative problem solving. The person must have some degree of competence, he/she must be curious and enthusiastic about the problem and must feel capable of solving the problem. In addition, there must be some security in the environment that allows the individual to explore and question while experiencing a moderate amount of the stress of challenge (Pelz, 1976). Given these characteristics, American managers, engineers, scientists and teachers tend to believe that the development of analytic cognitive skills and problem-solving approaches is necessary for using modern management systems, and for creating and often using modern technology. As a result, American training programs are generally based on these values and utilize techniques that require these skills.

This could be problematic when Americans train Chinese where all of the conditions for successful creative problem solving do not exist. As Bond (1991) points out the Chinese do not encourage creativity because of its 
"unsettling, revolutionary capacity" that may create luan (chaos) (p. 26). Creativity requires the conditions described above, and encourages experimentation, individual expression, and unconventional ways of thinking. In addition "its favours are not bestowed exclusively on those already designated as leaders, scholars, and established artists" and cannot be controlled (Bond, p. 26).

\section{Social Organization}

The way in which a culture organizes people into groups, structures organizations and institutions, and identifies roles and hierarchies within these social organizations has a significant influence on perception and communication. Likewise group structure and organizational systems reflect values and cultural assumptions. The roles assigned to a particular social position also have specific behaviors prescribed as appropriate and expected.

Two cultural patterns of social organization that have a significant bearing on communication between Americans and Chinese are equality and conformity. The Chinese values of collectivism, hierarchical relationships, and a past orientation to time tends to lead to social systems based on inequality and a high level of conformity to traditional values. The American values of individualism, egalitarianism, and a future orientation to time assume social systems based on equality, horizontal relationships and conformity to progress and change. In interactions between an American and a Chinese person the American is likely to work toward treating the Chinese as an equal to him or herself and equal to other individuals present and will wish to be treated likewise (Samovar, Porter, \& 
Jain, 1981). The assumption is that one becomes more comfortable and able to communicate more freely when interacting between equals. The Chinese will likely be acutely aware of the status and authority positions of all the individuals present and expect particular, formalized behavior appropriate to each person's status. To a Chinese person being called by the first name, as Americans tend to do as a way of equalizing relationships, could be overstepping the bounds of acceptable behavior and might be insulting.

A culture's educational system is a good example of the power of social organization in maintaining and changing cultural assumptions. Schools not only teach the subjects that the culture deems important but also instill cultural values, beliefs, modes of appropriate behavior, and cognitive styles in the students (Samovar et al., pp. 48-49; Cohen, 1969). Further differences in social organization between China and the U. S. will be integrated within the following sections.

\section{MODELS OF CULTURAL VARIABILITY}

The two models of cultural variability that will be used in this study to compare American culture and Chinese culture are Hofstede's Value Dimensions and Hall's Low-High Context Communication Schema. Both of these models of cultural comparison have been used by numerous intercultural communication researchers. For example, Gudykunst \& Nishida (1986) used Hall's model to study attributional confidence, and Chua and Gudykunst (1987) studied conflict resolution styles in low and high context cultures. Hofstede's dimensions have been applied by The 
Chinese Culture Connection (1987) to Chinese values and by Bond, Wan, Leung and Giacalone (1985) to responses to verbal insult.

\section{Hall's Low and High Context Communication}

Hall (1976) sees culture as primarily a communication phenomenon and he bases comparison of different cultures on communication styles. For Hall, communication is placed on a continuum with high context communication at one end and low context at the other. The United States is considered a low context culture while China is a high context culture.

He defines high-context communication as involving messages that have most of the information "either in the physical context or internalized in the person, while very little is in the coded, explicit, transmitted part of the message." A low context communication or message is where most of the "information is vested in the explicit code" (p. 91).

Hall characterizes high context communication, as compared to low context communication, as

... economical, fast, efficient, and satisfying; however, time must be devoted to programming. If this programming does not take place, the communication is incomplete ... . [High context] communications are frequently used as art forms. They act as unifying, cohesive force, are long-lived, and are slow to change. [Low context] communications do not unify; however, they can be changed easily and rapidly (p. 101).

In addition, Hall has associated indirect communication style and hierarchical power relationships with high context cultures and direct communication and diffuse power relationships with low context cultures (p. 113). 
Hall's description of high and low context culture behaviors is similar to characteristics of individualistic and collectivistic cultures discussed in the next section on Hofstede's value dimensions. Gudykunst and TingToomey (1988) conclude that low-high context can be included as an aspect of individualism-collectivism. They point out that the cultures Hall has identified as high or low context match the cultures Hofstede has identified as individualistic or collectivistic.

Ting-Toomey (1985) in her theory of intercultural conflict has related high-low context with individualism-collectivism and conflict styles. She offers several propositions that may characterize conflict in low and high context cultures that conform with characteristics of American and Chinese culture. Low context cultures (LCC) will value and express overt confrontation of ideas and will view argumentation by reasoning as positive expression of an open, democratic system. They are likely to assume a confrontational, direct, active, solution-oriented attitude toward conflicts. However, in high context cultures (HCC), much energy will be expended in preventing a conflict from arising and a non-confrontational, indirect, facepreserving and relationship-oriented attitude toward conflict will be assumed.

Individuals in a LCC will be able to view a conflict issue as separate from the person involved in the conflict. Whereas individuals in a HCC will view the conflict within an affective domain and view the conflict and the conflict person as the same. Conflicts are more likely to occur in a HCC when cultural norms and rules are violated. Whereas in a LCC conflicts are more likely to occur when individual expectations are violated. And finally, individuals in LCC will tend to focus on facts and move inductively 
to conclusions or first focus on fundamental principles and move to their implications. They tend to value analytic, linear logic and to approach conflicts from the mind. In contrast HCC will use the affective-intuitive style which employs appeals to the emotional response and the use of ambiguity and understatement to diffuse conflict. They value synthetic, spiral logic and approach conflicts from the heart.

Lieberman (1991) relates problem-solving approaches to Hall's (1976) low-high context cultures. She describes problem solving in several high context cultures which use holistic, concrete perception of the problem and group process to reach solution. In all examples, the members of the high context cultures, when presented with problems not previously confronted, were unable to create new processes for finding solutions. In an example involving a native American culture, an individual attempted to recount a story but could not remember all of its elements. As a result, the person was unable to tell the story. Such examples lend support for the association of cognitive style with high and low context cultures.

More research needs to be done to develop these associations but it can be assumed that, in a learning and problem-solving situation, high context cultures would tend to be relational-contextual (descriptive, holistic and field dependent) while low context cultures would use the descriptiveanalytic (analytic and field independent) cognitive style.

\section{$\underline{\text { Hofstede's Value Dimensions }}$}

Hofstede (1980,1983), from his study of members of a multinational corporation in 53 countries, identified four major dimensions of cultural variability: individualism-collectivism, uncertainty avoidance, power 
distance and masculinity-femininity. Hofstede emphasizes that not all of the characteristics within a dimension will be shown in each culture, that there will be individual differences within a culture and that each dimension should be conceived of as a continuum with most cultures being in-between the extremes.

In Hofstede's research $(1980,1983)$ individualism-collectivism and power distance correlated with gross national product. It was found that the wealthier, industrialized nations tended to be high in individualism and mid-to-low in power distance. Given this association Hofstede surmises that the dimensions of individualism-collectivism and power distance are likely to account for most of the problems that may arise in training programs for economic development.

Hofstede identified four areas where problems are likely to occur: differences in the social positions of teachers and students; differences in the relevance of the curriculum; differences in cognitive styles (Hofstede uses the term cognitive abilities which refers to similar processes as cognitive styles); and differences in patterns of teacher/student and student/student interaction (p. 303). Differences in cognitive styles has been dealt with in the previous section.

Other researchers have been able to support Hofstede's dimensions of individualism-collectivism, power distance and uncertainty avoidance. But I found very little research during the literature search that supports Hofstede's masculinity-femininity dimension. Therefore masculinityfemininity will not be used in this thesis to compare American and Chinese cultures. 
Individualism versus Collectivism. Gudykunst and Ting-Toomey (1988) have presented a review of the models of cultural variability in their book Culture and Interpersonal Communication which will be used as the organizing framework for this discussion. These authors point to numerous studies from many disciplines to support the claim that the dimension of individualism-collectivism can be used as the major concept to describe the differences and similarities between cultures. It is one of the major dimensions identified by Hofstede (1980) and Kluckhohn and Strodbeck (1961) and it has been correlated with Hall's low-high context schema by Gudykunst and Ting-Toomey (1988).

The dimension of individualism-collectivism represents the importance the culture places on the individual versus the group. According to Hofstede (1983), "The fundamental issue involved is the relation between an individual and his or her fellow individuals." In an individualistic culture the focus is on individual achievement, individual goals, autonomy and choices, while in collectivistic cultures the well-being and goals of the group as a whole are of primary importance, and interdependence and reciprocal obligations are valued.

Individualistic cultures are characterized by relatively loose and mobile relationships between individuals that are made possible by considerable freedom allowed individuals. The individual is expected to look after his/her self-interest and immediate family, while the extended family and community receive less attention. Individual achievement, self improvement and self-actualization are important goals, but this does not mean that the pursuit of these goals can be done with total disregard for 
other people. Observation of universal principles protects people from unprincipled self-seeking (Bond, 1990).

People in individualistic cultures value individual initiative, freedom to make choices from different options, mobility and friendships based on trust and emotional connection. The tendency to apply the same value standards to all people is common in individualistic cultures. Friendships are made on the basis of similar interests and activities and mutual assistance. There may be individual friendships that are associated with only one aspect of a person's life, such as a tennis partner. Members of individualistic cultures may join and leave a number of groups throughout their lifetimes, but these associations are usually temporary and interest- or goal-oriented. Individuals may join with others in a cooperative venture to achieve group goals that are perceived by the individual as also contributing to individual goals (Gudykunst \& Ting-Toomey, 1988).

Collectivistic cultures are characterized by close, long-lasting, stable group associations and identities. People are born or initiated into groups such as their extended family, clan or village. The group offers the individual security and survival and support in times of trouble in exchange for total loyalty and identification with the values, beliefs and opinions of the group (Hofstede, 1983). Collectivistic cultures value group identity and group interest, shared resources and survival of the group, group rights and obligations and group harmony. According to Bond (1990, p. 46), "Collectivists are encouraged to protect the harmony of established relationships and not to expend effort or resources on outsiders or strangers." Individuals are acutely aware that their actions reflect on and have larger social implications for the group, not only in the present but 
into the future. Friendships are based on similar group membership and social obligation and usually last a lifetime. Gudykunst and Ting-toomey (1988) say

... collectivistic cultures emphasize goals, needs, and views of the ingroup over those of the individual; the social norms of the ingroup, rather than individual pleasure; shared ingroup beliefs, rather then unique individual beliefs; and a value on cooperation with ingroup members, rather then maximizing individual outcomes... . People in collectivistic cultures tend to be particularistic and therefore, apply different value standards for members of their ingroups and outgroups (p. 41).

Several other cultural factors have been associated with individualism-collectivism. Mahler, Greenberg and Hayashi (1981) suggest that the norm of equity (distribution of rewards are based on the level of contribution) is associated with individualism while the norm of equality (rewards are distributed equally regardless of contribution) is associated with collectivistic cultures. This has implications in cross-cultural situations when the notion of what is "fair" may be an issue in relation to production goals and pay scales.

Ting-Toomey (1986) found that the norm of reciprocity can be associated with individualism-collectivism. Her study suggests that obligatory reciprocity is emphasized in collectivistic cultures while voluntary reciprocity is emphasized in individualistic cultures. And Okabe (1983) associates direct versus indirect verbal styles of communication with individualism-collectivism. Members of individualistic cultures tend to use a direct verbal style. This is characterized by the inclusion of the intentions, needs and desires in the verbal message and explicit, categorical words are employed. Indirect verbal style is emphasized in collectivistic 
cultures where the intentions, needs and desires are concealed in the verbal message and implicit, ambiguous words and qualifiers are used.

Individualism-Collectivism and Problems in Training. Hofstede (1986) has identified several cultural values and assumptions associated with individualism-collectivism in terms of education and training which may prove problematic in a training context involving teachers and students from both traditions. Collectivistic cultures tend to:

- place a high value on tradition in their teaching materials and approach;

- believe that education is for the young and that adults should not be students;

- emphasize learning "how to do";

- focus on the teacher teaching - individual students speak up in class only when called upon by the teacher or in small groups;

- stress maintaining formal harmony in learning situations;

- avoid situations where the teacher or students could lose face;

- perceive education as a way of gaining prestige in one's social environment and of joining a higher status group;

- value and display diploma certificates; and

- expect teachers to give preferential treatment to some students (e.g. based on ethnic affiliation or on recommendation by an influential person).

In contrast, individualist cultures tend to:

- value more highly new information and sources rather than tradition;

- believe that one is never too old to learn and therefore that adults are encouraged to seek continuing education;

- emphasize "how to learn";

- focus on student participation;

- believe that confrontations among students and between students and teachers in learning situations can be beneficial;

- be less conscious of face-saving and believe that loss of face has fewer consequences; 
- consider education a way of improving one's economic status and self-respect based on ability and competence;

- believe that acquiring competence is more important than acquiring certificates;

- expect teachers to be strictly impartial (p. 312).

Uncertainty Avoidance. The fundamental issue in uncertainty avoidance (UA) is how a culture deals with an unknown future. A culture copes with uncertainty to reduce anxiety and increase security in ways such as these: religion to explain and guide, law and rules to control behavior, technology to protect from disasters both natural and human-made, and expertise to rely upon. In comparison to weak uncertainty, strong uncertainty about the future tends to produce a higher level of stress, a more hurried social life and higher energy release which translates into a desire to work hard. The showing of aggressiveness and emotions is an acceptable way of releasing anxiety in strong UA cultures. This high aggressiveness level makes conflict and competition between people threatening therefore it is tempered and controlled by avoiding conflict and competition and by using group decision making and consensus. In weak UA cultures expression of aggression and emotions is not approved of and passive relaxation is the means for releasing anxiety. Hofstede (1984) points out that freedom implies uncertainty in one's own and other people's behavior, therefore totalitarian societies try to avoid this uncertainty (p. 111).

Strong UA cultures in comparison to weak UA cultures tend to be less tolerant of differences and more emotionally resistant to change, more conservative and attracted to law and order, more security conscious, less achievement oriented, less willing to take risks, and heavily reliant upon expertise and authority (Hofstede, 1984, p. 139). 
Hofstede (1984) makes a clear distinction that the way organizations deal with uncertainty depends upon the way uncertainties are perceived rather than on some objective amount of uncertainty. Members of strong UA organizations compared to members of low UA organizations tend to

... resist change more, have higher levels of anxiety, have higher levels of intolerance for ambiguity, worry about the future more, see loyalty to their employer as more of a virtue, have a lower motivation for achievement, and take fewer risks... prefer a specialist career, prefer clear instructions, avoid conflict, and disapprove of competition between employees... (Gudykunst \& Ting-Toomey, 1988, p. 47).

Uncertainty Avoidance and Problems in Training. In a training context involving a teacher from a relatively weak UA culture and students from a strong UA culture Hofstede (1986) anticipates several areas of potential conflict.

Teachers from weak UA cultures:

- are comfortable with unstructured learning situations, vague objectives, broad assignments and no timetables;

- are allowed to say "I don't know, but I'll find out";

- can use plain language;

- reward students for innovative approaches to problem solving;

- interpret intellectual disagreements as a stimulating exercise; and

- tend to seek parents' ideas.

On the other hand, strong UA students:

- prefer structured learning situations, precise objectives, detailed assignments and strict timetables;

- believe teachers have all the answers;

- expect teachers to use formal academic language;

- are rewarded for accuracy in problem solving; 
- interpret intellectual disagreement as disloyalty; and

- consider teachers as the experts who cannot learn anything from lay parents.

Power Distance. Power distance (PD) "deals with the desirability or undesirability of inequality and of dependence versus interdependence in society" (Hofstede, 1984, p. 93). Whether a culture is small PD or large PD, it has social hierarchies. It is how power is perceived, distributed and used that distinguishes small from large power distance.

In large PD cultures, power is perceived as an inherent attribute of society. As a result people, whether more powerful or less powerful, tend to accept their place in the social hierarchy as a matter of the natural order of things. Those in positions of less power have a greater dependence on the authority of those in greater power. Large PD cultures tend to "stress coercive or referent power, while small power distance cultures believe power should be used only when it is legitimate and prefer expert or legitimate power" (Gudykunst \& Ting-Toomey, 1988, p. 47). Parents in large PD cultures place a high value on children's obedience and students place a high value on conformity and tend to consider authoritarian attitudes as a social norm. In small PD cultures parents are less concerned with children's obedience, students place a higher value on independence and consider authoritarian attitudes as a matter of personality (Hofstede, 1984, p. 92).

Members of large PD organizations tend to prefer autocraticpaternalistic decision-making style in their managers while in small PD organizations members prefer a consultative, give-and-take style. In large PD organizations, workers fear to disagree with their boss, are reluctant to trust coworkers, and need and desire close supervision. Managers in large 
PD organizations see themselves as benevolent decision-makers, and they are more satisfied with a directive or persuasive superior. In small PD organizations managers make decisions after consulting with subordinates, see themselves as practical and systematic, admit a need for support, and prefer a participative superior (Hofstede, 1984, p. 92).

Power Distance and Problems in Training. In a training situation where the teacher is a member of a small PD culture and the students are from a large PD culture problems may arise from these differences in the cultural values and assumptions (Hofstede, 1986).

Small PD societies tend to:

- believe in "impersonal truth which in principle can be obtained from any competent person";

- believe that education is student-centered, with an emphasis on student initiative;

- expect teachers to "respect the independence of his or her students";

- allow students to "speak up spontaneously in class";

- expect students to "find their own paths";

- allow students "to contradict or criticize the teacher";

- believe that learning is more effective when there is more dialogue between teacher and student;

- allow students to treat teachers as equals outside of class; and

- like younger teachers more than older teachers.

Large PD societies tend to:

- believe in "personal wisdom which is transferred in the relationship with a particular teacher or guru";

- believe that education is teacher-centered, with an emphasis on order;

- believe that the "teacher merits the respect of his or her students";

- expect "the teacher to initiate communication" and permit students to "speak up in class [only] when invited by the teacher"; 
- expect the teacher "to outline paths to follow";

- prohibit students from contradicting or publicly criticizing the teacher;

- believe that "effectiveness of learning is related to the excellence of the teache;

- require students to show respect to teachers outside as well as inside the class; and

- respect older teachers more than younger teachers (p. 313).

\section{CHINA AND UNITED STATES COMPARED}

According to Hofstede's scale, the United States is high in individualism, moderately weak in uncertainty avoidance, and moderately small in power distance.

The People's Republic of China was not included in Hofstede's studies. But looking at the scores for Taiwan, Hong Kong, and Singapore, China can be mapped with some confidence while recognizing that there are significant differences among these three cultures primarily having to do with modernization. All three of these Chinese cultures were found to be very similar in their ratings on Hofstede's scale: high in collectivism, moderately strong in uncertainty avoidance, and moderately large in power distance.

I found only one study that applies Hofstede's value dimensions to Chinese in the People's Republic. Chong, Cragin, and Scherling (1983) administered the Hofstede survey to several managers in the PRC. Their results strongly support Hofstede's findings for the other Chinese cultures in collectivism and power distance.

Because of ideological and political reasons, there has not been much social science research conducted in China since the cultural revolution. 
Results of research that has been done are carefully controlled so that little information regarding the attitudes, values and personality of Chinese from the People's Republic has reached the West. Most of the recent research on Chinese psychology and communication has been collected in Hong Kong, Taiwan, Singapore and other Chinese communities in Southeast Asia and around the world. Bond $(1986,1991)$ and Yang (1986) maintain that making generalizations about the Chinese character using respondents from these locals is valid with some cautions. The population of Hong Kong, especially, is very representative of China as it is composed of relatively recent immigrants from "almost every major province of mainland China" (Yang, p. 107). Lew's study (cited in Yang, 1986) indicates that communist ideology and reform have not changed the basic values and personality of the Chinese. He says,

... in spite of superficial discontinuities, there are basic continuities in the latent cultural and psychological traits of mainland Chinese and Overseas Chinese. When a Chinese person from mainland China meets a Chinese person from Taiwan or Hong Kong, it is unlikely that they would think that they were people from different national cultures (p. 107).

Bond (1991) calls for more multicultural studies between the different Chinese communities to identify the finer distinctions among them. But he emphasizes that recent multicultural studies that have included different Chinese cultures indicate that, regardless of location, Chinese cultures are more similar to each other than to other cultures (p. 4).

While generalizations can be made from Hong Kong and Taiwan Chinese to Chinese in the People's Republic, they must be made with some caution. As Yang (1986) points out in his discussion of recent research on 
the Chinese personality, the effect of modernization in Taiwan and Hong Kong appears to be shifting traditional Chinese values toward those more commonly found in Western cultures. Given that the same level of modernization has not been reached in the People's Republic it is doubtful that the same level of change in values will have occurred.

\section{Individualism-Collectivism}

Confucian Tradition and Chinese Collectivism. In China's ancient agriculture-based society, mobility was very limited and subsistence depended upon the cooperation of many people for working the land. The inability to leave one's village and establish a life elsewhere and the need for cooperation in farming meant social relationships needed to be cordially maintained. Individual expression and needs were subsumed in maintaining the stability of the group. Direct confrontation was avoided as was expressing an opinion opposite from another's in fear of creating a lifelong opponent (Becker, 1992; Bond and Hwang, 1986).

In this system little changed from generation to generation, for the risk of trying a new technique or challenging the status quo could easily lead to starvation. Nature was full of unseen forces that needed to be propitiated lest devastation be brought down upon the village. Knowledge was vested in the elders of the village who had lived through various calamities and who would be consulted on how present problems had been dealt with in the past. This established a basic and recurring theme in Chinese society that it is better to copy old solutions to problems than to try risky new ones. Over the centuries this situation led to a hierarchical society where age and rank became the distinction for authority and power. According to Becker, 
"Once the superior person had been identified by age and rank, his word was taken as law, without further logical examination" (Becker, 1992, p. 235).

This was the history and social foundation of Chinese culture that Confucius was born into. His philosophy did not spring forth whole and new, but was rooted in tradition and a social system embraced by the people for generations. He gave form to an already existing ethos.

Chinese culture has been guided by the philosophy of Chung-ni $\mathrm{K}^{\prime}$ ung (551-479 BC.) or Confucius since the Han Dynasty, 2,500 years ago. Confucius was born during a time of intense political instability as the various kingdoms of the Eastern Chou Dynasty struggled for dominance. As an appointed administrator, his fortunes and positions changed with each shift in the political winds. This experience of constant turmoil and political chaos led to his concern for creating social harmony through proper ritual behavior (Bond \& Hwang, 1986).

Confucianism is a very practical, human-centered philosophy concerned with harmonious social relations in the here and now. According to Bond \& Hwang (1986) there are three basic aspects of Confucianism which guide Chinese behavior. The most fundamental Confucian precept is that human beings exist through and are defined by their relations with other human beings. The relationship between the individual and society is inseparable and interdependent (King, 1985). The second precept is that relationships are hierarchically ordered. And third, "social order is ensured through each party's honoring the requirements in the role relationship" (Bond \& Hwang, 1986, p. 216). Ethics in Confucianism are based on the relationship and the situation, not on a principle of some absolute good, nor on human rights (Yum, 1988). 
According to Yum (1988) Confucius focused on four principles of proper human conduct: jen (humanism), $i$ (faithfulness), $l i$ (propriety) and chih (wisdom or liberal education) (p. 377). Jen is considered the core concept of Confucianism and has been translated by Lau as benevolence, by Legge as perfect virtue (cited in King, 1985), and by McNaughton as "natural human feeling for others, graded according to one's relation to them" (cited in Yum, 1988). The practice of jen includes the practice of shu, reciprocity. Confucius explained shu as "what you do not want done to yourself, do not do to others" and entails an empathetic ability to take another person's role (King, 1985). Reciprocity does not mean that one expects or asks for an immediate return on something given but emphasizes taking the responsibility for remembering to reciprocate for something received (Chang \& Holt, 1991).

$I$, meaning faithfulness, loyalty or justice, emphasizes that human relations are "not based on individual profit, but rather on the betterment of the common good" (Yum, p. 377). I and shu lead to a system of mutual dependence and reciprocity within an environment of mutual faithfulness that may extend for generations. A person knows that in taking care of another, when the time comes he/she will also be taken care of. The concept of $i$ also leads to a desire to mix personal relationships with business relationships where one can depend on a more personal, human level of trust that cannot be found in a contract (p. 380).

$L i$, meaning propriety, respect for social forms or rite, was "perceived as the rule of the universe and the fundamental regulatory etiquette of human behavior" (Yum, 1988, p. 378). Li refers to the strict code of conduct prescribed for social relations. A person must be reserved, show deference 
to others, follow the appropriate rituals for establishing relationships, respect and honor one's parents, and obey authority.

Seligman's (1989) description of Confucius' "superior man" embodies all of the ideal characteristics and principles to which the proper Confucian aspires.

The superior man is modest, even self-deprecating; he is moderate in habits, generous, and given to compromise and conciliation rather than direct confrontation. He has no need to parade his belongings or his accomplishment before others. $\mathrm{He}$ is driven by a well-developed sense of duty. He endeavors to make others comfortable, and is solicitous of guests. He never loses his temper, and remains poised no matter what the situation. A man of integrity, he overlooks deficiencies in others and demonstrates honesty and propriety in all of his dealings (p. 46).

Confucius laid out his principles in the $W u$-Lunn, the five cardinal relations which represent the basic norms of Chinese social order. These five relationships, constructed in hierarchical patterns, are these: $i-$ righteousness between ruler and subject; $c h^{\prime}$ in - affection between parent and child; pieh - distinction between husband and wife; $h s u$ - order between old and young; and hsin - sincerity between friends. The emphasis is on the family as the primary social unit and the relationship between father and son is the archetype for all others. Hsiao (filial piety) is the core of personal identity and family and social existence (King, 1985). Without filial piety all other benevolence is impossible and a person who loves others before his or her parents is a "rebel against virtue" (Hsieh, 1977, p. 171). Hsieh goes on to say, 
[Confucian scholars] agreed unanimously that the realization of benevolence must begin with the love of children toward their parents. This means that, in the complicated relations among men, filial piety forms the primary and most fundamental unit of mutual connection between two or more persons, in which the practice of benevolence must first be fulfilled. By inference, all other relations among human beings should emanate from this basic virtue as their source; otherwise, they may not stay on the right course of benevolence for the attainment of peace and prosperity (p. 171).

The individuals within each relationship were expected to follow the rules which specified the rights and responsibilities for their respective roles. If the rules were adhered to and each person fulfilled his or her role expectations, harmony prevailed. Harmony in society could be accomplished only when each person's relationships were harmonious. The principle of filial piety demanded complete, unquestioned submission to the father's authority. This model of authority was reproduced in all other relationships - between husband and wife, subject and ruler.

The relationship between human beings and nature also played a role in Confucian principles, where it was believed that human conduct was reflected in acts of nature. Corrupt and improper conduct could disrupt the natural world causing havoc and ruin. The emperor ruled through the mandate of heaven and was considered the mediator between the forces of nature and human beings. Therefore it was necessary for the "Son of Heaven" to maintain harmony by doing the right thing at the right time (Fairbank, 1967, p. 54).

Bond and Hwang (1986) point out that the cardinal relationships involved considerable inequalities of power. The potential for the abuse of power by a superior put those in inferior positions in considerable danger. 
To counter this threat a "morality of compassion and righteousness" was enjoined on those in positions of authority and power (p. 216). Confucius emphasized rule by the "superior man" who governed through setting a standard of virtue and morality. If this authority was abused and leaders violated these moral precepts rebellion was justified. Rebellion was allowed only for the purpose of replacing leaders with others of higher moral character, not for changing the system (Hsu, 1987, p. 378).

Confucianism is a conservative philosophy that reveres tradition and is aimed at maintaining the status quo. It attempts to insure protection from chaos by citing hierarchical relationships as a necessary component of the natural order of the universe. It has led to social relationships based on mutual dependency and loyalty, warm human relations, consideration of others and group harmony (Yum, 1988). Confucianism instills a reverence for education as the means to achieving moral wisdom and power. On the other hand it has also led to extreme caution in innovation, lack of individual initiative, and great reluctance to make decisions (Bond, 1986, 1991; Yum, 1988, De Mente, 1989). In addition

...because of the sharp distinction between ingroups and outgroups, factionalism may be inevitable. Within such welldefined sets of social relationships, people have a highly developed sense of obligation but a weak sense of duty to impersonal social entities. Since the main criteria for proper behavior are the social relationships among the participants and the situation in which the interaction occurs, the Confucian tradition could open a door to double standards of morality and conduct (Yum, 1988, p. 386).

\section{Confucian Tradition and Contemporary Chinese Education.}

Beginning in the Han Dynasty, China developed a system of selecting 
officials based on the mastery of the Confucian classics. Becoming an educated person and passing the civil service exams was the only way a Chinese man could theoretically change his position in life and become a member of the ruling class. In reality only those who had the resources to invest in educating sons could ever hope to achieve an appointment. The exams required the student to recite and write the classics verbatim. It was believed that the discipline that was required to memorize the classics produced a civilized person (Bond, 1991, p. 29). In fact the purpose of education was "not to transmit knowledge or learn certain skills [but] to internalize a set of ethical principles that govern human behavior in all facets of life..." (Porter, 1990, p. 7). By learning the classics and passing the examinations the scholar was considered prepared to rule in a virtuous and moral way.

Upon passing the examinations, the scholar received an official appointment in the bureaucracy. As an administrator he would be called upon to resolve conflicts for the peasants and make decisions according to Confucian principles. He would also create legends, drama, folk stories and songs for the masses advocating a Confucian way of life (Bond \& Hwang, 1986). In this way Confucianism became completely integrated and accepted at all levels of Chinese culture.

This emphasis on education persists in China today. The purpose of education continues to be the development of moral citizens but no longer serves simply to produce officials for the bureaucracy. Education today is aimed at the modernization effort in which China is now engaged. Young people are called upon to serve the people and improve the country (Hawkins, 1981). 
The Chinese system of entrance examinations at the various educational levels serves to identify those students who are the brightest and direct them into the universities (Hooper, 1985). The limited availability of institutes of higher education in China (and Taiwan and Hong Kong) makes the competition for the limited spaces fierce and the pressure from family to succeed very intense (Bond, 1991).

In China, up until 1989, all university graduates were guaranteed a job. These jobs were assigned by the government based on availability and national need. It has been suggested that the policy of assigning students to an area of study and guaranteed lifetime employment led to the iron rice bowl attitude. This was characterized by low motivation for some students and workers to work hard after gaining entrance to university or upon getting a job. This attitude developed because students were often assigned an area of study that didn't interest them and they perceived that academic achievement was not related to eventual job assignment (Lin Mei Ling, personal communication, 1985). Perhaps most importantly a person could not be fired for failing to do the job (Waddle, 1987, p. 302). In 1989 the policy changed and there is generally no longer a guaranteed job. Students now must compete for many jobs by interviewing and producing their academic records for potential employers (Wenzhong \& Grove, 1991, p. 75).

China's educational system is still guided by Confucian tradition. The purpose of education is to teach students how to fit harmoniously into the scheme of human relations where the group takes precedence over the individual (Wenzhong \& Grove, 1991, p. 79). According to Bond, The teacher is the authority and is highly respected and is treated like a surrogate father with the same deference and fear (Bond, 1991). The teacher is not to 
be questioned; questioning could lead to the loss of face for both the teacher and student. The teacher, likewise, is expected to take an interest in not only the student's academic progress but also his or her moral, personal, and political development. The teacher is a teacher at all times and is available to students in the home or at the market to provide instruction and answer questions (Porter, 1990).

The role of the teacher as guide to individual moral development does not translate into individualized attention in the classroom. The Chinese classroom is teacher-centered and most of the time is spent with the teacher providing information to the students who take voluminous notes. Chinese educational tradition does not encourage self-expression (Wenzhong \& Grove, 1991). Liu (1986) and Bond (1991) contend that this lack of verbal interaction between teacher and students (and parent and child) leads to the low performance of Chinese on tests of verbal fluency. Students may reluctantly respond when called upon but seldom ask questions or contribute information spontaneously (Wang, 1981; Scoval, 1983). Doing so is a risk of loss of face, for themselves and for the teacher, few are willing to take (Porter, 1990). Wenzhong \& Grove (1991) report that poor students fear saying something stupid while the outstanding students fear standing out above their peers (p. 80). Porter (1990) reports that, after losing face, the ridicule a student may receive from classmates can turn to official criticism by college authorities and result in problems with future job assignments. This adds to the desire to avoid conflict and situations which may result in loss of face.

The Chinese style of learning continues to emphasize rote memorization and exams that objectively test memory of quantifiable facts. 
On cross-cultural tests of memory Chinese tend to excel (Liu, 1986). To learn Chinese script requires considerable time, repetition and memorization. In order to read a newspaper one must know 3,500 characters (Vernon, 1982). This early training in memorization and the traditional emphasis on learning from the ancient authorities leads to a style of teaching that rewards duplicating information found in books and provided by the teacher. In China, books are revered and considered absolute authority (Porter, 1990).

Wenzhong and Grove (1991, p. 81) summarize the teaching and learning practices in Chinese classrooms in contrast with American methods:

1. The transmission of knowledge is oriented more toward theory than practice and application. The preferred mode of thinking is deductive, not inductive or operational as it is in the U. S.

2. Great emphasis is placed on details and facts, which are often committed to memory. Americans worry little about remembering facts; instead, they focus on knowing where to find facts and how to use them creatively. The Chinese are uncomfortable with the American tendency to de-emphasize factual recall.

3. A key learning objective is to know and be able to state facts and theories as givens, as wholes. Chinese students are rarely able to employ an analytical conceptual style, which Americans value.

4. The context of learning is whatever is found in assigned texts or other readings; books are the sources of authority. Using books merely as sources of opinions or interpretations, as American teachers often wish to do, is not understood or appreciated by the students. 
5. The teachers whose classroom style is most admired are those who give clearly structured, information-packed lectures with much information written on the blackboard (which students copy verbatim). Experiential learning, problem solving, case studies, and participatory teaching methods are distrusted and may be resisted.

6. Tests are frightfully important because, like the imperial examinations of old, they are viewed as the absolute determinants of a student's future. Chinese students do not understand that American teachers use tests primarily to gauge a student's progress.

Guanxi and Face - the Grease of Chinese Collectivism. Bond (1986, 1991), Yum (1988) and Chang \& Holt (1991) emphasize that labeling the Chinese "collectivistic" must be done with some qualification. With the Confucian emphasis on relationship, the Chinese do not share a generalized collective sense of the common good but identify with specific ingroups. As specified by the five cardinal relations, a Chinese person is not expected to behave the same toward all people. There are distinctly different sets of rules for ingroup members and for outgroup members. Those ingroup members closest to the individual will be treated differently than those more distant. The individual's ingroup begins with the family and may extend to friends and others with whom he/she develops guanxi (relations). Guanxi, according to Chang \& Holt (1991) and Hwang (1983) is a system of developing relations as a social resource.

Kuan-hsi [guanxi] implies a special connection between people, a connection which brings along with it interactants' special rights and obligations, resulting from including the interactants as ingroup members (p. 256)... . There are clearly two sides to this coin: the ingroup member will always be protected and benefit when it is possible and necessary, while the outgroup member may be rejected [or simply ignored]. On 
the other hand, ingroup members are obligated to help members of their own ingroup, while the outgroup members are allowed to act free of obligation. It is in this regard that Chinese relations are both warm-hearted and cold-blooded (Chang \& Holt, 1991, p. 257).

In order to establish guanxi with another there must be some area of commonalty, such as being related in some way (even remotely), coming from the same hometown, attending the same school, or having the same friend (Pye, 1988, p. 49). It is this kind of information Chinese use when meeting people that helps to determine where they stand in relationship to one another. Once a connection has been established the individuals may be obligated to one another depending upon the closeness of the connection and other guanxi relationships that may be involved. In order to build one's guanxi network, attempts may be made to find and establish those familial or school connections even if extremely remote (Chang \& Holt, 1991; Hwang, 1983). When guanxi has been established it is said that one has developed a "back door" through which one is able to gain favors and resources.

The first step a Chinese will take when he or she experiences a need or has a problem is to review his or her guanxi network to determine who can help him or her. This may entail a complex web of interconnecting relationships involving several people's guanxi connections. For example, a woman needs to get approval for something from a particular ministry. Her uncle has a schoolmate whose sister works in that ministry. The sister has a schoolmate who has the authority to grant the necessary approval for the woman's request. The granting of the request depends on the closeness 
of the relationships, already established obligations and the potential of future mutual benefit (Bond \& Hwang, 1986).

Understanding the reality and nature of guanxi is essential for foreigners trying to do business in China. While the communist revolution in China attempted to shift individual identity and loyalty from the family and guanxi networks to the state, it was not very successful. There continues to be political education exhorting individuals to serve the people and there is a sense of national identity, but guanxi is how things work on a day to day basis. Recent research (Bond \& Hwang, 1986) has found that in terms of distribution of resources with the choices being equity, equality and need, Chinese tend to determine resource distribution based on ingroup affiliation and the status of the relationship.

For a foreign business person faced with an enigmatic situation guanxi may be operating. Guanxi may explain why something does or does not get done, why a particular person is hired for a job, why certain individuals are chosen for specialized training, why information is shared or withheld, and why an accident victim may be ignored by passersby. Wen (1988) states

Chinese are very sensitive to kuan-hsi. Whether to tell truth, to support, or to help the other tends to depend upon whether one has kuan-hsi with the other. A common saying states, When you meet a person, only speak 30 percent, do not tell all in your heart,' referring to the depth of kuan-hsi. Deeper kuanhsi persons are allowed to talk deeper, and more shallow kuanhsi persons, on the other hand, can only talk about something not serious, such as greetings (p. 32).

Guanxi and face are closely interconnected in that the "game of face" is often used to develop and maintain guanxi. The concept of face is central 
to all Chinese social encounters but it seems to be enigmatic even for the Chinese. The famous Chinese writer Lu Hsun (1934) wrote,

But what is this thing called face? It is very well if you don't stop to think, but the more you think the more confused you grow (p. 129).

Hwang (1983) sees the game of face being played in Chinese society primarily as a way to develop relationships for personal and family benefit. He says that in a static society where resources are controlled by a few allocators who are able to distribute resources in accordance with their personal preferences, the game of face is played to strengthen the guanxi between them (p. 245).

Hu (1944) draws a distinction between two general categories of face which reveal two sets of criteria by which conduct is judged: lian and mian $z i$.

Mian zi represents the kind of face one achieves through success. It reflects one's reputation or prestige accumulated by personal effort or by clever maneuvering. Face is the respectability or deference that an individual can claim for him or herself from others. It is based on social position and the extent to which he or she has fulfilled the obligations of that position (Ho, 1976). An individual's face is also judged according to the actions of those people closely associated with him or her. Mian $z i$ can be borrowed, struggled for, added to, padded, lost, gained, and given.

In order to maintain and gain prestige an individual must $g u$ mian $z i$, consider his own and other's face. This can be seen in the family which puts on a large wedding banquet even though it means going into debt. It is also reflected in the avoidance of criticisms of one's neighbors and in the 
teacher who exercises tact in regard to a student's poor work - giving him an opportunity to improve. One can tian jia mian zi (add to one's face) by coming to the aid of those less fortunate than one's self. Two people trying to outdo each other in a competition are said to zeng mian zi (struggle for face). It is also possible to gei mian zi (give face) to another by increasing his prestige in front of other people. This can be done by praising the person in public, or by showing deference for his or her advice. This is often used to stimulate one to greater effort, as a teacher may give face to a student which will encourage him or her to do better. The slighting of a person is often felt as not giving mian $z i(\mathrm{Hu}, 1944)$.

Performing a faux pas or neglecting a social convention results in a loss of some prestige and feeling of shame and but not intense humiliation. Mian zi bu hao kan (something does not look good on someone's face) is similar to the American saying "to have egg on her face." Niu mian $z i$ (keep some face) refers to allowing an offending party to retain a little face. Exposing a person's mistake or referring to a person's breach of conduct and making it public will cause a person to feel "it doesn't look good on his mian zi." A decent individual will avoid mentioning the problem and allow the offender to retain some self respect and have a chance for change and self renewal (Hu, 1944).

The concern for face is mutually restrictive and the individuals' actions are often dictated by needing to meet others' expectations. Reciprocity is the key to the understanding of face behavior.

Lian represents the

... respect of the group for the person with a good moral reputation: the person who will fulfill obligations regardless of 
the hardships involved, who under all circumstances shows himself a decent human being. It represents the confidence of society in the integrity of [the person's] moral character, the loss of which makes it impossible for him to function properly within the community. Lian is both a social sanction for enforcing moral standards and an internalized sanction... . The loss of lian puts the individual outside society of decent human beings and threatens him with isolation and insecurity (Hu, 1944, p. 45, 61).

Diu lian (to lose face) is a condemnation by the group for immoral or socially disagreeable behavior. Some acts which would incur diu lian are fraud, adultery, lying for one's profit, a broken promise (Hu, 1944, p. 61). Sometimes the loss of face is considered so serious that suicide is felt to be the only way to prevent total loss of face. In traditional China a woman who had been raped often committed suicide to prove her innocence. Today, young people who have failed to pass the college entrance exams sometimes resort to suicide. Hu (1944) has connected this practice to the Chinese sense of humility or modesty. To overestimate one's ability in order to gain power or stand out above others is seriously frowned upon. A person who has boasted and failed will not receive sympathy but will be ridiculed. According to $\mathrm{Hu}$,

A person with such poor judgment of his powers is termed qing fou (light and floating) in character; a person serious in his endeavors but careful in reckoning his abilities and circumspect in his dealing with others is call cheng zhuo (sinking and steady) or wen zhong (reliably heavy) (Hu, p. 49).

$\mathrm{Hu}$ (1944) goes on to say, the light and floating person cannot be trusted but the sinking and steady person makes a good citizen and trustworthy friend. Since it is not possible for a person to gauge his or her 
ability at every point nor to foresee every outcome it is wise to underestimate one's value. Foreigners doing business in China encounter this expression of humility in employees who downplay their abilities and contributions. This has caused some consternation on the part of foreign managers who find it difficult to determine the level of experience and skill of a potential employee who continually minimizes his or her abilities. Bond (1991) points out that this expression of modesty and the tendency to flatter others is called "self-effacement" in Western literature but would be referred to as "relationship honoring" in the Chinese tradition. This "deflection of self-enhancing remarks protects a group from fragmenting and becoming a vehicle which serves only narrow individual interests" ( $p$. 53).

The Chinese concept of face differs considerably from the American concept of face which is based in individualism. The American sense of face is concerned with the maintenance of one's self esteem. The American is concerned with projecting a self image appropriate to the situation and which creates a favorable impression on others. The American negotiates for face in each new social encounter, gaining or losing the respect of the individuals present (Bond \& Hwang, 1986; Goffman, 1967). This definition of face emphasizes individual self concept and implies social mobility and equality. This contrasts significantly with the Chinese definitions of face where hierarchical, permanent status must be considered (Bond \& Hwang, 1986).

Bond and Hwang (1986) compare the American game of oneupmanship at an American cocktail party with the Chinese game of face at a Chinese banquet. In the American context everyone can play the game, 
politely boasting and joking with each other, jostling for position. At the Chinese dinner party rank is fixed by the seating plan and everybody present knows where he stands in relation to everyone else. They are expected to follow $l i$ (correct behavior) doing the proper things with the right people, "bowing and gesturing in verbal ritual." In the American cocktail party the situation is fundamentally the same for everyone present, they all can choose who to talk with, how to behave and what language to use. The only limitations on any person's playing of the game are one's ability and ambition and the willingness on the part of the individual to risk his or her face in playing the game. For the Chinese attending a banquet each person's situation is determined by his status and the language and behavior must be suited to that social position (p. 245).

The differences between Chinese face and American face can lead to situations where Americans are unaware of the face issues within an interaction. The Chinese being more sensitive to the perceived status of the individuals in an interaction may be more attuned to the subtleties of possible face gains and losses than an American. Chinese attempts to save the American's face may be lost on the American or interpreted as manipulation or subterfuge. And the opportunities for the American to inadvertently cause his or her Chinese counterpart to lose face are many. The repercussions of causing a Chinese to lose face are serious and may result in failure of the endeavor or retaliation in some form in the future.

American Individualism. In contrast with China's emphasis on individual identity being grounded in a person's relationship with others, American individualism focuses on the self as a separate identity distinct from other people. A person in American culture tends to be independent, 
self-respecting, and responsible for his or her actions as guided by a personal set of standards. The individual depends upon himself or herself to make decisions rather than the external pressures of the group (Samovar, Porter \& Jain, 1981). Belief in the dignity and the rights of the individual is sacrosanct in American culture. According to Bellah, Madsen, Sullivan, Swidler and Tipton (1985),

Anything that would violate our right to think for ourselves, judge for ourselves, make our own decisions, live our lives as we see fit, is not only morally wrong, it is sacrilegious. Our highest and noblest aspirations, not only for ourselves, but for those we care about, for our society and for the world, are closely linked to our individualism (p. 142).

The roots of this attachment to individualism originate in the European colonization of North America and the American revolution for independence from Britain. Early colonizers in North America were outcasts who severed their ties to the homeland to create a new life free from the religious persecution they experienced in Europe. Their European way of life was changed totally by the physical challenges of the new environment and by leaving their ancestral homes and traditions. They had to look "forward to an uncertain future" and create a new culture based on change and the creation of a better life (Samovar, Porter \& Jain, 1981, p. 64).

The traditional extended family and clans were broken and replaced by the nuclear family which became the source of assistance and the focus of one's sense of responsibility and obligation. In this new and rugged environment, individual initiative, accomplishment and independence became the means for basic survival. "The more people were able to 
accomplish on their own, independent of others, the more able they were to survive in the unsettled land" (Samovar, et. al., p. 65). Being able to survive and thrive on one's own became a source of pride while needing and taking charity became associated with failure (p. 65). The success at taming the wilderness through individual initiative created an ethos that an individual can and should overcome obstacles in order to accomplish his or her goals and that there is no problem that cannot be solved. The Puritan ethic that connoted hard work with moral character still influences American values today.

The severing of ties to the past also meant a severing of the traditional status systems based on ancestry. The American struggle for independence was a rebellion against monarchical and aristocratic authority. It was inspired by classical Greek Republicanism and Reformation Christianity that promoted a "government based on the voluntary participation of individuals" (Bellah, et al. p. 142). The revolutionary writings and philosophy of Benjamin Franklin, Thomas Jefferson, and later John Locke and Walt Whitman further honed and shaped the themes of American individualism: individuals have freedom of expression and the right to pursue personal goals with minimal interference by government or other individuals; every individual has equality of opportunity for economic progress; work, achievement, and material comfort are the measures of success and the mark of a good person; respect for other individuals' rights is necessary for a democratic society to work; people can change and improve their situation if they want to - the future can be better; new is good; power and authority is not inherent but is earned; the 
power of government, institutions and individuals must be checked and controlled.

In time, the emphasis on independent survival and success and republicanism led to a social status system based on employment, wealth, and individual accomplishment (Samovar, et al., p. 65). This focus has led to a society that tends to reject or at least be uncomfortable with authority and hierarchy. Americans tend to dislike taking orders and the use of coercion and instead use persuasion through "examples, incentives and hints of failure" (Samovar, et al., p. 77). Interpersonal relationships are based on the belief that each person is worthy of respect and capable of making his or her own decisions. There is a presumption of equality and a lack of inherent hierarchy. Therefore when interaction takes place between individuals of different status there is a tendency to create an atmosphere of equality (Samovar, et al., p. 78).

Group affiliation is changeable, transient, and based on self interest. Groups are considered collections of individuals who have the right to express their opinions and participate in decisions. Americans may belong to many different groups throughout their lifetime and feel free to join and leave at any time without compunction. The ability to pursue one's own goals while participating in a group accounts for Americans' ability to cooperate with others as a team to accomplish a task. They are willing to accept the goals of the group to accomplish something they would not be able to accomplish on their own (Stewart \& Bennett, 1991, p. 106). The American tendency to break things down into parts for analysis also extends to relationships. In contrast to the Chinese who perceive an individual as a whole, an American is able to separate various personality attributes, 
opinions and background from individuals in order to effectively work or play with them (Stewart \& Bennett, 1991).

The challenge of surviving in the wilderness and the Christian belief that the world was created by God for the benefit of humankind led to a belief in human superiority over nature. It is believed that the physical world should be mastered and harnessed in the service of humanity (Samovar, et al., p. 67). This sense of control of nature has contributed to a highly developed science and technology. Science, based on the notion that reality is an objective phenomenon, operates according to rational, cause and effect relationships that can be discovered by human beings. Once these laws are discovered, natural events can be predicted and manipulated. These beliefs are reflected in the way Americans tend to approach problems and communication. Samovar et al., says,

\begin{abstract}
... American emphasis upon science reflects the values of the rationalistic-individualistic tradition. Science is disciplined, rational, functional, active; it requires systematic diligence and objectivity; it is congruent with pragmatism and efficiency and the tendency to minimize absolutes and ultimates... .

Americans tend to value objectivity, empirical evidence, rationality, and concreteness in their communication, and they often experience considerable difficulty in understanding persons who do not reflect these values (p. 68).
\end{abstract}

American Education. According to Bellah et al. (1985) America's public school system was founded on the belief that for a democracy to work the populace must be educated in order to participate responsibly in the process of government. College education through most of the nineteenth century was designed to produce a learned individual who would be an "uplifting and unifying influence on society" (p. 298). The research 
university replaced the college in the late nineteenth century influenced by the rise of the business corporation (p. 299). Specialization, research and natural science became the model for graduate education which coincided with the rising belief that the progress of science and technology would solve the world's problems. University education today, attempts to bridge the needs of American society by producing a person with a grounding in humanities and philosophy with a specialization of skill and knowledge that is needed in business and industry.

While the quality of education appears to be related to the economic status of the population it is possible for American children to get an education in the public schools through twelfth grade. The competition for advanced education is more intense and expensive, yet many high school graduates continue for a college degree.

American children are encouraged to become independent very early in their socialization and formal education. They are directed to explore their environment on their own, to make their own decisions and choices, solve their own problems and express their own opinions. In fact, helping one another is often construed as cheating in American schools. As noted in the earlier section on cognitive processes, American children are encouraged to question, consider new and different alternatives to problems and are rewarded for initiative and creativity in their education. At the same time they are expected to respect other individuals in their freedom of expression and autonomy of choices.

American education focuses on "learning how to learn" rather than accumulating facts and figures. Memorization is rarely used beyond grammar school. Rather students are taught how to find and evaluate 
information they may need. By high school, students are expected to be self motivated and relatively independent in determining a course of action for an assignment. Students are expected to be able to express their ideas in written essays demonstrating their analysis of a situation, problem or piece of literature. American students are

expected to show that they know the received wisdom by the accuracy and pertinence of their references to its key elements, and by the relevance of their criticism of it, not by extensive or literal summation of its content" (Porter, 1990, p. 53).

Bennett (1986) describes this focus of education as the "why" perspective that goes beyond the what and how perspective. Students

should not only be able to demonstrate their learning, but they should also be able to apply that learning in creative ways to new environments, acquiring new frames of reference with which to continue inquiry (p. 118).

Chickering (1976) contends that education is the developmental process of differentiation and integration which

... makes persons different from what they were before and different from each other... Increased differentiation occurs when one comes to see the interacting parts of something formerly seen as unitary, when one distinguishes among concepts formerly seen as similar, when one's actions are more finely responsive to individual purposes or to outside conditions, when one's interests become more varied, tastes more diverse, reactions more subtle - in short, as one becomes a more complex human being. It is to foster increased differentiation that a liberal arts college aims to free an individual from the limitations of outlook brought from his own locale, his family, his social class, his national heritage a freeing that opens him to all the possibilities and impossibilities of the world around him ... . Increasing 
differentiation, however, must be accompanied by increasing integration. Relationships among parts must be perceived or constructed so more complex wholes result. Concepts from different disciplines must be brought to bear on one another and connected in ways appropriate to varied tasks and problems (p. 82).

Clearly the purpose of education in the United States is the creation of unique, independent, individuals. Training programs designed to teach people to use American technology are steeped in this philosophy, consciously or unconsciously. Adult learning theory which is used to guide trainers in the development of training programs for adult workers also reflects these cultural values. A summary of some of the principles of adult learning theory reflects the emphasis on individual needs, individual differences in learning styles, an active approach to learning and individual accomplishment, and other American values and assumptions. These principles are:

- Participants must be motivated to learn. They must have an awareness of the need to learn, based on their own concerns or inadequacies, and an understanding of what needs to be learned.

- Learning is an active process, so participants learn better when more than one of their senses is used in the effort and when they are actively involved in the learning process.

- Most people need guidance to speed and reinforce learning and to prevent them from pursuing unproductive directions.

- Appropriate materials to aid sequential learning should be provided.

- A variety of learning methods should be used in training.

- It takes time to assimilate what has been learned, to accept it, to internalize it and to gain confidence in what has been learned. 
- Participants must see the usefulness of learning in relation to their needs.

- Learning must consistently and immediately be reinforced and rewarded, especially if participants behavior is expected to change.

- Standards of performance should be set for participants, so they can recognize their own accomplishments.

- There are individual differences in the way people learn.

These differences can be influenced by culture and must be taken into account as training programs are designed (Pusch, Patico, Renwick \& Saltzman, 1981, pp. 78-80).

Some or all of these assumptions may be relevant in the training of Chinese but careful examination should be made of them to determine their appropriateness in designing training programs for Chinese students. Americans who have attempted to use American methods in Chinese classrooms have often been met with confusion, passive resistance or hostility from their Chinese students. Chinese students have several criticisms of American teaching methods (Porter, 1990, p. 37):

- American teachers do not give out enough supplemental materials or provide outlines.

- Reading assignments are too large.

- Assigned reading of reserved books with limited access make it hard to review for tests and gain access for deadlines.

- There is not enough writing on the blackboard.

- It is hard to take notes just by listening.

- Encouraging students to raise questions has some good points and some bad.

- Students like to be given questions to consider when reading an assignment.

- Beginning classes right after lunch with no rest time makes it difficult to concentrate. 


\section{Uncertainty Avoidance}

China is considered a moderately strong uncertainty avoidance (UA) culture while the U.S. is moderately weak. Many of the characteristics associated with uncertainty avoidance by Hofstede (1984) can be found in Chinese and American societies.

When comparing cultures on the UA dimension it is important to keep in mind that it is the members' perception of uncertainty present in the culture and the extent to which specific coping strategies are used that are being compared, not some objective level of uncertainty present in each culture. Certain coping strategies are considered more indicative of the desire to avoid uncertainty than others. As noted in the earlier theoretical description of Hofstede's dimension of uncertainty avoidance, strong UA cultures tend to rely more heavily on rules, ritual, technology, experts and employment stability (Hofstede, 1984).

The general American optimism about the future, sense of mastery of nature and overcoming barriers, the concern with efficiency, and the functional approach to thinking allows the American to be less concerned with uncertainty than the Chinese. Americans tend to believe that failure can be avoided in the future by taking action in the present (Stewart \& Bennett, 1991). If careful planning has identified the various probabilities and therefore the necessary response and resources, the American tends to believe he/she will be ready to act in a variety of ways depending on the circumstances. The Chinese sense of fate and inability to affect events that are the result of many different operating forces makes uncertainty more uncomfortable. Disaster can strike at any time without notice. Few individuals have the opportunity to make decisions by assessing outcomes 
in China (Yang, 1986) and making the wrong decision can result in loss of face, and or punishment (Bond, 1991). In the face of these consequences, uncertainty can be life-threatening. Some of the coping strategies found in American and Chinese cultures are similar and others quite different. The primary contrast between these two cultures is the belief in individual control over one's life and surrounding circumstances. Americans tend to believe that personal action can affect their environment while the Chinese tend to believe in fate and forces beyond their control. The Chinese will say, "Mei ban fa" (it doesn't matter) while the American will say, "What can I do about it?" or "What could I have done to prevent it?"

A study by Baird, Lyles and Wharton (1990) provides a contrast between American and Chinese attitudes concerning uncertainty. The authors studied attitudinal differences between American and Chinese managers regarding management of joint ventures. The characteristics the Chinese managers identified as most descriptive of their personal management philosophy were these: the need to exercise power and authority, willingness to delegate routine or mundane tasks to subordinates and retain important decisions at the top levels, the need to follow specified procedures, and feeling that "uncertainty was the worst kind of problem with which a manager had to deal." In contrast, the American managers rated concern with uncertainty as least descriptive of their management philosophy (p. 59). All of these preferences conform to the UA dimension for China and the U.S. on Hofstede's scale.

In an example of conflicting cultural differences, Pollock and Chen (1986) report on a 1982 collaboration between American and Chinese scientists planning for water pollution control in the Huangpu River. The 
Americans analyzed the decision making process of the Chinese and concluded that the process used in the West, characterized by generating alternatives, accounting for uncertainties, and eliciting decision maker's preferences, is not used in China and will not be used in the near future. The American team found that their Chinese colleagues were very uncomfortable with uncertainties and probabilities. Pollock and Chen said,

Our impression was that any analysis would proceed under the assumption of complete certainty about almost all important aspects: costs, technological availability, construction timing, weather, effects of treatment on the measures of pollution, social benefits, governmental policies, and so forth (p. 36).

The American scientists continually tried to convince their Chinese colleagues that the computer models made available to them were not designed to predict results with absolute certainty but to generate probabilistic effects of treatment alternatives on pollution. The Chinese continued to request models that were more advanced than the one being used in the hopes of predicting results with greater certainty.

To cope with uncertainty Chinese culture tends to rely upon the strength of traditional Confucian rules which dictate appropriate behavior based upon status, relationship and morality. This ritualized behavior allows for little flexibility and therefore provides considerable predictability in individual behavior. Other behavioral control mechanisms in China such as neighborhood watch committees and political study groups within work units also serve a similar function (DeGlopper, 1988). Chinese culture also depends upon clear authority and expertise as a means of dealing with uncertainty. The hierarchy of relationship, the veneration of age, and specialization leads to a dependence upon and honoring of the authority 
figure and expert (Pye, 1988, p. 102). Extreme specialization in training, education and actual job performance produces individuals that are skilled in a very narrow field. This honoring of experts is extended to foreigners who work in China as consultants or teachers who are referred to as foreign experts.

Technology is fast becoming a preferred way to deal with uncertainty in China. Flood control projects on the Yangtze River is an example of using technology to protect against an uncertain environment. It is believed in China that modernization requires the latest, state of the art technology. Acquiring this technology had been China's primary goal for several years and most joint ventures have involved the transfer of some technology to China (DeGlopper, 1988). The usability and appropriateness of much of this technology is questionable. Foreign visitors to hospitals, research institutes and factories often see sophisticated, modern machines, computers and instruments lying unused but housed in places of honor and for display. Clearly there is a sense of pride in having this technology. In terms of uncertainty avoidance, it appears that possessing the technology, whether or not it is used as it was intended, provides a sense of security.

Until just recently, all jobs in China were assigned by the state and were held for life. An individual could not be fired from his or her job even if performance was not adequate. This situation has become known as the iron rice bowl. This job stability provided a great deal of security for having a steady income whether one worked or not. Often more than one person was assigned to perform the same job earning a steady wage from the government whether they were actually performing the work (Savada \& Dolan, 1988). 
While Americans tend to feel they have greater control over their environment and fate they still use coping strategies for dealing with ambiguity. The United States is a society where law has become the authority that guides behavior and upon which people rely for safety and control of uncertainty in other's behavior. In American business practices several coping strategies for uncertainty are apparent. Planning, meetings, memos and reports, use of consultants, accounting systems and contracts are all considered methods for dealing with uncertainty (Hofstede, 1984). American culture is less concerned with employment stability in the Chinese sense of holding the same job for a lifetime. But while successive employment is becoming the norm Americans do fear being out of work and desire protection from being laid off or fired. To gain this protection Americans resort to unions and contracts.

Americans doing business in China have encountered a situation where uncertainty is the norm for them and their usual coping mechanisms are not as useful. Planning and creating probabilities are only as good as the information that is used to make the decisions. In the U. S. the information American corporate planners use to make predictions is easily accessible, and is perceived as fairly stable and reliable. In the case of China, the information is usually incomplete and frequently variable, often making carefully laid plans worthless. The Chinese usually adapt to this uncertainty by expecting change and by not feeling bound by any commitments or contracts if the circumstances change (Lindsay \& Dempsey, 1983).

American faith in contracts is constantly being challenged in China because of this dynamic. To the Chinese a contract is binding only if the conditions present at the time of signing are present at the time of 
execution, which is usually never. Americans have very little access to information from the Chinese about the changing circumstances surrounding a project and are therefore more stressed by the uncertainties in the situation. Americans need to rely less on carefully crafted plans and contingencies based on known circumstances, and create a more fluid and flexible structure that can respond more easily to the constantly changing Chinese situation (Lindsay \& Dempsey, 1983).

\section{Power Distance}

China is a moderately large power distance (PD) culture while the United States is moderately small in power distance. The Confucian tradition of hierarchical relationships based on filial piety continues to influence power relationships in China today. In fact an emphasis on filial piety tends to lead to large PD cultures (Bond \& Hwang, 1986, p. 228). America's history of individualism, egalitarianism, and status based on achievement has created power hierarchies that are easily changed, associated with roles and dependent upon persuasion and performance for effectiveness. Formal authority in American culture is based on legitimized power where an individual is accepted by subordinates as having the right to rule. This is based on having earned authority by demonstrating skill and accomplishment (Morgan, 1986, pp. 159-160). The existence of hierarchical power relationships exist in Communist China as they did in the past. Today, position in the hierarchy is often based on ideology rather than birth or scholarship (Von Glinow \& Teagarden, 1988).

In today's China, workers are involved in decision making through the election of their unit supervisors and union activity but substantive 
decisions are made at the top level of the bureaucracy (Von Glinow \& Teagarden, 1988). Decisions at the worker level usually involve issues of social welfare, housing and medical care (Lindsay \& Dempsey, 1985). The 25 to 35 leaders at the top of China's bureaucracy set the political climate for negotiations and actually approve all large projects. The power of these individuals is more personal than institutionalized primarily as a result of guanxi (Lieberthal \& Oksenberg, 1986, p. 24).

China's bureaucracy is a vast institution which controls all areas of Chinese life. It is very resistant to change, slow moving, and cautious in its decision making processes. Decisions are made at the top, often in private, where real authority and information on the current policy rests. At the same time an elaborate process of consensus building may precipitate any decision. Leaders are not required to justify their decisions nor to disclose the basis or principles upon which decisions are made (Bond, 1991). Information is power and is not passed very far down the hierarchy. Individuals working at lower levels have no authority and are often unaware of the current slant of political ideology on which to base decisions. Political correctness, precedent, effect on relationships, and potential for personal problems to arise are the basis for most decisions (Lieberthal \& Oksenberg, 1986; Seligman, 1989).

For a worker to make any decision is risky, so it is best to do nothing. Seldom is one criticized for doing nothing but should a decision be the wrong one the worker will suffer for it later. This situation results in a system where all important decisions and many minor manners are referred up the chain of command through the unit leadership to the provincial government and finally to Beijing. The highest levels are 
therefore saturated with all manner of problems and minor issues to be decided (Seligman, 1989). If a decision requires the involvement and cooperation of different work units or bureaus the process is even more complex. Between different bureaus there is competition for scarce resources, very little communication, and often some animosity. Unit or bureau rank in the hierarchy of the bureaucracy makes it difficult for lower ranking units to gain the cooperation of higher ranking units. Gaining cooperation usually takes a personal connection (guanxi) between individuals in the unit; or the lower ranking unit offers a resource desired by the higher ranking unit (Lieberthal \& Oksenberg, 1986).

Within any unit there is a leadership group who meet regularly to make decisions and share information. Decisions are actually made by a process of consensus building behind the scenes and involves people at different levels in the hierarchy. There are individuals at various levels of the bureaucracy who are able to stop a process through an arbitrary exercise of their authority. These people must be informed, asked for advice, and convinced that to go along with this idea or project is in their best interest (Macleod, 1988). Exchanging written memos, engaging in informal conversation, and holding meetings eventually produces a group decision that can be ceremoniously cemented in the formal meeting with no opposition. While the leader will have significant influence in the process a decision cannot be identified with a single individual. If the decision proves to be wrong, blame is harder to place (Wenzhong \& Grove, 1991).

At the same time, consistent with Chinese traditional respect for age and hierarchical status, suggestions from powerful individuals with considerable guanxi and face will be honored often regardless of their 
appropriateness. Pollock and Chen (1986) in the pollution control planning project found considerable resistance from their Chinese counterparts to eliminate any option, regardless of its vagueness or feasibility, that had been suggested by an "expert" or "authority."

American decision-making and problem-solving are usually influenced by a concern for efficiency, the consequences of actions, the prevention of negative situations, and valuing a new approach over something that has been tried in the past. Americans tend to focus on ways to avoid obstacles that may prevent a successful outcome to a project. They believe that anticipation of all probabilities results in the best course of action for a particular purpose and can prevent or compensate for possible problems (Stewart \& Bennett, 1991. p. 36). Stewart \& Bennett (1991, p. 39) suggest that this attitude is based on the belief in a mechanistic universe where time is a linear sequence of causes and effects. The planning process which begins with a vision statement and goals and then identifies the steps required to accomplish these goals assumes a linear conception of time and causation. This belief that all occurrences have a cause is reflected in American management's concern with "why?" questions. Why did he or she behave that way? Why didn't a certain technique work? Why didn't the shipment arrive on time and who is responsible? This encourages identification of the decision makers and problem solvers and identification of the responsible agent.

Most decision-making in American culture is located in the individual. People are expected to make and or participate in the decisions that affect their lives. When decisions are made by a group each person 
expects to offer his or her opinion and influence the final decision which is most often determined by a majority vote.

In the American workplace decisions are generally made from the top down by particular individuals who are identified as being responsible for specific decisions. Once a decision is made, it is the leader's job to convince the workers through persuasion and subtle pressure that it is the right decision and should be implemented. This style of decision making results in relatively fast decisions but often lengthy implementation (Adler, 1986).

The Chinese are more likely to accept situations as given and therefore would be less likely to take action to change a fluctuating situation. The situation will unfold as it will given the changing circumstances and no intervention is necessary or often possible. If a supplier will be late in delivering materials, the Chinese production may simply be delayed. American managers tend to see most situations as problems to be solved. They, therefore, will attempt to compensate for the late delivery by, for example, finding a different source for the needed materials or substituting something else. In this situation the American manager may identify a situation as a "problem" that needs solving long before the Chinese manager would see the same situations as a problem (Adler, 1986).

Chinese leadership style has been labeled "didactic." Information is power and is thus carefully shared by the leader with subordinates who remain dependent. The leader rarely openly states a position but keeps options open by guiding the department or organization through a "somewhat nebulous but nevertheless powerful set of personal intuitions." 
A leader's reputation and authority is based on his or her ability to intuit the correct strategy (Redding \& Wong, 1986, p. 278).

Bond and Hwang (1986) reviewed the research on preferred leadership style among Chinese and concluded that Chinese prefer a benevolent, authoritarian leader who defines clear-cut tasks for each group member and is able to take skilled decisive action while being considerate of the feelings of the followers (p. 251).

American democratic leadership style tends to locate decisions concerning policy and major goals and directions with higher management, and leaves the finer details of how to implement and accomplish these goals to middle management, work teams and individual workers. In democratic leadership it is important that the middle managers and workers feel they are involved in the decision and therefore committed to its success. The democratic leader, therefore, solicits ideas and feedback from the workers. He or she

spends time listening, summarizing, integrating, and guiding what is being said, making key interventions and summoning images, ideas, and values that help those involved to make sense of the situation with which they are dealing ... (Morgan, 1986, p. 176).

On the whole, American workers have considerable autonomy in deciding how to accomplish the tasks they are assigned. As long as the leadership has provided clear objectives and expectations it is assumed the workers are doing the job and don't need constant monitoring. Making deadlines and final production goals are the criteria used for judging the individual's work. 
Baird, Lyles and Wharton (1990) confirm Bond and Hwang and their conclusion are consistent with the strong PD rating of the Chinese and the weak PD rating of the Americans. In this study Chinese and American managers were ask for their description of their preferred management style and ideal joint venture supervisor. Chinese managers emphasized a preference for "merit rewards, and an impersonal, less participative and more individual style of joint venture management" (p. 61). They preferred an authoritarian decision-making structure in which subordinates followed instructions while important decisions were made by higher management. They preferred a very paternalistic supervisor who provides rewards for effort, exposes employees to other departments or levels of management, maintains friendly relations and is considerate of individual feelings (p. 65).

The American managers "favored a personal, more participative, more team and consensual approach to managing joint ventures" (p. 61). They preferred a joint venture supervisor who explains performance standards and the quality of work expected, demands high work standards, focuses group attention on important matters, and provides feedback, rewards and information about change. Considering feelings and maintaining friendly relations were less desired (p. 65).

The authors point out that the different attitudes in team involvement in decision-making can present serious problems for American managers involved in joint ventures with the Chinese. The Chinese may express interest in worker participation while in actuality expect decisions to be made by management alone. They caution American managers in the use of quality circles and employee suggestion programs in Chinese enterprises where the American notion of teams and democratic 
participation does not exist (p. 65). They advise American managers to pay attention to the Chinese desires for paternalistic, authoritarian use of power by guiding, helping and reassuring workers, using positive reinforcement and considering workers feelings rather than involving them in decisions (p. 67).

Lindsay's and Dempsey's (1983) experience in China supports the contention that involving Chinese, who are not leaders, in decision-making is not appropriate. The authors trained Chinese at the Beijing Institute of Foreign Trade in modern American management theory and techniques. When they attempted to involve the students in decisions regarding the design and content of the training program, the institute leaders accused the Americans of failing to do their jobs and forcing their responsibilities onto the students. The same authors (1985) trained students at the Beijing Institute of International Economic Management in management techniques. The students were required to come up with a decision within a small group. The trainers did not assign a group leader. They found almost identical processes in all the small groups. After an initial period of complete silence an individual nominated a group member as leader and the others agreed while the nominee attempted to nominate someone else. This was followed by each person stating his or her position with no discussion, questions or feedback until they all had said something, then the leader made the decision.

Bond (1991) reports that Taiwanese who were required to make individual decisions in a test situation experienced stress and made many attempts to avoid making a decision or individual choices. He notes that the respondents in the study 
... were more likely to panic under the pressure of time, pass off responsibility, procrastinate, and rationalize away problems than were their Western counterparts. This pattern of response is understandable in a person who has been trained since his or her early years to defer to superiors or to a group when he confronts new circumstances alone (p. 85).

On the other hand Nelson and Reader (1987) report on the successful use of quality circles at Shenyang Heavy Machinery Plant and at Beijing Diesel where $75 \%$ of the 10,000 workers are involved in groups. In both cases after the training and implementation of quality circles "quality greatly increased" (p. 152). More research needs to be done in these plants to determine the reasons for the success of quality circles in these situations.

Consistent with Ting-Toomey's theory on the relationship of high and low context with conflict, the high context Chinese expend considerable energy-avoiding conflict and maintaining harmony. Avoidance of conflict is very important to the Chinese who believe that any kind of dispute can lead to luan (chaos). They therefore employ a number of indirect techniques to prevent conflict and resolve it if it surfaces. The use of mediators, both formal and informal, is commonly employed which allows the opposing parties to save face more easily than direct confrontation (Ma, 1992). A Chinese leader is expected to anticipate and diffuse potential conflict. A leader's responsibility is to intervene when conflict occurs and then to resolve the issue backstage by talking independently with the opposing parties. If a meeting is to take place involving the opposing parties their conflict must be resolved before the meeting takes place. Bond and Hwang contend, "The overall leader is the master puppeteer carefully balancing contending parties" (Bond \& Hwang, 1986, p. 262). 
Besides the use of mediators other non-confrontational approaches to resolving conflict are used. Their strategies include avoidance techniques such as withdrawing and waiting, and looking at the long view of things and passive aggressive techniques such as playing helpless, going slow, not understanding, rumor, gossiping and making false promises (Bond, 1991; Bond \& Hwang, 1986). They consider these approaches more likely to result in a restoration of harmony while still allowing them to control the outcome of the conflict (Bond, 1991).

The Chinese indirect style of discourse is connected to their need to avoid conflict and maintain interpersonal harmony (Bond \& Hwang, 1986; $\mathrm{Ma}$, 1992). According to Bond and Hwang, a Chinese person, when engaged in a discussion, will first provide a picture of the context within which the issue is operating and the problems the individuals involved share and are constrained by. Only then will the individual present his or her own position (Bond \& Hwang, 1986). The indirect style is also characterized by the use of qualifiers such as "perhaps," "fairly," "somewhat" and "maybe" and a limited use of personal pronouns. There will also be much flattery of the other party and much repeating of the other's position and statements previously made (Bond, 1991). According to Bond,

The aim of such style is to protect the relationship and allow the parties to the conversation maximum freedom of manoeuvre. A tentative approach permits the relationship to evolve harmoniously. No party will be frightened away from eventually presenting his or her true position by another's assuming an uncompromising stance. So, the Chinese feeling is that the truth is discoverable if people proceed circuitously. Silences are an important element in this process (Bond, 1991, p. 53). 
This author experienced many instances in China where a Chinese person was reluctant to say "no" and therefore would say "maybe." A desk clerk in a hotel was asked if there was a restaurant in the hotel and he responded by saying "Maybe we don't have a restaurant" rather than be forced into saying no.

The indirect conflict management techniques the Chinese prefer to use often appear to Americans as dishonest, hypocritical, and manipulative. The Chinese tend to believe direct expression of a conflict which can release chaos, leads to lasting enmity. In contrast, the low context Americans tend to believe that "when given the opportunity to know the affect of one's behavior on a situation, one can choose to change to enhance the relationship" (Bond, 1991, p. 66). Americans tend to believe that without a confrontation that "clears the air" there is little chance for the relationship to continue with any sense of trust. In fact, Americans often believe that working through a conflict can strengthen a relationship (Hocker \& Wilmot, 1985). That is not to say that all Americans always directly confront their opponent in a conflict. Americans also use indirect means to express their anger and dissatisfaction, but these means are usually perceived as counterproductive to resolving the conflict and are often considered ways of escalating the conflict. Americans usually expect an honest expression of feelings in a confrontation where both sides of the issue can be "laid out on the table" (Stewart \& Bennett, 1991, p. 96). The implicit faith in "talking things out" includes an assumption that perspectives differ and, in a low context culture, one person may not have all the information that explains and justifies the other's behavior. The only way for the "real facts of the case to emerge" is to talk about it face to face. 
Bond (1991) emphasizes that this approach to conflict would not work in the Chinese context:

The Western tradition of straight talk, open debate, friendly disagreement, and loyal opposition has no place in an interpersonal system focused on relationship rather than 'truth', given that relationships are mostly hierarchical and involve wide discrepancies in usable power. Indeed, it is precisely this hierarchy that constitutes 'truth', not some Platonic form discoverable by logical or scientific inquiry. As the Tao Te Ching puts it, 'A good man does not argue; he who argues is not a good man.' This is the Mandate of Heaven and sound guidance to Chinese leaders below (p. 55.). 


\section{CHAPTER III}

\section{METHODS}

This chapter discusses the methods used in conducting this study. The phenomenological world view is discussed as the basis for the qualitative method of data gathering and analysis. A detailed description of the process of finding respondents, developing interview questions and conducting the in-depth interviews is provided. An ongoing constant comparative method of data analysis was used to analyze the interview data. The final analysis of the data resulted in several major categories of problems each with many subcategories.

\section{META-THEORETICAL CONSIDERATIONS: THE SOCIAL CONSTRUCTION OF REALITY AND PHENOMENOLOGY}

Understanding how American trainers perceive and interpret their encounters with Chinese in a training situation is best approached from the humanist philosophical tradition of phenomenology. Phenomenological investigators deal primarily with the description and explanation of the individual's interpretation of his or her own experience as it unfolds (Kim, 1988).

Littlejohn (1983) describes the epistemological and ontological traditions of social science inquiry as falling into two basic world views 
(WVI and WVII): humanistic and scientific. Different labels are assigned for these philosophical positions by different scholars. Hawes (1977) contrasts phenomenology with positivism and Morgan and Smircich (1980) prefer to conceive of these traditions as a continuum from extreme objectivism to extreme subjectivism. Regardless of what label is applied they all agree on the differences in the nature of reality to which these traditions ascribe.

World View I or the objectivist tradition views reality as a concrete, objective structure that exists outside of human conception but that affects everyone. This reality can be broken down into distinct parts. The behavior and relationship of these parts can be objectively studied and known through hypothesizing and careful, measured testing and observation. The goal in this kind of research is to discover universal laws which govern phenomena and can be generalized over time to all situations. Behaviorist methods that seek causal relationships are most often used in this tradition, although many methods can be adapted to these core assumptions (Hawes, 1977; Littlejohn, 1983; Morgan \& Smircich, 1980).

At the other end of the spectrum is phenomenology. The phenomenological or WVII tradition is based in the notion that reality is a social construction arising from human interaction with one another and the universe. This constructivist view of reality is one of process where the universe is real, a cacophony of sensory events in constant movement and change. But this reality can only be known as it is filtered and processed by a human being who then renders an interpretation (Kelley, 1963). This reality takes on an objective appearance and becomes reified as interpretations are 
shared and passed on to future generations through communication and other symbolic modes of expression. This is the process of creating culture and social order (Berger \& Luckman, 1967).

According to the constructivist view the universe is a "kaleidoscopic flux of impressions" which human beings need to organize and interpret (Whorf, 1956). This is accomplished by creating categories or boundaries around selected sensory events through the principle of figure and ground and comparisons of similarity and difference. The individual's distinction of what is figure and what is ground is learned and tested through socialization and communication. Individuals use these constructs to guide their choices and behavior and to make predictions about future events in order to accomplish their goals. Without prediction the human being would encounter each situation as a new event and there would be no culture, and no social order (Applegate \& Sypher, 1988; Berger \& Luckman, 1967; Kelley, 1963; Stewart \& Bennett, 1991).

In this process the human being is an active creator and choice-maker and therefore has the ability to change current constructs of reality. In addition to having unique biological characteristics which produce unique physical perceptions, this ability to adapt and change constructs results in individuals having different experiences and interpretations of their perception of events. It is this subjective experience and interpretation that the phenomenologist is interested in exploring to uncover the processes by which people make sense of and order their reality. According to Hawes, "A phenomenologist advocates finding out what members, acting in their everyday capacities, do to constitute their social worlds and how they do this communicatively" (Hawes, 1977, p. 36). 
According to Littlejohn (1983), communication research arising from the phenomenological perspective attempts to "describe the rich context in which individuals operate," "stresses the individual subjective response" and is "based on the assumption that communication itself is a vital vehicle in the social construction of reality." He summarizes the characteristics of WVII theory and research as follows: the researcher's interpretation is stressed; tacit processes and overt behavior are uncovered; social knowledge is seen as arising from symbolic interaction; individual differences are stressed; and communication is viewed as a process (p. 21).

\section{QUALITATIVE RESEARCH METHODS}

Qualitative methods of inquiry, such as in-depth interviewing and participant observation, have been designed to discover the ways individuals perceive phenomena and to produce descriptive data (Taylor \& Bogdan, 1984, pp. 5-8). Several principles common to qualitative methodology that have been described by Rist (cited in Taylor \& Bogdan, 1984, pp. 5-8) are relevant to the current study:

- Qualitative research is inductive in that theory is developed from the data.

- People are viewed holistically within their contexts.

- Researchers are sensitive to how they influence the people they study and they try to be as unobtrusive as possible.

- Reality is defined by the people being studied and the researcher tries to experience that point of view.

- The researcher's preconceived beliefs, perspectives and predispositions are suspended.

- All perspectives are considered equally valuable. 
- People are treated with respect and their humanity is honored.

- Validity is emphasized rather than reliability and replicability.

- All settings and people are worthy of study.

- Qualitative research is a craft that requires flexibility - there are guidelines but no rules .

The purpose of this study is not to verify an existing intercultural communication theory but to discover how a sample of corporate trainers working for American companies interpret their experiences training Chinese. This is an exploratory, phenomenological field study which uses the qualitative method of in-depth interviewing for data collection and an interpretative, on-going method of data analysis. This study does not propose theory, but is the first step toward developing theory. This study addresses two research questions:

1. What problems do trainers, working for American companies, report they experience in training Chinese students from the People's Republic of China?

2. To what extent do cultural differences between Americans and Chinese account for these problems in a training context?

Given that research of this type focuses on individuals' subjective experience, it is not possible, nor desirable, to establish a fixed research plan. The research proceeds flexibly, guided by the people being studied and their "process of interpretation" (Taylor \& Bogdan, p. 9). Nevertheless, qualitative research is a systematic process with "demanding, though not necessarily standardized, procedures" (Taylor \& Bogdan, p. 7). 
In-depth interviewing does not rely on a set of strictly worded questions that are asked in exactly the same way to every respondent. Instead the interviewer is guided by general areas of interest and flexible questions that can be changed and probed depending upon the responses. As the research progresses the data begins to have a focus that guides subsequent investigation.

Glaser and Strauss (1967) propose the constant comparative method for qualitative research. The data is examined as it is collected and the researcher notes themes, intuitive hunches, and ideas. The researcher is concerned not only with what respondents say and do but also with what they may have omitted. As the data accumulates, themes from different interviews are compared and relationships are proposed toward the development of "concepts and theoretical propositions" (Taylor \& Bogdan, 1984, p. 133). The data is coded in a clear and systematic way. The coding involves combining data that support a particular theme or idea and assigning appropriate categories. Themes and categories may be eliminated or expanded as the analysis continues. The categories are refined until the themes are clear and supported by the data. The final phase, called discounting the data by Deutscher (1973), involves interpreting the data within the context in which they were collected.

\section{Respondents}

A total of nine trainers, from eight companies were interviewed for this study. Eight were men and one a woman. Potential respondents were sought from a variety of sources. The Intercultural Institute in Portland, Oregon, the Northwest China Council of Portland, Oregon, and personal 
friends were the initial sources for potential respondents. These sources yielded eight of the respondents who were interviewed. The eight who were chosen had the relevant experience training Chinese and were willing to be interviewed.

Other organizations contacted for possible respondents included the Seattle Area China Council, Portland Chapter of the American Society for Training and Development, the Portland Trade Center, various private consulting companies, and professors at Portland State University. In addition, snowball sampling (Coleman, 1958) was used in this study. The trainers interviewed suggested other individuals who had experience training Chinese who were subsequently contacted for interviews.

Six of the potential respondents were sent a letter (see Appendix A) which introduced the researcher, briefly described the research, and requested an interview. This letter of introduction was used to prepare the respondent for the request and to project a professional and non-threatening image of the researcher (Kotarba, 1980). The letter was followed by a telephone call within two weeks of mailing the letter. Five interviews were granted and appointments were arranged during this one series of telephone conversations. In one case the respondent needed to clear the request with management before agreeing to an interview. In this case the respondent was called the following week and an appointment was then scheduled. One respondent was personally approached by the researcher during a week long seminar where the respondent was a presenter. The respondent granted an interview at the end of the week after the seminar was over. The interview with two respondents who worked for an American company in Hong Kong was negotiated through a personal friend 
of the researcher who worked for this company in the home office. The two Hong Kong respondents were contacted by the company secretary who conveyed the request for an interview. The secretary notified me by phone that the interview would be granted and when the two respondents would be available. A time for the interview was agreed upon and the secretary notified the respondents of the plans.

Eight of the respondents worked for American companies based in the Pacific Northwest. The ninth respondent's consulting firm was based in Arizona. Two respondents were Chinese-American, two were Hong Kong Chinese working for a Portland, Oregon based company, and the others were Caucasian American. The ages of the respondents ranged from late twenties to late fifties.

The companies' years of experience doing business in China ranged from one year to ten years. All respondents had trained Chinese, designed training programs for Chinese, directed the training programs and/or trained trainers of Chinese. Each of the respondents had been involved with their company's training program for Chinese from its inception. Four of the companies' training programs involved training the Chinese only in their U. S. plants, two involved training on-site in China, one conducted training on sites in China and Hong Kong, and one involved both training in the U. S. and in China. One training program could be classified as primarily orientation, four programs were strictly on-the-job training, and two combined classroom instruction with hands-on experience. One respondent reported on several different training experiences involving a variety of types and methods. 


\section{In-Depth Interviews}

In-depth interviewing, also known as intensive or unstructured interviewing, is designed to elicit a rich, detailed picture of respondents' experiences (Lofland \& Lofland, 1984, p. 12). Taylor and Bogdan (1984) define in-depth qualitative interviewing as

... face to face encounters between the researcher and informants directed toward understanding informant's perspectives on their lives, experiences, or situations as expressed in their own words (p. 77).

In-depth interviewing was determined to be the most appropriate method for the current study for several reasons. In-depth interviewing is particularly appropriate when research interests are clear and well-defined, settings or people are not accessible for direct observation, time is limited, the research requires a broad range of settings or people, and the research focus is subjective human experience (Taylor \& Bogdan, p. 81).

In-depth interviewing is designed and conducted as a conversation and "seeks to find out what kinds of things exist in the first place" (Lofland \& Lofland, 1984, p. 12). Therefore in-depth interviewing questions are flexible, not set pieces that are asked in exactly the same way or order with each subject. In order to elicit the richest material from subjects, the interviewer must take the time to create a comfortable environment and establish trust with the subject. This may require spending time in preliminary conversation, laying the foundation before the interview topics are brought up. The interviewer also must be open to non-verbal nuances and verbal disclosures that may guide the interview in unanticipated directions (Lofland \& Lofland, 1984; Taylor \& Bogdan, 1984). 
As noted above, there are several conditions that may make in-depth interviewing the ideal method for the investigation. But there are some limitations to in-depth interviewing that the researcher must be aware of and account for during the investigation. According to Becker and Geer (1957), interviewers, by virtue of not observing subjects in their environments, lack the perspective of context and the depth of understanding that perspective can bring. Specifically they point out that interviewers may misunderstand responses because of language differences and have different interpretations. Also, respondents may be reluctant to articulate certain things that interviewers might otherwise be able to observe in the respondents' environments. Interviewers must fill in the blanks and make "assumptions about things that could have been observed and some of these assumptions will be incorrect" (Taylor and Bogdan, p. 82).

\section{Interview Schedule}

Chapter I discussed the relationship between communication problems and cultural differences and elaborated on the ways cultural differences between the U.S. and China may affect training. The interview schedule was therefore based on first identifying problems American trainers perceived in training Chinese and then probing them for explanations to gain insight into their thinking behind a perceived problem. There were two phases to the study. Phase I involved two respondents who were asked very open and general questions about their experiences training Chinese. Phase II involved seven respondents and a more detailed list of questions which were based on the themes that emerged from the Phase I interviews. 
The interview schedule for Phase I consisted of three basic questions (see Appendix B). The first was aimed at obtaining demographics, and background information on the nature of the business the respondent's company had with China. It also was aimed at establishing a conversational atmosphere by getting the respondent talking about his or her company and China experience. The second question focused more specifically on the training program. And the third question asked about problems, difficulties or conflicts. Throughout the conversation clarifying questions were asked about the respondent's role, the timing and sequence of events, and other significant individuals. The respondents were often asked to elaborate on specific points and to provide more detail. Many of the probing questions asked the respondents for examples or stories to illustrate their points. In addition they were sometimes asked how they felt when they were dealing with the problems they described. They were also asked to describe the problems their Chinese trainees experienced and to speculate on causes or explanations.

On-going analysis of the Phase I data yielded a set of initial problem categories that were used to design questions for Phase II. As new categories emerged they were included in the subsequent interviews as questions. The basic set of categories as reflected in the final interview schedule (see Appendix C) were fairly well established by the end of the fifth interview. The interview schedule was continually revised and adjusted according to the needs of the immediate interview. The question order as well as the wording of each question was flexible. Some questions were answered by the respondents within the context of other questions and therefore the question was not specifically asked. And at times a question was not 
included because it was irrelevant for the context. As in Phase I, probing questions were asked to elaborate on certain points and gain a deeper, more detailed explanation for a specific response.

The two Chinese-American respondents expressed concern prior to the interview that focusing on problems would be construed as criticism by their Chinese partners or the public. As noted in Chapter I this concern may be a reflection of the difference in cultural values between the American propensity to focus on the problem in order to improve the situation and the Chinese desire for formal surface harmony to avoid conflict. It may also be a very justifiable concern for their future business relations with China given the Chinese sensitivity to criticism and their highly effective intelligence system. The respondents were assured of complete confidentiality but one of the Chinese American respondents avoided using the word "problem" throughout the interview and used the Chinese indirect style of communication.

\section{PROCEDURES}

\section{Interviews}

Phase I interviews were conducted between March and July, 1989 and Phase II interviews were conducted between July and December, 1989. Ten interviews were conducted with nine respondents. One respondent in Phase I was seen twice because of lack of time in the first interview and to clarify particular points. One interview was conducted with the two Hong Kong Chinese respondents together. The researcher had agreed with their parent company supervisor to interview them together because of their 
limited time in the United States (one week) and because they worked together to train Chinese in the PRC.

Five interviews took place in the respondents' offices at their place of business during regular business hours. One interview was conducted in the researcher's office at Portland State University for the convenience of the interviewee. One interview took place in a hotel room in Portland, Oregon where the two people from Hong Kong were staying for a business conference. One interview took place at Marylhurst College, West Linn, Oregon during a conference on intercultural communication.

The respondents were told in the introductory letter that the length of time needed for the interviews would be from one to two hours. I always asked the respondent how much time we had for the interview before we began. I found that once we were talking the respondents often extended the time. If I had not completed the questions before the time was through I asked the respondent if we needed to stop. In all but the first interview they extended the time until I had completed the questions. I was able to schedule additional time with the first respondent at a later date to complete the interview. Several of the respondents said they enjoyed the interview and talking about their China experience. The interview allowed them to think about their training program in a way that they had not done previously.

Before beginning the interview, I introduced myself and the research project. I told the respondent that I was a graduate student at Portland State University conducting research for the master thesis. I explained the intent of the research and that I would be asking questions about his or her experience training Chinese. I emphasized that the objective of the research 
was to better understand American-Chinese interactions and to come up with ways of improving training programs for Chinese. I then asked them if they had any questions about the project.

I explained that all information they gave me would be kept confidential, that neither in writing nor speaking would I disclose the identity of the company or the respondent. At this point I gave them a copy of the Informed Consent Form (Appendix D) and asked them to read and sign it if they felt comfortable with the guarantee of confidentiality. One respondent asked to make a copy of the informed consent form for his files and I agreed. I then asked if they minded if I tape-recorded the conversation as it was easier for me to listen and remember if I didn't have to take notes. No one refused to be tape recorded.

\section{Recording Data}

The two Phase I interviews were conducted without a tape recorder but extensive notes were taken. A tape recorder was used during the second interview with the one Phase I respondent who was interviewed twice. All Phase II interviews were tape recorded. There were no technical problems with the recording equipment during any of the interviews and all of the tapes were clear and easily understood. All respondents said they didn't mind being recorded. One respondent did ask me to turn the recorder off at one point when she was reporting an incident she felt was particularly sensitive. 


\section{Transcription}

Field notes were made for each interview the same day or within one day to keep the impressions fresh. Field notes consisted of early ideas for categories, interpretations and hunches, my impressions of the respondent's feelings, nonverbal behaviors, and my own reactions to the information and the individual.

For the Phase I unrecorded interviews, the interview notes were reviewed within one day of the interviews. All interview notes were logged within three days of the interviews. The interview notes and the field notes were read several times, and compared to begin to gain a sense of the issues that were important to the trainers.

For the Phase II recorded interviews, each tape was listened to within two days of the interview and notes were made of first impressions to add to the field notes. Field notes were made of all interviews. During the interviews, quick notes were often made of items of importance that came up in the interviews, ideas for probing questions, and impressions. These notes were immediately expanded into field notes after each interview.

All tapes from the recorded interviews were transcribed over a longer period of time. To ensure confidentiality, each respondent was assigned an identifying code based on the order of the interviews and the company. This code was used on the transcription to identify the respondent. Two copies were kept of the transcription; one was a working copy while the master was placed in my home safe along with the original tapes. 


\section{Data Analysis}

In keeping with Glaser and Strauss' (1967) constant comparative method, the data was analyzed and compared as it was gathered. Reading and re-reading the field notes and interview notes of the first interview yielded several ideas and impressions. These early issues were worked into the next interview which were then examined for further developments along the same themes or new ones. This on-going analysis of the data produced a set of preliminary categories of problems that then formed the basis for the interview questions for the rest of the interviews. As data were continually analyzed and compared, nuances, concerns, perspectives, metaphors, examples, and images would emerge and subsequently influence the interview schedule.

Once the interviews were completed and transcribed, the data were examined again as a body. At this stage the data were read and re-read until the material was thoroughly familiar. The hunches, themes, metaphors, and feelings from the field notes were incorporated with the interview notes. The responses to each question from each interview were compared to find patterns of similarities and differences. The categories represented by interview questions were not considered the final categories, so the data were scrutinized for new themes, concerns and notable absences. During this process, small unified sections of data relating to specific themes were identified.

From this intense study of the data, a set of problem categories slowly emerged. The previously identified sections of data were coded by category. At this stage the data took on the appearance of a puzzle. The major categories and subcategories were assigned a color. Sections of the data were 
then circled, underlined or checked with the color associated with the related categories and coded with their level of importance. Names of categories were put on slips of paper and were shuffled in many different configurations. Names were changed, categories combined and eliminated, major categories were created and subcategories were lined up beneath them. Finally a cohesive and meaningful set of major categories and subcategories with supporting data from the interviews was established.

These piles of pieces of data were examined as a group to find relationships and to see if they made sense as a whole. I was continually asking "What was the common thread, what was missing and why?" This resulted in further refinement of the categories with other sub-categories being created, categories being merged and renamed, and new categories being identified. Finally, major problem categories with their subcategories were identified and supported by the data. 


\section{CHAPTER IV}

\section{DATA DESCRIPTION}

This chapter presents the data collected in the interviews conducted for this study. This description is divided into two parts: first, an explanation of how the categories are organized, general observations and a brief overview of each training program; and second, a description of issues or problems identified by the respondents.

The problems and issues that emerged from the data analysis are organized into three levels. The first level are the major categories which identify the general theme that pervades the subsequent subcategories and problems. The three major categories are Power and Authority Training and Learning Problems, and Work Attitudes and Behaviors.

Within these major categories the subcategories define an activity, a cultural institution, or psychological characteristic such as Decision-making, Work Habits and Motivation. Listed under the subcategories are the specific problems and issues that the respondents reported. These problems and issues are stated in words used by a respondent or are compiled generalizations from several respondent's comments. Direct quotes from the respondents are presented as support for the specific problems.

In many cases it is apparent that a particular quote is relevant to more than one problem. Each quote is listed under the problem that it best 
illustrates. Rather than repeat quotes under different problems, some problems are supported by only one quote that best represents the sentiments of several respondents. Some problems have more supporting quotes than others. Frequency was only one reason a problem, word, or metaphor emerged as significant. Field notes and the nonverbal aspects of the interviews were helpful in indicating the importance respondents gave to particular problems or issues. Intensity of emotional expressions associated with a particular problem or story, the amount of time a respondent spent on a particular issue or story, and how often he or she referred back to a particular incident were also factors in determining the problems. Sometimes this resulted in a problem with only one supporting quote.

At times it was difficult to separate problems into independent, discrete categories. Therefore certain themes and interpretations are interwoven and repeated throughout the problems. For example a common theme that emerged in the interviews was "fear." The respondents frequently attributed "fear of getting into trouble" as the reason for Chinese behavior in many different situations. This theme is interwoven throughout the problems and is found as an explanation for a lack of motivation, lack of responsibility, and unwillingness to make decisions. "Responsibility" was also a pervasive theme that was found related to motivation, decision-making, work habits, quality and other issues. 


\section{OVERVIEW OF CATEGORIES}

Category I, Power and Authority, contains these subcategories and problems:

Bureaucratic Maze describes the difficulty the respondents had with the Chinese power structure and identifying leaders and decision-makers. The specific problems and issues in this subcategory are:

- It's Hard to Tell Who's in Charge, and

- No Explanations Are Provided for Actions.

Decision-making recounts the respondents' difficulty understanding and influencing how decisions are made and gaining access to information in China. The problems and issues are:

- Chinese Display No Individual Initiative, and

- Chinese Allow No Access to Information.

Getting Things Done describes respondents' exercise of authority and their strategies for dealing with the Chinese system. The problems and issues are:

- My Authority Was Not Always Recognized, and

- Everything Takes Longer in China.

Communication involves the problems the respondents had identifying and using the lines of communication within Chinese organizations. The problems and issues are:

- Communication Is Only From the Top Down, and 
- Chinese Managers Don't Share Information Among

Themselves.

Connections reflects respondents' frustrations with the Chinese system of guanxi. The problems and issues are:

- Nothing Gets Done without Connections,

- The Connections System Inhibits Quality, and

- There Is No Company Loyalty.

Category II. Training and Learning Problems, contains these subcategories and problems:

Language involves issues and attitudes concerning language differences, including the use of interpreters and translated written materials. The problems and issues are:

- The Language Gap Inhibited Our Effectiveness,

- Translators and Interpreters Don't Have Technical Backgrounds, and

- The Relationship with Interpreters Is Important.

Training and Learning Processes includes respondents' comments concerning the Chinese reluctance to ask questions, classroom behaviors and cognitive processes. The problems and issues are:

- Chinese Take Lots of Notes and Remember Everything You Say

- Chinese Are Reluctant to Ask and Answer Questions and Ask for Help, 
- Chinese Don't See How All the Parts Fit into the Whole,

- Chinese Have Trouble Going from Theory to Application,

- The Training Should Be Tailored to the Student's Specialization,

- Tests Can Cause Students to Lose Face.

Problem Solving describes differences in problem identification and respondents' perceptions of Chinese methods of problem solving. The problems and issues are:

- Chinese Are Good at Modification and Practical Solutions But Lack Creativity,

- Chinese Rely on Experts to Solve Problems, and - Chinese Don't Recognize Problems.

Technical Sophistication explores the limited exposure to technology the Chinese have had and the affect it has in training and utilization of new technology in Chinese plants. The problems and issues are:

- Chinese Expect High-tech Equipment Even When It

Isn't Appropriate, and

- Chinese Have Limited Exposure to Technology.

Selection of Trainees is mentioned as a key factor in the success of training programs but often respondents were unable to influence the selection process. The problem is:

- The Chinese Select Trainees Who Are Not Always Appropriate. 
Category III. Work Attitudes and Behaviors, contains these subcategories and problems:

Motivation was the issue that was mentioned most often as a problem by the respondents. The respondents describe what they believe is necessary for workers to be motivated and they provide interpretations about what appears to motivate Chinese workers. The problems and issues are:

- Chinese Get Paid the Same Whether They Work Hard or Not,

- Quantity Rather Than Quality Is Emphasized in

Chinese Industry

- You Can't Fire Chinese Workers for Poor Work,

- Individual Initiative Is Dangerous,

- Giving and Losing Face Can Be a Strong Motivator,

- Chinese Trainees Will Respond to Material Rewards, and

- Curiosity Is a Motivator.

Responsibility concerns the frustration the respondents had with identifying individuals responsible for getting things done, and the willingness or unwillingness of Chinese people to take responsibility. The problem is:

- Few Chinese Are Willing to Take Responsibility.

Work Habits involves comparisons between Chinese and American work environments, worker behaviors and attitudes including 
discipline, quality control and teamwork. The problems and issues are:

- Chinese Don't Work as Hard as Americans,

- There's No Teamwork in China and

- Chinese Have No Concern for Quality.

\section{GENERAL OBSERVATIONS}

Several issues emerged from the interviews that are not problem categories but are worth noting. The fact that the respondents were primarily managers and engineers appeared to influence what they wanted to talk about during the interviews. Many of the comments tended to pertain to general areas of doing business in China rather than specifically to training. While training was the focus of this study only one respondent was a professional trainer and had received any formal training in how to teach or train people. The other respondents were assigned or volunteered to develop a training program and carry out the training of Chinese. They were all technical, management or sales people in their respective companies.

Only the computer company and consultant/trainer used professional trainers or instructional designers in the preparation of the manuals and basic training design which were then adapted for use in China or to train Chinese in the U.S. All other companies used their engineers and technicians to write their manuals and prepare training materials. The purpose of this study was not to evaluate the training programs in terms of training principles or adult learning theory. Further 
research needs to be done to determine whether using training professionals to design and present the training would positively impact these training programs.

The respondents all became involved in their company's China project because they were attracted to China. Some respondents' interests began in childhood while others' interests were more recent. In all cases the respondents expressed tremendous respect for the Chinese. They expressed strong feelings about their experiences in China, saying, "... it was a fantastic experience, just fascinating," "I loved it over there, I really did. And I liked the people. We just really had a great experience," "China can be incredibly frustrating, exasperating, but it gets into you. China pushes you in ways you never - well, China makes you examine everything you thought was true about yourself and about reality."

All respondents recognized to varying degrees that cultural differences were involved in the problems they experienced in China. They were thoughtful and sincere in seeking understanding about their experiences and analyzing their own reactions to Chinese culture. The respondents had spent considerable time thinking about specific encounters, conflicts and confusing situations and offered interpretations they had developed to explain Chinese behavior.

In general they all felt China had great potential to be a full partner in international trade. They believed that reaching the production standards expected in world markets would take many years and would require the adoption of some Western business practices. Their comments must be considered within the context of a representative of an American company training Chinese in the use of American technology and American 
manufacturing methods. Contextual evaluations are necessary when trying to determine better or more appropriate ways of doing things in any culture. As was noted in the introduction of this thesis:

By identifying cultural strengths and weaknesses of our foreign partners and integrating them into our own cultural patterns, the results of our interactions can be far more satisfying and productive (Stewart, 1978).

\section{OVERVIEW OF COMPANIES}

A brief overview of each company and their training programs will provide a context for the discussion of the problems and issues which follow.

\section{Earth Moving Equipment Manufacturing Company (EMEMC)}

The earth moving equipment manufacturing company provided extensive training for Chinese workers in a manufacturing plant in northern China. The Chinese plant had been producing machinery for twenty years based on design and technology that was forty years old. They approached this American company to upgrade their technology and skills. The American company hoped to have world-quality equipment produced in China that could be exported to other Asian countries as well as sold in China. For every piece of equipment produced in this plant using the American technology the American company would receive a royalty. The contract involved a transfer of technology and training.

Four groups of twelve to fifteen Chinese were brought to the U.S. for two weeks to two months of training in all aspects of steel making and 
fabrication of earth moving equipment. Prior to this licensing agreement the American plant had never produced manuals describing their procedures. Their processes had been handed down from worker to worker often from father to son for their entire history. In preparation for the training of Chinese they developed twelve volumes of documentation describing every procedure in their plant. These manuals were then sent to the Chinese for translation. The English versions of the manuals were the basis of all training provided for the Chinese workers.

The American company designed a "rigorous schedule" for the Chinese trainees in order to maximize the limited time they had in the U.S. The training consisted of classroom lectures and on-the-job-training. The respondent reported,

They spent four hours in a dedicated classroom environment going over the theory of what they were going to do, then they would go out to the shop for maybe two days and actually do it, actually weld, actually charge the furnace, actually make molds along side our shop people under the guidance of the shop supervisor.

Company engineers and managers were the instructors. All the lectures were in English based on the manuals and supplemented with slides, videotapes and models. The training stressed "detailed step-by-step procedures for how to do every process required to produce a quality product." The Chinese brought their own interpreters who translated the lectures and responded for the trainees when answering or posing questions. On-the-job-training put into practice the theory the trainees learned in the lectures. No interpreters were used for the hands on training but was described as "show and tell." 
The Chinese were housed in a local hotel which provided cooking facilities. They brought food with them from China and cooked together. They organized their living space communally, sleeping together in one room, cooking in another and meeting and studying in a different room. Some dinners out and sightseeing were provided by the American company as well as trips to their other plants in various locations in the U. S. and Canada.

After the training in the U. S. two American managers were sent to China to further the training and assist the Chinese in implementation. Three years after the training and technology transfer the Chinese plant produced its first piece of equipment. The respondent said, "They are not world class quality yet but certainly quality that is adequate for use in China. They could not compete yet on the world market but they have made dramatic progress."

\section{Computer Company (CC)}

The American computer company sells computers and licenses software to various Chinese universities, research facilities and manufacturing plants. Their Hong Kong office handles the sales, training and support services for China. The respondents were two Hong Kong Chinese responsible for sales and training in China. The American home office has produced extensive documentation in the form of manuals and training courses for their customers. Professional instructional designers and trainers were used and consulted in the development of these materials. The Hong Kong office has developed a relationship with one of their major customers, a prestigious Chinese university, to translate the 
manuals into Chinese and provide basic computer training for the company's Chinese customers. The training package consists of basic computer training at the Chinese university and then specialized training using the company's systems in Hong Kong.

Small groups of Chinese customers are brought to Hong Kong for thirty to sixty days of training. The training is conducted by company engineers and is based on the American courses. The format is lecture and then practice on the computers. The courses are modified for the Chinese trainees by providing additional description of basic computer terms and processes and by a slower pace. The manuals provide the foundation but each engineer uses his own methods and system for training. The trainees work in pairs at each computer work station.

All training is conducted in Putonghua (Mandarin) but all training materials are in English. The training is tailored to each student depending upon what he or she produces in China. Each student brings a specific project from their work unit to design during the training. The respondents stressed that their success is dependent upon the students completing their design project before returning to China. This provides proof that the student has learned the necessary processes and that the machine works. The respondents pointed out that the full creative potential of their computer product is not taught in the training. But in accordance with the extreme specialization of jobs in China the training is tailored for each student. 


\section{Heavy Machinery Manufacturing Company (HMMC)}

After eight years developing relationships in China the American company entered into a joint venture with a Chinese manufacturing company. The Chinese plant had been manufacturing similar equipment for over twenty years but their design and technology was based on the old Soviet system and was outdated. The commitment from the American company involved limited training of key Chinese managers and technical documentation for upgrading. It did not involve extensive transfer of equipment or monetary investment. Since the initial agreement the American company has been sending components to China for assembly. At the time of the interview the Chinese plant had yet to produce a piece of equipment manufactured in China.

Three members of the Chinese joint venture were brought to the U. S. for orientation. Only one spoke English and he served as the interpreter for the others. The training was a basic orientation to the operation of the American company. Site visits were set up "to give the Chinese the whole big picture of the manufacturing process and organization." They were introduced to the key American managers and engineers who were their contacts and resources for information. They toured several of the company's plants around the U. S., were shown the processes for manufacturing the equipment in the U.S. plants, and were given the technical plans and manuals for manufacturing the equipment. They were taken "into the field" and introduced to the company's customers to "observe the customer's application of the company's product."

The American company had produced manuals for manufacturing each piece of equipment that described the processes step-by-step with 
numerous pictures of the processes. These manuals had been developed by managers and engineers and had been used successfully to train managers in Europe when new plants were opened. In Europe these manuals were translated into the language of the trainees, in the case of China only the English versions were provided.

Upon their return to China the three Chinese managers were unable to form a team and work together effectively. Within six months the respondent fired the newly hired general manager and replaced him. While this team of managers appeared to be effectively working together, at the time of the interview, the joint venture still had not manufactured any products.

\section{Transportation Equipment Manufacturing Company (TEMC)}

This company sells transportation equipment to China and has a joint venture manufacturing plant in northern China which produces parts. The American company then buys these parts from the joint venture. Their contract specifies that in return for selling their products in China the American company must return some of their financial gain to help China's modernization. Part of this obligation is fulfilled by providing on-the-jobtraining for Chinese engineers in the American company's home office in the U. S. Every year, five to ten Chinese engineers are selected to go to the U.S. to work for two years in the American company.

The respondent for this company had been working with this program for over ten years and had been involved since its inception. Once a year he goes to China to interview the pool candidates. The candidates are chosen by the Transportation Ministry from all over China. The respondent 
has developed very specific criteria based on Western values that he uses to rate each candidate. His top-rated candidates are then selected to go to the U.S.

Once in the American company The Chinese engineers are completely integrated as regular employees and expected to perform at the same standards as the other employees. Except for some sensitive security areas the Chinese engineers have worked in most areas of the company. The manager of this program sees their exposure to American work methods and rewards as one of the strong points of the program. The Chinese are introduced to over-time pay, employee-of-the-month recognitions and other incentives to increase quality and production.

The only formal training they receive is a pre-departure program in China that prepares them for living in the U. S. and provides English instruction, and a company orientation in the U.S. The company orientation they receive in the U.S. is no different from the orientation each new employee would receive. They are then individually assigned a work area and put to work immediately. The Chinese are never grouped together but are placed independently. The training from this point is all provided by the managers and supervisors of their work areas and is specific to a particular assignment.

\section{Metal Building Construction Company (MBCC)}

The respondent from this company and his Chinese-American partner had worked for four years to make this deal in China. They sold and contracted to supervise the construction of the first foreign-built warehouse in a small coastal town in southern China. The respondent and a friend 
traveled to China with all the materials and tools to supervise the construction of the building. They were provided a Chinese work crew and two interpreters. After a couple of weeks of trying to just supervise the work the two Americans decided they would have to work themselves if they wanted the project completed in the thirty days they had planned.

The training they provided was strictly on-the-job-training of the most basic type. Only a few of the fifteen workers seemed to have any construction experience and only one had any experience working with metal. They discovered their training had to be very specific and they could not rely on the workers showing or explaining a process to each other. Each task and each worker had to be shown step-by-step exactly what was to be done. They found they had to watch the work crews carefully to see that they were doing the task correctly and that they were staying on the job. "Vanishing workers" plagued them and they resorted to American methods of trying to fire workers, threatening to strike themselves if their needs weren't met, and offering rewards to individuals for jobs well done.

They found Chinese resourcefulness admirable in their ability to produce by hand a missing part and repair a part that had been damaged. The respondent pointed out that in the American context replacing these parts would have cost time and money. Whereas in the Chinese context a new part could not be ordered from the factory so they took the American model and modified it using local resources and in just a few days produced something that worked. 


\section{Shoe Marketing Company (SMC)}

This company began its association with China in 1980 when China was just beginning to work with Western business. The respondent spent eight years in northern China attempting to help several shoe manufacturing plants upgrade their technology and procedures to meet the standards necessary for export. This American company wanted to buy shoes from China but they had to meet very specific and high standards. The respondent was responsible for establishing relationships with these plants and training the workforce in quality control. While the top management of these plants appeared to be enthusiastic about the project, middle management and the party representatives were not. The workers appeared to resent being told to make shoes for the foreigners and they resented being told how to make shoes. The respondent spent hours in meetings with the top management and had little contact with the line worker.

The training consisted of lectures to the workers about quality specifications. The lectures were presented in English and translated by a Chinese interpreter. The Americans had hundreds of shoe samples available to use as examples for each specification. Very exact specifications were necessary, for example, the range of acceptable heel heights were within millimeters, colors had to be exact, deep royal blue couldn't be a shade lighter. The respondent reported that the Chinese thought rejecting shoes that didn't maintain these narrow specifications was "nuts." The respondent was never able to provide training to the workers that upgraded their skills and processes which he felt was necessary to accomplish his goal. 
After failing to reach an acceptable quality they pulled out of China. A few years later, working through their manufacturers in Taiwan, they entered into a few joint ventures in southern China. This situation is now working and they attribute this success to the timing, the location and the fact that it is Taiwanese who are running the plants and training the Chinese to take over management in several years.

The Taiwanese approach managing these plants as they do in Taiwan, with greater regimentation than is common in China. While this situation appears to be working better than the company's experience in northern China it also has its own problems. The workforce has rebelled against middle management resulting in a manager being beaten up three times outside the plant. The plant manager insisted the people responsible come forward and threatened to fire all employees if they didn't. The employees went on strike and refused to work. Whereupon he fired them all and walked outside and put up a sign to hire new workers. Within days he had 400 applications for 60 positions.

\section{Book Distribution Company (BDC)}

This company is a wholesale bookseller to libraries all over the world. Their contract with China includes a requirement to provide training for two Chinese library workers each year. The Bookseller has been able to establish minimal criteria for selection of the trainees but would like to be able to require a higher level of English proficiency. Initially the Chinese trainees were brought to the U.S. company for three months. They would spend two months working in a local university library and one month working in the company. The students lived in dormitories on the campus 
of the local college and they ate their meals in the cafeteria. Many of the problems the respondent mentioned were related to the logistics of meeting the housing and transportation needs of the Chinese students and finding local universities willing to train them.

The training was strictly on-the-job training provided by the college librarian and the company workers. The tasks involved in the training at the company were very basic: packing books for shipment, filling out order forms, and checking references in source books. The objective of the training was to familiarize the Chinese with the U. S. operation in the hopes that they would improve the accuracy of their ordering process. The orders the Bookseller receives from China are often indecipherable or simply wrong resulting in books being shipped to the wrong libraries. The respondent who manages this operation said the company found this training of limited benefit to the Chinese because the systems in the U.S. and China were so different and because the resources available in the U.S. are not available in China. But the accuracy of orders coming from China did improve.

Recently the American company has changed the training by providing a scholarship to a university that specializes in training foreign students in library science. The students now spend three months in this program and one week at the American company.

\section{Consultant/Trainer $(\mathrm{C} / \mathrm{T})$}

This respondent has his own consulting and training company based in the United States. He is also on the faculty of an international management institute and is a highly respected author and researcher in the 
field of intercultural communication. The respondent has been working with companies doing business in China for several years. His training programs for China are often used as the framework for his training-oftrainers workshops. The respondent did not focus on one particular training experience in China but generalized his experiences and those of his clients and illustrated his points with different stories.

\section{PROBLEMS AND ISSUES}

\section{Power and Authority}

Under this heading the subcategories Bureaucratic Maze, Decisionmaking, Getting Things Done, Communication and Connections all deal in one way or another with respondents' perceptions of how power and authority work in the Chinese system. Many of their frustrations focus on their expectation that there are individual leaders and decision-makers who wield the power. The respondents inability to identify these individuals and personally interact with them was a continual source of frustration for them.

Bureaucratic Maze. It's Hard to Tell Who's in Charge. Respondents consistently expressed frustration and perplexity at how the Chinese bureaucratic system worked. Finding the "right" person to deal with, ask questions of and gather information from seemed to take considerable effort and patience. Respondents were never sure they were dealing with the "right" person. This category is intimately related to responsibility which was often mentioned in connection with frustration with Chinese bureaucratic structure. Identifying the person responsible for making 
decisions was important to the respondents as they would often find their plans blocked or rejected after they thought they had agreement. An explanation was rarely provided of who was "responsible" for this decision and "why" the plan or project was rejected. The respondents were left to speculate on their own.

Several respondents described the Chinese bureaucracy as obscure and mysterious. One respondent said, "It's an amorphous jell instead of a structured organization; which for Americans is very frustrating." Even after working with an individual for years a respondent was still unsure what his contact's role was and whether he was really a leader. He said,

... the bureaucracy, the administration system in China is a lot different than ours and it is virtually impossible to find who is responsible for anything in China. Once you think you have him - he is not responsible anyhow, someone else who you probably never met is... the number one man we negotiated with from the beginning of the contract - as close as we can tell - we think he is the plant manager.... It's never been totally clear in my mind whether the guy that we are dealing with is head of the whole thing or the head of just the part that we are working with. And this is after some fifteen visits, and he has been there three times. I'm still not sure what his exact role is.... there isn't the chain of command as we know it, it doesn't exist in China or if it does it is a very nebulous thing. (EMEMC)

The SMC respondent accounted for his difficulty getting answers to his questions and approvals for his plans as a reluctance on the part of the Chinese to "stick their necks out." He recognized that there were several layers to the Chinese bureaucracy and inferred that decisions were passed from one layer to another because of fear of negative consequences. He 
believed passing the decision from one layer to another spread the responsibility. He said,

You would never get an answer on a problem because they had to go through so many levels because nobody was willing to stick their neck out a little bit and say, 'Yeah or No.' They had to ask their superior and his superior. They were always afraid that it might get back out someday. Especially in dealing with foreigners you know that's always been a problem. A lot of them would tell us that privately that they had to be really careful about what they - how supportive they were of us. In fact, we had - I can think of two specific management level people that basically were too supportive of us and they virtually disappeared. We never saw them. I mean, you could tell they were sticking their necks out a little bit and for instance Mr. - , he was transferred, so that happened quite a few times. So it was a problem.

The EMEMC respondent expressed much frustration at not being able to identify the key leader - the one person that in his mind makes things happen. He came to the conclusion that consensus was the process the Chinese used. To cope with this situation the respondent assumed that everyone and anyone could be a leader and therefore he expressed his concerns to a broad base of people hoping he would eventually, perhaps unknowingly, speak to the right ones. He also took the tack that repeated expression of concerns might get noticed. At one point during the interview he threw up his hands and shook his head in exasperation and said,

I don't think there's any accountability. Nobody seems to be responsible. You can't find who the key person is. And maybe there isn't a key person. It may be management by consensus. I don't know. We've come to the conclusion that's what it is. There doesn't seem to be any one key person you can go to make something happen.... we live with it. We continue to work with the same people we've been working with pointing 
out the problems - repeatedly pointing out the problems. [You say the same things] many times to the same people. You say to anybody you can and as often as you can, hoping that eventually it will find root and grow.

As might be predicted the two Hong Kong Chinese who worked for the American computer company seemed to have greater access to the inner workings of Chinese culture than the American respondents. When asked how they know who the leader is one respondent said,

I mean it is always the guy that talks - that talks and makes the decisions. When you ask a question, then everybody looks at that guy, then you know that that is the guy who makes the decisions. Right? If that guy nods his head, then you know he is the top guy.

Later in the interview when discussing selection of trainees and the importance of identifying the key people to train, one of the Hong Kong respondents said, "... you just ask them. They will tell you if they are a leader, if they are just out to supervise." This openness to direct questions was not common to the American respondents' experience in China. In contrast several of the Americans felt that the Chinese intentionally tried to keep the Americans off balance by never clarifying who was in charge.

No Explanations Are Provided For Actions. The lack of clarity in who had power among the Chinese left the respondents in the dark about who rejected certain proposals and why. One respondent said,

Both factory managers were a hundred percent behind us; really felt strongly about the whole program. But in both cases the party leaders really didn't have an interest. I mean, they were required to deal with us but didn't have the real initiative to make it work and they were always - from what we found out later, we didn't know what was happening at the time, but 
in talking to these people a year later - we found that they were, you know, vetoing a lot of things that we were proposing all the time. So we really had a conflict there. Most of the time the party won out. And we didn't know then that's why things we thought had support suddenly were dropped. (SMC)

Decision-making. The general frustration with the Chinese bureaucracy not only focused on who was in charge but also the process. One respondent said, "I just don't understand how they make decisions. They must make decisions, I know they do, but how and who and when, I don't know. I'm baffled by it. I's frustrating."

Chinese Display No Individual Initiative. After identification of the decision-makers, the second issue that was mentioned most often was the lack of individual initiative by Chinese in making decisions. The phrase, "They are so used to being told what to do..." appeared in several interviews as the interpretation for why individual decision-making does not take place. One story by the EMEMC respondent best characterizes the attitudes of the respondents. This respondent saw the lack of individual initiative as symbolic of all the "problems" in China and related individual initiative to responsibility. There was not only a sense of concern with how the lack of individual initiative affected the work but there was also an abhorrence of the idea of not having individual choices. This respondent, when put into a position of having his choices limited, felt compelled to exercise his right to make his own decisions. He said,

It really didn't affect the training but it is symptomatic of China's problems - it all comes back to not taking responsibility. For example in each group there was one leader designated for the group. We don't know if he was the political leader or his rank, we really didn't care. But he was the one we would deal with. We would go out to a restaurant - one of 
these groups we spent two weeks on the road touring Canada and the U.S. Obviously we had to eat. We would go into a restaurant and they prefer to go into a Chinese restaurant. This one guy would do all the ordering, nobody else had a choice. Nobody else would order and he would try to order for us too. And I would say, No I don't want to do that. I want this. I don't want what you're ordering.' The Chinese are so used to having someone tell them what to do that nobody questions the idea that someone else can tell them what to eat! First of all we're used to having a selection to choose from, obviously they're not. They eat whatever is put before them. Here for the first time they were given a choice of what they could eat and they still let someone else order for them. 'You order for me and you order whatever you think I want to eat.' We had a hard time accepting that.

Another respondent felt that even the welfare of the group was not enough to motivate a Chinese to make an individual decision. He said,

They are so used to being told what to do that the idea of individual action - It is not the same as Japanese culture where they do things for the group. In Japan people will make individual decisions not for themselves but for the group. In China I can't find anybody who is willing to make an individual decision, relatively speaking. (HMMC)

In contrast to the above respondent's experience, the respondent from the TEMC had a totally different experience with the trainees his company brought to the U.S. These Chinese trainees were more independent and expressed their own opinions and desires. This respondent said,

If there are ten of them we can almost come up with ten answers. He wants to do this, he wants to do that and that sort of thing. Or what to eat? So as a group they have a hard time making a decision. Just the fact that they talk against each other and they squabble all the time. 
Chinese Allow No Access to Information. As also indicted in several of the quotes in the earlier category It's Hard to Tell Who's in Charge, another aspect of Chinese decision-making that frustrated the respondents was the lack of access to information. They often could not gain access to the kind of information they were used to having and upon which they based their own decisions. A story from the $\mathrm{MBCC}$ respondent illustrates the frustration respondents had getting accurate information:

They would pretty much tell you what you wanted to hear. For instance, we asked them if they ever had nasty, stormy weather in this part of China, you know, cold and rainy or bad windstorms, because bad winds are things that make it very difficult to build a building like this. And we were concerned about that because the building was designed for typhoons or high wind loads but we didn't want to be assembling the building during typhoon season. It could mean that one, we could have serious damage or we could have some major delays. We wanted to make sure that we came to China to do the job but not in the typhoon season. I asked that question when I was here in November. No, no, no problem, no. That time of year, all nice and sunny and hot, all the time.' We had probably been there a week or so, then all of a sudden, you know, it's ninety degrees and in about an hour and a half one afternoon the weather changed and it must have dropped down to about fifty degrees and the wind came out of the north and it was a terrible wind and it blew for four or five days. I swore that it would have blown that whole, building down to the ground. I just knew that when we went back out there, there would be nothing left, but it was still standing ironically.... So we said, 'How long is this storm going to last? You said it never storms this time of year.' 'Oh yeah, storm all the time, this is bad typhoon season.' So then the storm is all over and we said, 'You guys going to have any more storms?' 'No that very unusual, rarely happen this time of year.' So, what you see is what you get!

Getting Things Done. My Authority Was Not Always Recognized.

The respondents recognized that to get things done in China required a 
different way of doing things even if they didn't always know what that might be. Their attempts at exercising their authority or roles as they would in the U. S., by directing workers, going to decision makers for action, and simply ordering food in a restaurant, often didn't get the expected response. They then resorted to some extreme measures in order to get things done, such as, refusing to work, doing the work themselves to make sure it was done correctly and quickly, trying fire workers, and relying on interpreters to resolve conflicts. One respondent said, "... the frustration of getting things done, you've got to be very patient in China. And even talking to the top people, Lao - , my friend who I think is the head of the factory - we get lots of good lip service but we don't get an awful lot of action."

Another respondent talked about the contradiction he found in China regarding the stereotype Americans have of the Chinese system. The "totalitarian nature" of the communist Chinese led him to expect a system where workers were forcefully told what to do and under threat of punishment did just what they were told. He somewhat wistfully compared the Chinese system with the American system where the boss seems to have greater authority:

Just going to the top man, even though he may be the president of the company doesn't have the, either doesn't have the authority or doesn't want to use the authority to say 'You're going to do this.' There doesn't seem to be any, say discipline in the way we think of it in the Western world where you may not like what the boss says but if the boss says it you're gonna do it - In China, the boss would have to find a way, some way other than just direct, 'Do it my way,' find some way to convince this worker that he wants it done this way. You can't just tell them. (EMEMC) 
After trying to supervise the construction workers for two weeks, the MBCC respondent and his partner decided they would have to do the physical work themselves if they wanted to stay within their timeline. He said,

So we started by instructing him what we wanted and he tried to tell his people what to do and it was just going real slow.

We went through that series for about two weeks, and especially [partner] just couldn't take it any more. He would get so frustrated and he would tell them to, 'Get off the ladder,' and he would run up and do it. Then he would come back down on the ground and would watch them for awhile and then he would say, Get out of the way,' and then he would go up there and do it again. Finally we decided ... we had better go to work on this deal ourselves or we are going to be here forever. You know we might be here for six months or a year, I don't know.

In another example, the respondent said he was used to receiving good service at restaurants in the U.S. where the role of patron is respected and catered to by the service personnel. He was staying at a Chinese hotel in the small coastal city where he was erecting a warehouse. After the Chinese leaders who negotiated the contract had left, the quality of the food that was served to him in the restaurant deteriorated until one night his partner suffered a case of food poisoning. He had made repeated attempts to ask the wait person for better food - food that he saw other patrons in the restaurant receiving - to no avail. Finally he approached one of his interpreters to deal with the situation and was so frustrated by this point that he threatened to strike unless his needs were met:

I got hold of -, one of the interpreters... and I told -, 'Look, you know what is going on in here, I don't.' I said, 'We have a menu and a few days ago you interpreted the menu for me and I told you exactly what it was we wanted for dinner and we got 
something else. The hotel tells us they don't have any fresh shrimp, we see the guy at the next table with it and he has a big plate of fresh shrimp, so somebody is playing games. You either get it straightened out or we are not going to work tomorrow. I don't care which, it's your choice.' 'I tried to figure it out. I talk to them and I tell them what we want and they give you something else.' 'I don't want to argue about it,' I said. You just figure it out. Either you get the menu straightened out and this is what I want. Or we are not going to work tomorrow.'

Everything Takes Longer in China. The adjustment the respondents had to make in terms of how time was viewed in China was difficult for many of them. They all expressed an understanding that time was viewed differently in China and that patience was necessary. The MBCC respondent said that being in China was like being on a sailboat:

In working in China one is obviously - as you know, the transportation is difficult and that relates to time in America because time is so very important. In China time is nothing, therefore it's like being on a sailboat... In China you know where you are going but you have no idea when you are going to get there. Same thing with building our building or putting together any sort of a business deal or project. You may know in your mind what it is you are going to do and you may have a good feel for the fact that you will achieve it, but you have no idea when that will be. If you are traveling by train, plane or by car, you have no idea when you will get there. (MBCC)

Another respondent had very similar feelings about time in China:

... you never know because dealing with people in China takes a long time. I think one of the things that bowled us over when we got there was that in China, time is nothing! We learned that very quickly. (HMMC) 
Actually experiencing how slow change happened in China required a restructuring of their ideas of progress. For example:

They are not world class quality yet but certainly quality that is adequate for use in China. They could not compete yet on the world market but they have made dramatic progress. In one respect we say dramatic, but it's taken three years to get this far and that doesn't seem very dramatic but under Chinese rules it's pretty dramatic. They've made some dramatic improvements in quality and it took a lot longer than we had anticipated and they had anticipated, but at least they have made progress. (EMEMC)

\section{Communication. Communication Is Only From Top Down.}

Communication deals primarily with the problems the respondents saw in Chinese work units resulting from the completely vertical lines of communication. The lack of lateral communication between managers, between workers involved in the production of the same product, and between different departments was seen as inhibiting China's manufacturing and effective utilization of resources. Several respondents believed it was this stress on top down communication that prevented them from accessing channels of communication in Chinese organizations or work units. The themes of responsibility, chain of command, access to information and getting things done are also found in respondents' comments related to barriers in lines of communication. The $\mathrm{C} / \mathrm{T}$ provided a succinct summary of the problems American's find with the Chinese lines of communication:

Compared to the American social system, the Chinese system is very compartmentalized, differentiated - very fragmented. The lines of communication are almost totally vertical, from the top down. So lateral communication between workers or 
work groups in a manufacturing process rarely takes place. The boundary people - the people who interface with different departments don't exist. This makes it very difficult for the Chinese to coordinate and synthesize a manufacturing process.

This lack of lateral communication between departments or workers and even managers within the same joint venture was mentioned by several respondents. The EMEMC respondent watched two work bays located side by side that were engaged in manufacturing processes that were in sequence with each other. He said that when one bay of workers had completed their work on the product it took several weeks to get it moved to the next bay only a few feet away. He related this situation to a lack of communication and the unwillingness of anyone to take responsibility to get it moved. He said,

The workers communicate with one another, they'll join each other on their tea breaks but the people who are responsible for this, they communicate - I'm sure they do... but what they say to one another I don't know. I don't have any reason to think that there is any animosity between the two [two work bays side by side]. It's just a matter of - 'It's not my responsibility.'

Other respondents found the vertical, top-down communication prevented them from interacting with the line workers and middle management which made it difficult to correct problems, offer suggestions for improvement or actually provide skills training. He reported,

... upper management was as about as close as we could get to the workers and that's always - that was always a problem. That is a real key there because we always found some real sharp upper management in every factory... But if you don't have the middle management, you can't communicate it to the workers. It just gets lost in the flow of things... . We could go on the lines and talk to the workers and explain what we 
wanted, but if you didn't have the middle management behind you, that would just go by the wayside. (SMC)

It was pretty much ... all the communication was through the top people - well with the translator, but with the top people. There wasn't really a lot of two-way communication with the workers. When we were on the lines we did talk to them and if we saw something ... if we saw a shoe with a major problem way down the line we would show it to them and try to explain what was wrong, but most of the time it was all with the top people. (SMC)

Chinese Managers Don't Share Information Among Themselves.

The HMMC respondent found the Chinese managers of the joint venture didn't communicate with each other or openly with him, but seemed to covet the information they had. He said,

They have recently begun subcontracting some of the work some of the manufacturing processes. I'm not sure which processes or exactly why they are doing this. When I talk to the different managers none of them seem to know what the others are doing. And they don't - when I talk to one of them and give him information they don't share the information I give them among themselves. When I ask about the subcontracting agencies I get really vague answers but always strong assurances that they are top quality.

Connections. Nothing Gets Done Without Connections. For the most part the respondents expressed concern about how necessary it was to have good connections to accomplish anything in China, for Chinese and for foreigners. Finding out how to gain access to the right connections was a difficult and frustrating process for the respondents. One respondent said,

I wasn't ready for ... how everything there is based on relationships and connections, and that very little is written down. You just have to learn through experience who has 
connections to get done what you want to get done. The learning process there, to find out that is sometimes painful. But I've never been in a country - I've worked in Korea and I have traveled a lot in Asia and I have never seen another country where connections are so important. That's how everything works. Connections in Korea and Taiwan are very important but nothing like China. (SMC)

This same respondent felt that the system of connections in China provided some protection to certain individuals. He reasoned that the only way Chinese could be assertive and accomplish anything for foreigners was to have a strong system of connections to back him or her up. He said,

This one particular woman is in charge of the [Chinese Bureau]. She is probably one of the most progressive Chinese that we have ever met and she has been involved in our program since 1983, since we first went to [City]... . We thought from day one, it's just like how does she keep from getting, you know, just totally thrown out of this, our business, because she is always taking the steps that would. You would think that someone above her was going to put her in her place... . She'll come in and say, 'You're right, you should leave that factory, they are not up to your standards.' Their standard line would be, 'Well, we are trying to upgrade, give us more time.' She would just cut them off and say, We will try to find something else, some other factory for you.' That's the type of attitude that's unusual there... . We don't know her background, but it's very likely that she's got a father or someone that's very high up in the government in [city]. She's from [city] originally, so it's probably all connections that's allowing her to be this liberal. (SMC)

In a few cases, respondents shared experiences that illustrated how important relationship is in China. The HMMC respondent went to China to hire a general manager for the joint venture. He placed ads in local newspapers and interviewed several candidates. He hired a man who had good experience as a manager, who spoke English well, and had many of the 
other characteristics the respondent believed were necessary for a good manager. When the newly hired general manager came to the U.S. with the other Chinese managers of the joint venture they argued continuously. The conflict persisted when they returned to China until the respondent eventually fired the general manager. The respondent recognized to some extent that relationship was a key ingredient in this conflict. While he didn't indicate a full understanding of the importance of guanxi in Chinese culture he said that it was important that the next manager he hired was an engineer and a member of the manufacturing association to which all other plant employees belonged. He said,

I wanted to assemble a central management team in [town] that would be very entrepreneurial and aggressive in developing the project from the China end. I wanted a general manager well he had to speak good English first of all, but then I wanted someone who would be progressive, who had lots of energy and curiosity. So I advertised and interviewed several people and ended up hiring - . But as I said that didn't work out so I later hired - from [city] who was an engineer and already a member of the [equipment] manufacturing association. This team is working out better.

The Connections System Inhibits Quality. The system of connections was viewed as a barrier to China's modernization, specifically to reaching the quality standards the world markets demand. Respondents saw a system based on relationship and favors resulting in the hiring and promotion of unqualified individuals. They felt talent and skill would have to become the primary criteria if China expected to compete in international markets. The comments from the SMC respondent is representative of this concern: 
Until that changes [connections system] and they start being concerned with people's abilities, which I don't see, especially in northern China, they are going to have a hard time coming up to the standards of the rest of the world I think.

Another respondent reported,

As you probably know relationship and guanxi is extremely important in China. It's how business - how everything is conducted. We [American business people] see the system of guanxi as nepotism. And all the problems that are associated with hiring and promotion based on family ties or favors are present in China... They're going to have to change this system eventually to hiring based on skill and expertise and merit rewards. They lose a lot of talent by not doing this. $(\mathrm{C} / \mathrm{T})$

There Is No Company Loyalty. Another way connections was seen as a problem was in the realm of corporate loyalty. The respondents could see the loyalties of their Chinese partners extended to Chinese outside the company and felt this meant a lack of primary loyalty to the company. The respondents believed that if these outside relationships came first the company would suffer. The HMMC respondent said,

... this group is working together better but I still don't see a real sense of loyalty, or identity with [the company]. Everyone seems to care more, or, ah, have these alliances with people and work units and networks outside the [company]. Their identity with and loyalty [to the company] is secondary to those alliances. They seem to be the strongest bonds. And it bothers me because [our company] all over the world treats its employees very well. Very few people leave the company and there is a strong sense of loyalty. I'm not sure how to develop this in China but in order for this venture to work they're going to have to work together better and, well they have to make [the company] most important... . (HMMC)

I think what's really happening there is the government is attaching certain requirements - the government is saying you have to use these suppliers and you have to subcontract 
with these particular plants. And that's another example of how the loyalties outside the company are - well, these loyalties are driving the decisions of the [Chinese company] management. (HMMC)

The Chinese-American respondents had a different experience with the issue of loyalty. The respondents' first loyalty was to their companies while the Chinese trainees expected the respondents' loyalty to be based on their identity as Chinese. The trainees tried to establish and use guanxi based on the identification as Chinese. The BDC respondent said,

... they [Chinese trainees] find more freedom to talk to me because they think I would understand their needs and I would be on their side and would try to bargain for them. They fail to understand that I represent the company in dealing with them. I don't represent their people. I have to answer to the board of directors, to the management. They fail to understand that. (BDC)

Another respondent reported,

... What they want to do is to try to outdo one another. One guy tells me, or several of them at different times, 'Mr. (respondent) tell me what you want me to do for you, something you want to do, I want to do that for you.' (TEMC)

\section{Training and Learning Problems}

The problems and issues that specifically related to the training of Chinese were Language, Training and Learning Processes, Problem Solving, Technical Sophistication, and Selection of Trainees.

Language. The Language Gap Inhibited Our Effectiveness. Language was mentioned as the number one problem in training Chinese by every respondent. One respondent summed it up by saying, "The biggest problem in training Chinese is the language. It's the biggest barrier without 
exception." One respondent whose program had been going on for ten years found that English proficiency was the most important factor in the success of their Chinese trainees:

I look for their language capability which is the key. I would single one thing out that is the one single number one most important factor... . The program has been very successful and in all cases we find out their productivity is definitely related to their proficiency of English. (TEMC)

For the most part the respondents found that the Chinese trainees were able to read English adequately and those trained in engineering schools in China could read technical documentation which is internationally standardized. But their listening and speaking skills were quite poor. And "very few students would take a crack at speaking." Many of the respondents' businesses involved sophisticated technology with a specific terminology. In the computer industry, which is constantly evolving, new terms are continually created which must be translated into Chinese. As one respondent remarked, there are no equivalent words in Chinese for many of these new technical concepts, so in many cases they are making them up:

For the terminologies that we use specifically to our industry, for example, this is a very new technology and a lot of terms are not readily available. It is an ongoing thing and like for instance, the 'windowing system' and you know all of these new buzz words. We have translated some of them and the Chinese have also translated some of them, and for a lot of the terminology there is just no Chinese equivalent. We are gradually actually making it up. (CC) 
They also found that translating written materials into Chinese requires considerably more description to explain a concept than would be required in English:

They not only translate it, there has to be more description. Sometimes you can't even just translate it because I think it is just too far away, too different - maybe you give them a whole description about it - it takes more explanation to say it in Chinese. (CC)

The respondents had different levels of fluency in Mandarin and different attitudes about learning and using the Chinese language. The two Chinese-American respondents spoke Mandarin, the two Hong Kong Chinese spoke both Mandarin and Cantonese, and the consultant/trainer was fluent in Mandarin. The SMC respondent who spent over seven years working in China studied the language in various ways the entire time he was there and was able to use the language to an extent but never became fluent. He said, "... we made the effort the whole time we were there to study the language even if it was, just you know on our own but with a book... ."

The MBCC respondent and his partner used Mandarin phrase books and attempted to use the language with the men they worked with. He said they tried for several days to speak to the workers but were met with blank stares and no verbal response. They thought, "What's the matter with these guys, don't they like us?" Finally they learned that Cantonese was the language the workers spoke.

Another respondent represented a very different attitude toward the use of Mandarin. He said, "Never, we never have our own interpreters. That's their problem. You want to do my work, you gotta know my 
language. From day one we made that as a rule. We are not going to worry about your language. That's hopeless. So they accept that."

Translators and Interpreters Don't Have Technical Backgrounds. The $\mathrm{CC}$ training in China and Hong Kong was the only program that taught in Putonghua (Mandarin). All of the trainers and support personnel spoke Putonghua but the training materials were in English. All the other programs used English materials and the trainers spoke English. In these cases the Chinese brought their own interpreters with them who translated during the training sessions. The EMEMC had a staff member who was fluent in Mandarin who would sit in on training sessions to monitor the accuracy of the translation. They also used a Chinese-American engineering professor to translate a critical section of the technical documentation. While many of the respondents mentioned that having their own interpreters would have been a great benefit, the costs of hiring an interpreter with the necessary technical background inhibited them. At the same time many of the problems they mentioned stemmed from the poor translation that took place in the training sessions, particularly regarding technical material. The EMEMC respondent's comments are representative of this concern:

Going through a translator particularly in a technical subject is difficult especially if the translator is not a technical person... we had a Chinese speaking fellow on our staff ... who would sit in at some of the sessions just to observe translation. And I know from [his] comments that much of the stuff was lost in translation. The translator - some of the translators were quite good technically but some of them were used to talking other subjects, business or something. When it came time to talk metallurgy and welding, they just couldn't get it across. So I think an awful lot was lost in translation that wouldn't have been lost if we had the ability to have all this stuff translated by 
a technical Chinese. It's very costly, as you are well aware, to get reams and reams of stuff translated in Chinese, particularly if we are relying on somebody who is technically trained. We tried a translating service here in town and it was a joke from a technical end. (EMEMC)

The Relationship with Interpreters Is Important. The respondents who worked in China often developed close and trusting relationships with their interpreters and came to rely on them for many things. In all of these situations the respondents had at least one enthusiastic story to relate about an interpreter that they particularly liked and considered a friend. The word "progressive" often came up to describe the characteristics they most liked about these people and why they seemed to get along so well. "Progressive" was also used to describe other Chinese the respondents thought had been particularly helpful, willing to share information or challenge the Chinese system in some way. "Progressive" was the highest compliment the respondents paid to a Chinese and usually was attributed to those Chinese most Western in their behaviors.

In a couple of cases the respondent's company intended to find jobs for the Chinese interpreters within the company. This did not always happen but the respondents expressed that they had really wanted to "take him home with me" or "would really like to keep him." One respondents said,

Most of the time we had a pretty close relationship with our translators...the translator was excellent. In fact, there was a possibility that we were going to hire him and train him to work for [company] later. But that didn't pan out. Anyway he was definitely on our side. That is an important factor whether, you know, how translation goes. If they want to twist it they can very easily. (EMEMC) 
Another respondent reported,

We spent a lot of time with him outside of work and we became good friends and you know, he was the type of guy that would give his right arm to be able to work for us later and come to the States and he just had a real progressive attitude.....we had to be pretty careful when we started talking about ... like the party representative and stuff like that, because he was a party member and we didn't want to get him in too much hot water, so we tried to stay away from that if we could. But, he is pretty open about you know, say if we said, "The factory manager seems like he is really dragging his feet, what do you think?' He would usually be pretty honest and say, 'Yeah, you're right, he doesn't want to do that. So you had better change your approach or try to give up that idea because he is not going to change.' He was pretty good about directing us and trying to get around the system. (SMC)

\section{Training and Learning Processes. Chinese Take Lots of Notes and}

Remember Everything You Say. A couple of respondents remarked on the Chinese tendency to take many notes and to remember precisely what was presented. The EMEMC respondent warned that you need to be careful about what you say because the Chinese will remember:

... they take copious notes... . I take it the Chinese education system stresses learning by rote, so the more you write down the better off you are. You give a technical exchange and go back several years later and you may make the same comment and if you didn't say exactly the same thing as you did before someone in the back of the room will say, Well last year you said this... .' You have to be very careful because they take notes of everything that is said. Very curious, very detailed.

\section{Chinese Are Reluctant to Ask and Answer Questions and Ask for}

Help. Whether within the classroom or on the job, the respondents found the Chinese students generally reluctant to ask questions or to admit to a lack of understanding. In the classroom the respondents felt limited by the 
language barrier when they would ask the students a question. Some of the respondents understood that, for a Chinese, asking and answering questions could threaten face. The two Hong Kong Chinese described the process the Chinese students go through before answering any question or making any decision:

For the Chinese, they always talk first before they do anything ... Chinese, it's like Japanese for example, I mean, they will all get a consensus of opinion before they start doing anything. It's very different from Americans. Americans, a lot of them are individualists, right? Where Chinese say, 'Do you think that's right?' 'Yes.' 'Do you agree?' 'Yes.' 'Okay, let's' - so probably then we do it. Or sometimes if that guy is paired with the leader, then the leader says, 'I think we could do it this way,' and this guy will automatically follow their way.

The EMEMC respondent described the same process within his classroom:

If a question would be asked, the translator would translate and then ... there was twice the amount of time for the hustle bustle among the Chinese discussing what had been said. Then they may come up with one or two questions about what had just been presented. I think they were probably very cautious about answering questions. Face is almost as important in China than it is to the Japanese. Not quite as much... . All the questions were answered as a consensus... . But you don't know what you were getting was from the group or was from the interpreter.

The greater frustration for the respondents came with the reluctance of the students to say they didn't understand or to ask for help when they had a problem and couldn't continue with the work. The TEMC respondent said, 
They don't have a good habit to completely understand the question and answer, or the assignment before they charge along. They make the supervisor to believe that they understood the assignment, but they didn't, because of the Chinese way. And then later they got taught a good lesson, they got blamed. 'Why didn't you ask me if you didn't understand?' That doesn't take long but in many cases they all sorta go through that... 'I had better understand this assignment or I'm gonna be the one to get blamed, not him.' That was a good way - American way. And it tends to be the problem in China a lot of times... . I always tell them, 'Don't pretend. If you don't understand, ask. There is always a good open question attitude towards your management or your lead man,' whatever the case. They learn. (TEMC)

\section{Another respondent said,}

A lot of times it is very hard to know whether the trainees understand what had been said. They have a tendency of nodding their heads and they say, 'yeah, yeah.' So you don't really know how much they have absorbed. (BDC)

The MBCC respondent found that the Chinese workers would stop work and "vanish" instead of telling him they had a problem and couldn't continue:

... we would be keeping an eye on them. If we noticed that for some reason everybody was standing around, or everybody had just vanished, which happened a lot. They just went to get a glass of tea or to take a nap or to have a cigarette or whatever they did, they just vanished. So you knew that something had happened, they had a problem. So you go check it out and pretty soon you'd figure out what was the problem and get them back on track.

The BDC respondent felt that embarrassment about their language ability inhibited the Chinese trainees from speaking, asking for help or saying they didn't understand: 
Well, I think they are very polite, where in the U. S. people are more straightforward - they tend to be anyway, and people are not shy to ask questions and they [Chinese students] seem to be shy and they tend to not ask questions if they thought they hadn't understood what was said because of the language barrier. They are too embarrassed to want to admit that they haven't caught it. Now, when they are with me, they can ask me in Chinese so they would ask me a lot of questions. When they are with other people, our colleagues would say, 'Do you have any questions?' and they said, 'No.' And then when some colleagues asked them questions to see if they understood what was being said, it was very clear they hadn't got it sometimes.

\section{Chinese Don't See How All the Parts Fit into the Whole. The C/T}

related a story about analyzing a manufacturing process in a Chinese factory. The final product would not assemble correctly because all the parts were not designed to fit together precisely. He used this story to illustrate a problem he labeled as "difficulty in seeing the gestalt." He said that this kind of thing happens in China because of the high compartmentalization and specialization of the work tasks. None of the workers who made the parts were concerned with how the part fit into the whole product. They did their work and their work only. This story also illustrates the extent of the isolation that results with the lack of individuals to facilitate communication between workers and work units. There was no one who had the big picture and coordinated the different tasks to make sure they complimented each other.

Another respondent expressed a similar opinion about the workers having no sense of how their work fit into a larger scheme of things:

I didn't see any evidence at the worker level that they had any understanding of how what they did fit in with the rest of the process or the plant. I don't think that many of them had ever 
seen what went on outside their particular work area. I don't think many of them ever realized what went on in other parts of the factory and how their work fit into the whole big picture of the plant or the Chinese economy. (EMEMC)

Chinese Have Trouble Going from Theory to Application. The C/T said one of the problems he found working with the Chinese was the difficulty they have putting theory into practice. In his experience Chinese were able to absorb, discuss, and reproduce theory, diagrams and concepts but had difficulty applying them. He compared this to his experience training Americans who he said, "... are generally able to read a manual and then conduct the necessary operations... . The Chinese find it difficult to make the connection from cognitive processing to behavior." He said that this inability to go from what is read to doing "... often results in expensive equipment sitting unused because it was never set up properly." This situation will be discussed further in Technical Sophistication.

The CC respondents' experience appears to concur with the consultant's experience. Each Chinese customer is given a full set of manuals in English for the computer system. The Chinese also have an opportunity to purchase a Chinese version of the manuals from the Chinese university that is translating them. But the respondents find that the customer seldom refers to the manual to solve a problem he or she may have. Instead they telephone the company's support people in Hong Kong and ask them to solve the problem over the telephone. The support people point out that this problem can easily be solved by looking in the manual. This reliance on the "experts" to solve the problems will be discussed further in the section dealing with Problem Solving. 
The EMEMC training program was specifically designed to show the Chinese how to go from theory to practice and the steps necessary to advance from their current stage of development to where they wanted to be. This program combined intensive, theoretical classroom instruction with demonstrations and then practice in the plant. He said,

In the contract itself we laid out exactly what skills would be taught and how much time would be devoted to each skill area. The skills involved every phase of the manufacture of the products that we were expecting them to make... . We made the assumption that they were basically foundry men to begin with. We assumed we didn't have to start from ground zero and explain the whole process... . They knew what the foundry processed was and how to melt. What we had to do was show them how to go from where they were to where they wanted to be... . I think this emphasis on 'how to' for every process was why the training was so successful. (EMEMC)

The HMMC respondent expected the managers from the Chinese joint venture to be able to take the technical documentation he provided and in China make the necessary changes to begin manufacturing the product at American standards. This plant had been manufacturing similar products for over twenty years so he believed they knew how to manufacture. His training program was strictly orientation providing overviews of the company and the processes but no specific step-by-step skills or process training. He found the Chinese became quite anxious after they had been in the U. S. for a few weeks touring the U. S. facilities:

About half way through their stay they seemed to get very discouraged and anxious - really overwhelmed. They kept saying things like, 'I don't see how we are ever going to be as modern - ever reach the level of development that you have in your plants.' They seemed unable to see how they would go from where they are now to - how they would reach their 
goal. I kept insisting that they had been making [product] for many years so they must understand manufacturing processes and planning. I mean they did produce [product]! So I didn't understand why they were so anxious, so concerned. We gave them all the technical documentation they would need to upgrade. But they didn't seem to be able to see the steps necessary for getting from here to there. I guess there was a problem because they still haven't produced a thing. There's still no production coming out of that plant.

Other respondents described similar problems in their training efforts. Most of the respondents found that they needed to explain in great detail and demonstrate step-by-step each procedure to each trainee. Directions needed to be explicit and concrete. This was recognized by the respondents as limiting to creativity.

... the Chinese tend to like to be told exactly what to do... . They don't like things to be left alone to themselves to create or to develop. They say, 'I'll leave it to you to tell me what should be done.' They get a little timid about this whole burden on their own shoulders. 'Here are three drawings, get them drawn up by tomorrow.' They love it. TEMC)

Another respondent said,

... to install the wall panels or the roof panels we pre-drilled all of the panels so all they had to do was to put the screws in the hole. They didn't have to guess where the screws went. There was already a hole in the panel to put the screw in ... . We would mark the stack where all the holes need to be drilled and then we would show one of them where to drill the holes... So, in that situation, we took the guess work out of it for them by having the pre-drilled holes in the sheets, so that when the sheet went up on the walls, and because we were working with them to get it nice and straight, then they would put the screws in where they were supposed to be. (MBCC)

The TEMC respondent said, 
If an assignment requires innovation and creation, personal judgment, they tend to be very worried, because of the responsibility, versus one, which is the routine. You go through the motions. $X, Y=Z$ or zero, or whatever it comes out that way, they like those because that's what the next guy will do, that's what I'm doing. But if you ask a guy to choose A or B, tell me your own feeling, A is better than B, they are very timid about it. (TEMC)

\section{Another respondent reported,}

We each had one work group of about five - six guys. We would work down the line showing them exactly what to do, watching them do it, and then moving on to the next guy and the next task. If we didn't do this we'd go back and find that it wasn't done right. (MBCC)

The Training Should be Tailored to the Student's Specialization. The computer company respondents attributed their training success to the fact they require each student to bring a real project with them to the Hong Kong training. In this way they tailor the training to each student and provide training for only those skills and processes the trainee will use on the job. The respondents recognize that the full potential of their computer system cannot be taught to the Chinese trainees because of the high specialization of the Chinese system and the fact that creativity is not encouraged. So they focus on training the student to do only his or her job. The respondents said,

If they design TVs then it is too big a scope to learn the electronic design tools... . So electronic design won't be put into the training. And the real live example is related to his job and also this is his responsibility, so he just come to our company to learn to do his own job. And it seems the whole training process, the whole training program is a tailor-made program for him. 
... even though in the training course it may include 2 or 3 customers and each customer may be doing different things; at least each one of them has a chance to do a real live example right on the spot there. So if they encounter any problem, then we can explain it in much deeper detail. Whereas if you just used examples from our training manual, it could be too simple or it may not be related to their work... .

Their approach is also designed to circumvent another potential problem that is related to responsibility - technical sophistication - and the tradition that places the responsibility for the student learning on the teacher. If the student completes the design of a real product it is proof that the computer system works and if there are future problems the system cannot be blamed. They said,

If they have never seen a real live example - it has never been done once and if they have problems, when they get back, a lot of them would put the blame on the machines. A lot of them said, Nah, it doesn't work.' They didn't think it is their problem, especially when they get pressures from their leader. And they say, I mean, 'The machine is no good, it doesn't work, and we have gone through 60 days training and it still doesn't work and so it's not our fault ... we have learned everything.' That is why we encourage them to finish at least one real live design before they get back so they have confidence.

\section{Testing Can Cause Students to Lose Face. None of the training} programs included tests or evaluations of any kind. The CC respondents felt their training design which required the completion of a real project was a built in evaluation, either it worked or it didn't. They also emphasized at the end of the interview that they would strongly advise not testing Chinese students in a training program. They felt that the potential for a loss of face by the student was too great to risk and in their business that could translate into lost sales. Another respondent remembered that they had originally 
planned on having several tests during the training but excluded them on the advice of a consultant. He said their decision to drop the tests was also aimed at protecting themselves. Their contract with China made them responsible for the students' satisfactory performance after the training. In the Chinese tradition of the teacher being responsible for the student's learning, this American company was held responsible for the effectiveness of their training:

There really wasn't enough evaluation done on our part to see whether they really had done the job. I think there was a reluctance on our part to evaluate too strongly. Part of the contract said if they were unable to produce a satisfactory product after following our instructions we had to give back all their money. So there was a clause in the contract, a penalty clause if you will, that put the onus on us to make sure they did a good job. And I guess not giving them any opportunity to say that we didn't do a good job - the concept in China is, you're the teacher you teach me a subject and give me a test, if I fail the test it's your problem not mine. And in some cases I guess that is true but it certainly isn't always true. And we were reluctant to perhaps risk having that be true. (EMEMC)

Problem Solving. Chinese Are Good at Modification and Practical Solutions but Lack Creativity. The lack of creativity was explained by the CC respondents as understandable given the lack of incentive and the risk involved in trying something new and different in China. They said,

... because in the last 10 to 20 years they have gone through the cultural revolution and all these things and creativity means someone that has a vision ... somebody that has some idea of something new. I mean these things are dangerous in China. When somebody says, 'I want to create that thing,' it means that he is taking a risk and Chinese are not good for taking the risks. 
The $\mathrm{C} / \mathrm{T}$ summarized the Chinese talent for adapting and modifying rather than creating new and different products. He said,

The Chinese are known masters of duplicating a process, of breaking down an object to see how it is put together and then copying it. They also have unique skills in adapting objects and machines for uses for other than they were designed. But coming up with a new way of doing things is not of significant value in Chinese culture.

The CC respondents reported that the Chinese call this process of adaptation "localization:"

What this means - they take a TV that is made abroad and they say they want to make their own TV. So, use some Chinese components, add a little bit of Chinese flavor here and there, use the Chinese standards rather then the Japanese standards. You know modifications, rather than create a new thing, right?

This practical skill of adapting and modifying was often admired by the respondents. The MBCC respondent had several examples of how the Chinese construction workers found a way to solve a problem that would have been more time consuming and expensive in the U. S.:

... the doors on this building were sliding doors ... . Each door has a roller assembly, one on each end of each door... . Somehow we were either shipped one short, or lost one ... . And obviously this was real critical, because in China you can't go to a local hardware store and buy one. One guy says, No problem,' and took off and went some place downtown and came back a few days later - taking a sample with them and had one made. It wasn't made in the same way, but it would do the same thing... . They had taken some heavy steel and crudely cut it out with a torch, ground it down and put it all together to make this duplication of a wheel assembly. That was real clever. What would we have done at home? We 
wouldn't have made one. We would have waited until we could have bought one. That might have taken a week depending on how sophisticated the part was, but we would not have been able to make one without a tremendous amount of expense. We would get all technical about it

... we were installing the last door and someone came to me and said, We have a problem, one of the pieces of track has been run over by a forklift, what are we going to do?' I said, 'I don't have a problem, you guys do, you figure it out.' You know that they straightened that piece of track by beating on it and prying on it and doing whatever they did to it, and it was as straight or straighter than it was when it was brand new... . I was impressed because there again, at home if someone had run over a piece of track they would have called the factory and the factory would have had to ship a new piece out. There would be a time loss as well as a pretty big expense to get the new part there. Not those guys! They knew they couldn't go get one so they just fixed the old one. I think they were very clever in doing things like that.

The EMEMC respondent also found the Chinese skilled in adapting the American processes to the Chinese situation. The Chinese did not have the same raw materials available in China so had to modify the processes to accommodate the differences in resources. He said,

We showed them the way we did things and why we did things in our particular plants. Because of different facilities in their plants and more importantly different raw materials in their plants we knew and they knew that they could not translate and take everything we do and go back like a recipe in a cook book and implement it. They would have to modify some of our practices in order to utilize their raw materials with their facilities and they did a very good job of doing that - of adapting our process to their own... . We told them what the end result would have to be, how strong it would have to be but they would have to adapt their raw materials to meet that end point. And they did that very well. 
One CC respondent emphasized their training was extremely practical and involved nothing creative. Once a problem was solved that solution would always be used and never improved upon. He said,

The trainee that come to our training courses - and their objective in being sent here is to achieve - learn how to design just the thing that they make, maybe a TV, say. So that's what we teach them how to do, just design a TV. We don't teach them anything creative. So they follow the instructions we tell them and don't change anything and they can achieve their goal, design a TV. If they have a problem - as soon as solve the problem, always use that method. They don't care if there is a better way or easier way.

Chinese Rely On Experts to Solve Problems. Several respondents expressed frustration at the unwillingness of the Chinese to attempt to solve a problem on their own. The Chinese most often would simply stop work if they encountered a problem, or call upon the experts to solve the problem. As mentioned in the section on asking for help, the MBCC respondent found that he could often assume that the workers had a problem when they would disappear. The $\mathrm{CC}$ respondents found that the trainees would prefer to call Hong Kong and ask the support service personnel to solve their problems rather than attempt to solve them on their own by reading the manuals. They said,

They call for technical support to solve their problems. I think they are very easy for them to solve themselves. If they would just read the manual they would find it out. But, no they just ring us. And then maybe our engineers would find it in the manual, then they would tell them and they would solve the problem... Because they cannot solve it by just come out of their brain. They should do something to solve it. Because the problem is very simple to our engineers. But we think it also 
very simple to them. They do one or two steps more, but they maybe just think, 'I can not.' It's easier to ring.

Chinese Don't Recognize Problems. In many cases the respondents would recognize as a problem a situation that would not be seen as a problem by the Chinese. Once the "problem" had been identified as a problem then the Chinese would attempt to solve it. The $\mathrm{MBCC}$ respondent considered a lack of ownership or lack of pride in a job well done as the reason the Chinese did not see a need for improvement. He said,

I think once that they recognized that it was a problem, they did not have a problem necessarily in solving it. Here in America, if you are building a warehouse, there is an owner. He has pride in ownership so therefore, he is concerned about how well the doors slide. They [Chinese workers] didn't own the building so they didn't have any pride of ownership, therefore, if the doors were in place as far as they could see, that's all that was necessary. How difficult it was to slide them open and closed was insignificant... . They are very heavy and very awkward and so we had to explain to them that, that was not the way they were supposed to operate and that we had to do some things to them to make them easier to open and close. So there again, if you identified the problem to them they were able to solve it by showing them what the problem was.

One of the most interesting stories told by the respondents illustrates how very differently the Chinese workers viewed a potential problem. Their approach to solving the problem turned the problem into the solution. The respondent reported,

... generally you would have a complete concrete slab in place before you do the steel work. That way, when you drive the forklift or any of the equipment on the job site, you are driving it on the concrete slab. They didn't have it in place. They had poured a perimeter footing all the way around the building with some cross beams ... all the way around the building ... 
was all nice soft sand, so we were forever getting the forklift and cranes stuck in the sand. Why they did it that way I'm not real sure. The reason they said was that because it was sand they knew that the sand would settle, so if they poured a concrete slab on it, the slab would crack. So what they were doing off to the left of the building site, is they were pre-casting hundreds and hundreds of these little blocks that were approximately two feet square and six to eight inches thick. When we got all finished with the job, then they came and set these into place to make the floor, like bricks or cobblestones. So as the sand continued to settle, they could readjust these stones by putting more sand under them to keep them level. And from an engineering point of view, this is a very bad idea because the dead load of a metal building is very light. We tried to explain that to them. If they had designed and built the slab as we had indicated in our drawings and our materials, then it would have supported itself on the sand, and if it settled, it would have all settled together. But because the dead load was not real significant, the amount of settling would be also real minimal... . The [Chinese laborer] thought the floor would crack and didn't want to get in trouble for a cracked floor so he decided to pour all these little cobblestones and nothing was going to crack because it already is cracked - it already has all these joints between the stones anyway. (MBCC)

Technical Sophistication. Chinese Expect High-tech Equipment Even When It Isn't Appropriate. Most of the programs involved some transfer of technology, either technical documentation or the actual equipment. In many cases the Americans felt that the expectations the Chinese had about receiving the most sophisticated technology was a problem. They had some difficulty convincing their Chinese partners that much of what they wanted wasn't appropriate given their current state of development and their goals. The experience of the EMEMC respondent is characteristic of this problem:

The current management of the factory were quite interested in putting in equipment that we didn't think was necessary. They wanted - they had been like a little kid that had been under a rock for forty years and all of a sudden the rock was taken away 
and there is a whole new world of technology. And they felt, 'We want all this new technology,' much of it that wasn't necessary for what they were trying to do. And we tried to encourage them, 'Let's start off with what you have and as you improve,' they wanted to computerize everything. Wanted the state of the art this, and state of the art of that, that really wasn't necessary. We reached a compromise in which they did install some new equipment. But for the most part they were working with the existing facility.

The CC respondents realized that one of the reasons the Chinese wanted all of the technology immediately was a function of the budgeting process in Chinese ministries. When the Chinese had the money to buy technology they felt they had better spend it because they may not get it again. But this put a burden on the trainers to train the Chinese on all the technology whether or not it would be used. They said,

... most of the Chinese customers they buy a lot of software. It's not like Hong Kong or Singapore or U. S. or Europe where they will buy only what they need. But China, when they buy something, they want to buy the whole library, they want to buy everything. I mean because most of the companies outside, they could get a budget every year, but China - may not yet have another budget for the next five or ten years. So when they buy something, they want to buy the full range of products. And they want to be trained on the full range of products even if they won't be use them all. It's a lot of training. (CC)

Chinese Have Limited Exposure to Technology. The limited exposure to technology was mentioned as a problem in training Chinese in the use of sophisticated equipment as well as in the proper assembly and full utilization of equipment they bought from abroad. The $C / T$ mentioned in the earlier section on going from theory to application that he saw many 
pieces of equipment sitting unused in China because the Chinese had been unable to set it up properly. He said,

... one of the biggest problems is their limited exposure to technology and - they just haven't had the experience that we have with machines. They have limited mechanical aptitude. We are exposed to many different kinds of machines from childhood but the Chinese - so we take a lot of things for granted - but for the Chinese the bicycle is probably the most complicated machine that most of them have personal contact with. I mean China's industry is not that old, just since the war and the Soviet Union came in and developed their industry, and as you have seen, it hasn't changed a bit since then... .

The CC respondents said,

I think Chinese engineers have limited exposure to the technology ... and to the knowledge of the computers, to the operating system, to everything. Whereas engineers from the outside, they probably have seen a lot more. They have more experience and so we can start less basic, we can have more assumptions about what they will understand... . (CC)

Another respondent said,

They have some beautiful equipment for quality control, inspection equipment, analysis equipment but it's all sitting in a demonstration laboratory not sitting out in the factory where it could be used. It's great for taking visitors to and showing off all these great tools they have but when you walk in you have to take the dust cloths off of them. They're all covered up so they won't get dirty. That's not the way you use equipment. There is lots of equipment but I didn't see much of it being used. (EMEMC)

The $\mathrm{C} / \mathrm{T}$ respondent pointed out that American socialization exposes Americans to a highly mechanized environment. By the time children enter school in the U. S. they have interacted with and perhaps helped repair different machines: automobiles, electronic kitchen appliances, home 
computers, bank cash machines. This exposure instills a level of trust in machines that he found absent in the Chinese. Because of this lack of "trust" the Chinese had a need to continually manually manipulate selfadjusting, computerized equipment - thus defeating the purpose of the equipment. He related a story about a Canadian who was sent to a province in northern China to train a group of Chinese workers in the use of modern road surfacing equipment:

He spent three weeks in China trying to train these workers to use this machine. For a training that would have taken three days in Canada after three weeks he still hadn't made any progress with the Chinese workers. All this machinery was computerized and all you had to do was to dial in the information about the road surface and the machine would automatically release the correct thickness of road material. But the Chinese workers would not accept this feature of the equipment. They didn't believe it would automatically adjust to the different conditions. After he had set up the computer to operate the machinery they would jump in and manually adjust the parts of the machine causing it to operate incorrectly. He kept telling them to keep their hands off but they kept tinkering with it. He finally constructed a circle, a fence, and put the workers inside it to keep them away from the machine.

This limited exposure to technology also made it difficult for a respondent to convince the Chinese trainees that all the steps in a process were necessary. It was his belief that it was their lack of technical understanding and their fear of getting into trouble that inhibited them from trying his way:

We have steps that we follow in the fabrication process to ensure that the dimensioning all comes out right. We've had trouble convincing them that some of these steps are necessary. Our welding engineer who was over in China when they were fabricating the first of these units had trouble convincing them, 
and is still having trouble - for example if I want something that's perfectly flat and part of the nature of the process when you cast steel and it's heat treated it tends to warp and bend and may come out of shape. You put it in a little press and you press it straight. But because steel has a certain amount of elasticity to begin with and you press it straight it will spring back a little so what you have to do is press it beyond the point where you want it and let it come back. Well they are scared to death that if they press it beyond that point that it will break. And we tell them that, It breaks it's not very good anyhow so go ahead.' And we still can't get them to follow our instructions... . As a result, the first bucket they produced instead of having a straight edge it was bent. As I've said its not world class but its satisfactory for what they are doing. But it isn't the way that it should be in the long run. They are just afraid that if they push it too hard it will break and then they'll get in trouble. (EMEMC)

At the same time many of the respondents admired the skill level of many of the Chinese they worked with. In some cases they wished they could hire these workers to work in their American plants. They reported:

Even before we started the program, we recognized the high caliber of their people, very, very technical caliber, in this case it's all technical engineers. (TEMC)

... they had some very good craftsmen. In fact a comment from our welding supervisor - he'd like to keep that guy, he was a very good welder. Once we showed him what to do he was a good welder. (EMEMC)

... if we could have we would have loved to have brought home at least five of these guys because we were friends and because they were good workers and they were enjoyable to be around. (MBCC)

Selection of Trainees. Chinese Send Trainees Who Are Not Always Appropriate. It was generally agreed by the respondents that training the right person was key in whether the whole program would be successful. 
But they found that they were not always able to select the people for training nor had they much influence on the Chinese selection of the trainees. In addition to learning the specific skills and knowledge necessary for the technical transfer, the Chinese had other purposes for the training. Many of the programs involved travel out of China either to the U. S. or Hong Kong which offered opportunities to experience a different culture, purchase material goods not available in China and gain status from having been abroad. As one of the Hong Kong respondents said, "For these people that want to come out to Hong Kong or Singapore for training, it's a big incentive for them. They all want to come. I mean they are desperate to come." Given the prestige of going abroad, who was chosen to go was often based on status or guanxi rather than who would be doing the actual work or using the equipment.

In the case of the $\mathrm{CC}$ respondents they recognized the importance of training the right people:

When you are talking about the objective of training - if, from my side, the objective is after the training the people, they can come back and stand alone to work in it properly so that they won't cause a lot of support problems or support service needs to our office. I think this is a very important fact here. You want to control, you want to select a right trainee... This is the first step you want to do.

At the same time they had to be careful to not insult anyone by suggesting that a particular trainee may not be appropriate. This could result in lost sales since many of the Chinese sales negotiators ended up being the trainees. They said, selling process will receive the training. So I think you never 
want to touch it because even - they will send some people who are not actually the people who need to be trained. But you don't want to mess with it because they could affect the sale. It is the people who have the muscle.

Given that some trainees may not be the actual users or workers, the CC respondents try to identify the "key people" who will then go back and train others:

Sometimes there are users who really, actually - like engineers that will actually be using the system. But in most cases, most of them are directly involved in sales and they would have the training. So we know this is a fact, and we are not going to change it, but we still want the training to be successful. So we identify who - maybe in a group of four or five - who is the boldest. You want to train them ... I think that he is the key person ... the key guys that we know, even though they may not use the systems every day, when they get back at least they can teach the other people. That's why we spend more time with those making sure they understand the concept of it and to learn as much as possible so they can pass the knowledge on to the people when they get back.

The TEMC respondent had a high degree of control over who was selected for training in his program. From the program's inception this respondent was able to interview and rate his choices for training from a pool selected from all over China. The criteria that he used was based on Western values and behaviors. He developed a numerical rating system based on English proficiency and personality characteristics. He largely attributes the success of his program to his selection of the right people who are able to quickly adapt to living and working in the U. S.:

I use several criteria for rating them, language of course is the most important. Then I look to see how open he/she is, how timid, afraid or reserved. I'm looking for people who are more 
outgoing, more open, more willing to share information about themselves. Those indicates the easiness with which this person could adjust - more chance for success. It is very important, very important. I tend to look for people who are younger in age... . Young people are more adventurous or daring, more gutsy, not set in their ways. With exceptions, not all the old timers are like that... . I look for, hopefully, for people who are not married. Which I have completely failed, most of them are married. That's their way of giving me candidates - to insure they are going back to their families... . There are many subtle things. I also watch how they dress and we had a chance to eat or drink to see how Westernized they are... . I got to see their mannerisms. That's a very, very interesting subject we are touching here. In our society, there are certain things that are taboo and equally so in China. Those things taboo here can be very acceptable in China... . The noise they make and the way they sit... . For example it's quite acceptable to put your bones and things, scraps, not on your plate, but just in all cases almost, I dare say, on the tablecloth or sometimes on the floor. You know that. That's a very surprising to me even, you know, I was born in China. I left when I was 12 , so I remember a lot of things but I never remembered that ... . Maybe the communists did that to them, I don't know.

The TEMC respondent wasn't the only one who felt age was an important factor in the selection of trainees. The $\mathrm{MBCC}$ respondent found having an older, experienced supervisor was very important. He felt the other workers looked up to him and would listen to him. And the CC respondents believed it is more difficult for older students to learn.

Therefore they preferred to train younger students. They said,

A lot of them are not very young. For example, in our industry right here in Hong Kong the average age for the designer would be between from 25 to 35. But in China a lot of them are in their $50^{\prime} \mathrm{s}$ or $60^{\prime} \mathrm{s}$. And it takes a much longer time for them to learn than a 30 year old engineer. It makes a lot of difference. They learn much slower. 


\section{Work Attitudes and Behaviors}

The subcategories under Work Attitudes and Behaviors are Motivation, Responsibility and Work Habits. Of all the problems the respondents discussed, Motivation and Responsibility were mentioned most often. Responsibility has been a theme throughout the previous problem discussions but it warrants its own category because of how often it was mentioned and the intensity of the respondents' feelings about it. Over and over respondents claimed the Chinese were not motivated to work hard, do a good job, make a decision, improve a product, take responsibility, admit mistakes and so on, because there was no incentive and because of fear. The lack of reward for doing better or doing more was seen as a critical barrier to Chinese modernization. It was universally felt that the fear of getting into trouble kept the Chinese from any expression of creativity, innovation or attempt at improvement.

\section{Motivation. Chinese Get Paid the Same Whether They Work Hard} or Not. Every respondent in one way or another said the Chinese lack motivation because they all get paid the same regardless of quality or quantity of their work. Coming from cultures where monetary reward has been the major incentive for decades it was difficult for the respondents to be in a culture where money did not have similar power. Without the ability to reward with money they were often at a loss as to how to motivate the workers and trainees. They all felt that this situation was going to have to change if the Chinese wanted to modernize and compete in the world markets. The lack of monetary rewards and the problems they associated with that were often related to the system of connections or guanxi. 
The BDC respondent had strong words to say about the lack of Chinese motivation. Her comments are characteristic of many other respondents' feelings:

I think creativity comes also with motivation. If there is motivation, there is creativity. I think you have to have motivation and they seem to lack extra motivation... . But because of the, what do you call it, the iron rice bowl situation...the fact that no matter how hard you work or how hard you try, you are paid only scale. The scale is set. And people as I said, are used ... . I would hate using the word 'lazy' but I am not so sure, that they are laid-back over there people are laid-back. If you don't get it done today, there is always tomorrow, whereas we have deadlines. Over there, there are hardly any deadlines, so they don't feel the responsibility. If something is wrong, fine, it wouldn't affect your pay, or it wouldn't affect your review. Usually they don't do any review or merit increase anyway, so there is no incentive. Right now they realize that is the case, so they are trying to institute bonus schemes. I heard that the bonus schemes now have gotten to the point that everyone gets a bonus and it is all the same anyway. So what is the incentive, you know, to excel? I really think in order for them to change their attitude is to give them frequent review and motivation, merit increases and awards posted somewhere. You know, some kind of reward to get them motivated. Of course, I cannot use things to stereotype all the Chinese people in China. There are exceptional people. People who do research in China, they have originality. They have creativity. They have to in order to go to work and they have to be interested, otherwise they wouldn't be doing that kind of work.

The $\mathrm{MBCC}$ respondent also attributed a lack of monetary incentive to the workers slow pace and lack of attention to doing the work correctly. He said,

So that is one of the reasons why we found we had to work with them because they were not motivated like our people. 
Whether that building took a year or one month to build they all got paid the same so there was no motivation whatsoever.

\section{Quantity Rather Than Quality Is Emphasized in Chinese Industry.}

The SMC respondent attributes his lack of success in China in the early 1980 's to the fact that the factories he worked with were told to work with him and didn't really want to make shoes for his company. He believes they would have preferred to continue to make shoes for the domestic market where they could sell every shoe they made regardless of the quality. This is a point made by several respondents. They said, the factories in China have not been able to keep up with the domestic demand and are able to sell everything they make. As a result they have had no motivation, no incentive to improve their products or change the way they do things. One respondent said,

Just, you know, they weren't capable in making the type of shoe we wanted or weren't interested. That was a big factor too, you know; these factories were told they were going to make shoes for [company] whether they wanted to or not, whereas the factories we have now, they are hungry, they want the business. So that's another big factor that I didn't mention, especially in 1981. These were hard-core communists we were dealing with and they could care less if they were dealing with foreigners. They would just as soon make their shoes for the domestic market and sell everyone of them as fast as they made them and not have anybody telling them how to make them, so that is another big factor. (SMC)

You Can't Fire Chinese Workers for Poor Work. Connected to a lack of monetary incentive to motivate Chinese workers, the respondents said that the inability to fire Chinese workers resulted in a lack of motivation. This Iron Rice Bowl which guarantees a job and a salary to every worker for 
life was mentioned by several respondents as a serious problem. As the BDC respondent said above, "But because of the, what do you call it, the iron rice bowl situation...the fact that no matter how hard you work or how hard you try, you are paid only scale" and cannot be fired, there is no incentive to work hard. The MBCC respondent attempted to fire a worker only to be told by the other workers he couldn't do that. His solution was to remove the worker from the work team and make him sit and watch:

... in America we could fire the workers that we didn't like. In China you couldn't fire them although we tried it. We had worked on the job maybe one week and there was one guy that I just didn't care for. I had kind of a personality conflict with him because every time we asked him to do something he would moan and groan about it and he complained constantly. So I said, 'Okay, you're fired.' They said, 'You can't fire him.' I said, 'Okay, then he can go sit in that pile of sand. He can come to work but he is not to work on the job, he can just sit in that pile of sand and sleep or watch, or whatever he wants, but keep him off the job because I think he has got a bad attitude.' He said. 'Well, you can't do that in China.' I said, 'I can.' I said, 'If I can't fire him I just don't want him to work because he gets in the way.' So you know how the thing is in China, so he lost face. (MBCC)

Individual Initiative Is Dangerous. On the whole the respondents felt creativity, making a decision, doing anything different, is taking a risk that might get one into trouble. It was commonly felt that there are no incentives worth enough to motivate a Chinese to take these kinds of risks. The CC respondents explained the cultural background for this caution:

Chinese are not really famous for creativity. A lot is the culture. All they want is to complete the job. Their real intention, because in the last 10 to 20 years they have gone through the cultural revolution and all these things and creativity means someone that has a vision - someone that 
wants to create something - somebody that has some idea of something new. I mean, these things are dangerous in China. When somebody says, 'I want to create that thing,' it means that he is taking a risk and Chinese are not good for taking the risks. It is the culture, the whole governmental structures, it doesn't encourage that. That's why it is gradually improving. Say, for example, for the last number of years, every time when you tried to ask them questions. A lot of them would answer ... they would say theoretically, 'Yes, well, I guess that's true.' They would always put a condition there, right?

... but it doesn't work the same in China - personal accountability for individuals - it is impossible. When you waste an opposing card - you'd better don't do it. It is a big risk. How much more is he going to earn? Five more dollars more? Big deal! Right? It isn't worth the risk. If it [decision] proved to be a wrong one it's a disaster or it doesn't need to be proven a wrong one but one day - this decision could be attacked by somebody who is on the opposite side. So you're in a disaster already. It doesn't need to be wrong. The right thing could be wrong. They are prudent.

Another respondent reported,

They are repetitious, not creative. I think it's unfortunate because they have so much potential but they don't dare to, or don't know how. I guess that was the way they were brought up in their regime. They were not left alone to think on their own or to air what their opinions are, to test it out, it is being suppressed... . We don't have enough time for them to become creative. But if they could stay two years more, maybe we see some real creative work. (TEMC)

Giving and Losing Face Can Be a Strong Motivator. When asked how they motivate the Chinese workers or students when they can't give them raises and can't fire them a few respondents said they appeal to face and achievement. This approach included attempts by the TEMC respondent to award the trainees with recognition as employee of the month, certificates for completion of training, and other documents that would go into their 
files. These opportunities created a sense of competition among the trainees for these awards which the respondent viewed as good and healthy. He said,

They want a letter saying - document so they can show someone back home. So when one goes home a résumé or a file this big with all the information and the document, whatever rewards, if you can call it that, accommodations and some only have a little, that shows they have been better. They have a better chance to get promoted.

The CC respondents appeal to their trainees desire for "achievement." The CC trainers reasoned that if the student could complete a real project during the training they would gain much face upon return for having achieved this goal. He or she may have a better chance of being promoted or could receive special favors. He said,

Sometimes with Chinese, there are many things you can do to motivate them. For Chinese, face is one thing, right? And when they get back and when they do something great, they have face. And so you just have to find where the hot buttons are ... they know they can have a lot of face when they show their leaders something real live achievement, then they might even get promotions, or they get special incentives, or the next time when they get another trip overseas, then they will be the ones selected.

In an example involving loss of face rather than gaining face, the MBCC respondent tried to fire a worker who complained constantly and didn't want to work. When told he couldn't fire people in China the respondent insisted the worker not join the work team but remain on the side-lines. That night the worker was visited by the supervisor and other workers who engaged in a criticism session with the worker. This criticism 
session resulted in a complete change of attitude and behavior. The respondent said,

And so that night the supervisor talked with him and some of the other people and he was sorry that he had complained and had made such a big deal out of things that maybe weren't such a big deal after all, and he turned out to be one of our best workers... . So it's an interesting experience for them to see that the Americans have a little bit different way of thinking, and maybe it is not so bad after all.

In another example the loss of face, while not as easily seen as the above example, shows the power of face in motivating blocking behavior. A respondent had a conflict with an individual in the Chinese plant who became a serious blocker in the manufacturing process. The Chinese chief metallurgist dug in his heels and refused to follow the American technique, arguing that his method was correct. The respondent believed that it was only a technical disagreement that could be resolved by further technical explanations. He had the documentation translated into Chinese believing that the conflict was one of misunderstanding that could be clarified with more accurate information. He also wanted it clearly documented that the directions for the American process were clear and available in the event the Chinese tried to blame the American company for the poor quality that would result if the Chinese method was used. He said,

... the melting supervisor [chief metallurgist] did not agree that what we were proposing was the proper way to do it.

Throughout the entire - in the initial precontract negotiation time he argued with us, he argued with us during the training time. It came to a contest of wills, we were not going to proceed until he agreed to do it our way because his way was not going to produce a satisfactory product. And we went so far as to have this particular portion [of the documentation] translated 
into Chinese by a consultant that we use in California who worked with us during the phase. He is from Mainland China and his doctorate is in metallurgy so he understood what we were trying to do. And he translated the particular instructions that were critical to producing good steel, into Chinese. That's the only thing we translated into Chinese because of the cost of translation. But we wanted no misunderstanding that this is how it's gonna be done. And the guy is still arguing with us. He is still a weak link in the process... . We sent our melter over there to train them over there and he came back - he was bald to begin with but while he was over there he pulled it all out. He just couldn't get the guy to do it the right way. I don't think that there's anything other than a technical disagreement. He had been trained in his school to do it this way, we're telling him to do it this way and we are telling him why we do it this way but he is still convinced that this is the way to do it. I think it's strictly a technical disagreement. As can happen in the field of technology.

\section{Chinese Trainees Will Respond to Material Rewards. The TEMC}

respondent introduced the Chinese trainees working in the U.S. to

overtime pay. He feels this has been very successful and has resulted in the trainees requesting to work overtime. But it has produced jealousy among the Chinese trainees who see an unfair advantage to those who work in an area that requires overtime work. He said,

Maybe because of the monetary gain by working overtime, they always ask me if I can influence [company] to give them more opportunity to work overtime. Also, because of the work load, the nature of the work requires overtime and the other guy happens to be in an area doing research work who got a more flexible schedule, don't have to work overtime and don't get paid, so he come up with less money than the guys that always work overtime and they come back and tell me. They said, 'We think it's fair that one works overtime all the time and they should give some of the overtime money to us.' You do?' I said. 'How is that?' 'Because he gets too much money, we don't get any.' I said, 'But he earned his, you didn't work.' 'But we want to work, we don't have the 
opportunity.' I said, 'Tough luck. That goes for [company] engineers too. It's the same. You want to make an exception? No way!' They want to divide somebody else's money.

The MBCC respondent reacted to the lack of monetary rewards by singling out individual workers he liked and whose work was particularly good by giving them American cigarettes. He discovered that American cigarettes were a status symbol among the workers and they would often display them in some way rather than smoke them. He said he would never give a gift of cigarettes to an individual in front of other workers out of concern that the worker would be the target of jealousy.

Curiosity Is a Motivator. The curiosity of the Chinese was a source of delight for many of the respondents and was mentioned as one of the things that motivated trainees and workers. The respondents reported:

One thing I haven't mentioned is the immense curiosity of the Chinese. It's wonderful to watch, they are like children. They have no inhibitions what so ever. You take them through the factory and they would run off. It's like taking a group of school kids through OMSI [Oregon Museum of Science and Industry]. Unless you herd them together they are going to run everywhere they can. They would write down every title of every book on your desk and they take copious notes. They want to learn everything... . (EMEMC)

... some of them might have been better [than American workers] because they had the curiosity. With an American construction worker, he may not have the same curiosity. They did have that. (MBCC)

Responsibility. Few Chinese Are Willing to Take Responsibilty. As seen from many of the previous categories and quotes, responsibility was a major theme in the respondents' interviews. They felt that very few people in China were willing to take responsibility for anything or were held 
responsible for their work. It was felt that a lot energy went into avoiding taking responsibility and ignoring problems. They felt that this situation often compounded problems because it was not an individuals' responsibility to correct early problems or mistakes or bring them to someone's attention. In many respondents' comments this unwillingness to take responsibility was related to fear of getting into trouble. On the one hand the respondents could understand, given their recent history, why the Chinese were reluctant to assume responsibility in making a decision, correcting a problem or pointing out a mistake, but on the other, were very frustrated by the situation and very critical. One respondent said, "There's no accountability, none. Nobody seems responsible... ."

The MBCC respondent said he had to watch the workers carefully because they would disappear and leave the task they had been assigned and instructed to do to someone else. He told this story to illustrate not only the lack of responsibility the workers felt toward their jobs but their lack of understanding of the need for precision in performing the tasks:

We would mark the stack where all the holes were to be drilled and then we would show one of them where to drill the holes. In fact, when we first set up somebody to do that, he was sitting there drilling holes and then half an hour later we would look over there and he was gone. Where did he go? He went to take a nap or something, and he had shown one of his buddies how to do it. But his buddy wasn't drilling holes in exactly the right place even though it was marked. He didn't quite transfer the whole message to his friend; he just said, 'Drill holes.' So we had to watch them pretty close and say, 'Look this is your job and your responsibility to make sure this is done correctly.' (MBCC) 
The EMEMC respondent reported two incidents involving the workers his company trained in the U.S. that represented lack of responsibility. In both cases the production process came to a stop because the respondents believed no one took the responsibility or had the authority to make the next step happen. This also illustrates the problems the $\mathrm{C} / \mathrm{T}$ respondent identified as the lack of "boundary" people who interface between work teams. He said,

The people [Chinese] who do the welding are in one division, the people who do the heat treatment are in another division in the company. There are two separate bays. There is a crane that runs up and down here with the bays side by side, they share the same common structural parts. To get the component moved from the heat treating bay into the fabrication bay took weeks. No one would accept responsibility for having it picked up from this bay and putting it into the other bay. And that was with one of our [American company] engineers on site.

The first castings that they produced according to our procedures were in 1988. April of $88 \mathrm{I}$ observed the production of these first castings. They still have not left the factory and this is almost 1990. They move from one part of the factory to another but there's no sense of urgency for getting these things out. There's no one who really feels the responsibility for - if its my responsibility for seeing that this casting gets out the door and into the customer's hands.

Again fear of getting into trouble was attributed as one of the reasons Chinese didn't take responsibility or were unwilling to take any risks by doing anything differently. The respondents said,

'Why do we want to ... it's such a hassle. Why do we want to do that?' No. If somebody decides that, okay, say, "From now on we are going to hide all the pipes and put the pipes in the wall" - he is running a risk himself. He is exposed to, 'You 
said that you wanted to do it this way, and if there is any problem it is you guy's responsibility.' Who wants to do all that in China? They don't get incentives for doing that. Right? And so they buy our tools, maybe not because they want to do the job better - it's just that they can't do the job without the tools. (CC)

One of the reasons I came up with later was that - nobody wants to take the responsibility, because their neck is on the line, right? If they had poured the slab like we told them to pour it and the slab cracked; if someone came from the [Chinese Department] from Beijing to look at this project and the floor is all cracked, what is he going to say? 'I have made a mistake?' He can't do that, so he knew the floor was going to settle. He didn't know how much and he didn't want to risk his neck, so he decided to pour all these little cobblestones and nothing was going to crack because it already has all of these joints between the stones anyway. That's the way I figured it. (MBCC)

[Quality] requires an individual to take responsibility for his actions. To believe, to know that he's being backed up ... . If you and I are part of a chain of producing a product and your job is to put the plastic on this thing and my job is to put two batteries on this piece and I send it to you with only one battery - thinking that's not my responsibility, my responsibility is putting a piece of plastic on it. If I complain about not having two batteries in there maybe I will get into trouble. The guy who complains has got to know that he's doing the right job to come back to the other guy to learn to put two batteries in there. So he has to feel that he has responsibility for his actions and that doesn't exist. (EMEMC)

As mentioned earlier in Technical Sophistication the CC respondents circumvented a potential problem by designing their training to prove the correct functioning of their computer system. They were concerned that the Chinese students would blame the equipment rather than their lack of understanding if they had problems after the training. This tradition of placing the responsibility for the student's learning on the teacher would be 
extended to the machine. In this example the $\mathrm{CC}$ respondents also mentioned the concern with "pressure" from the leaders as a motivation for placing the blame on the machine. They used the term "pressure" several times and when ask to explain in more detail what they meant by pressure they talked about expectations and concern for getting into trouble:

If they have never seen a real live example - it has never been done once and if they have problems, when they get back, a lot of them would put the blame on the machines. A lot of them said, Nah, it doesn't work.' They didn't think it is their problem, especially when they get pressures from their leader. And they say, I mean, 'The machine is no good, it doesn't work, and we have gone through 60 days training and it still doesn't work and so it's not our fault ... we have learned everything.' That is why we encourage them to finish at least one real live design before they get back so they have confidence.

As mentioned in Language the respondents occasionally encountered a Chinese person who they considered more "progressive," someone who they perceived was more assertive in promoting the respondent's interests and who was assumed responsibility for something. This characteristic was mentioned by several respondents and it appeared they trusted progressive Chinese more and liked associating with them more than other Chinese.

Progressive attitudes was mentioned by the SMC respondent as one of the reasons his company's current joint venture in southern China was more successful than their first foray into China the 1980 's. He said,

We've got a couple of people within the joint venture, on the Chinese side of the joint venture, that are very progressive. They are willing to talk to management - they are really willing to stick their necks out for us, and that filters down throughout their infra-structure. So that helps. 
We spent a lot of time with him outside of work and we became good friends and you know, he was the type of guy that would give his right arm to be able to work for us later and come to the States and he just had a real progressive attitude... .

This one particular woman is in charge of the [Chinese Bureau]. She is probably one of the most progressive Chinese that we have ever met... .

Work Habits. When respondents talked about the differences between American work habits and Chinese work habits they emphasized four areas with which they particularly had problems: The first - Chinese don't ask questions or ask for help when they have a problem - was presented in Learning and Training Problems. The other three - Chinese don't work as hard as Americans, Chinese have no sense of teamwork, and Chinese don't have any quality control - are presented here.

Chinese Don't Work as Hard as Americans. Several respondents talked about the difference in hours, pace, and the intensity of work that is expected in the U.S. versus the expectations in China. When respondents brought Chinese to the U. S. for training, in general they did not accommodate the Chinese work style. They designed their programs according to the American custom of eight hour days, half hour to one hour lunches and back to work immediately. While these respondents were aware of the Chinese tradition of a nap after lunch they were not interested, at least initially, in providing for this break in the training. In one case the respondent said they had considered doing it more the "Chinese way" but had decided that one of the training objectives was to show the Chinese the American way of doing things. This interest in exposing the Chinese to the "American way" was mentioned by several respondents who clearly felt it 
was the better way and that the Chinese would benefit from learning it. The EMEMC respondent said,

We considered doing it more the Chinese way but we felt that would be counterproductive to what we were trying to do. We had anticipated their - we considered doing it in a more relaxed manner as we did when we were in China. We would never just sit down and start talking. We would have to have a cup of tea and go through all the pleasantries of - a half hour later we would start talking about what you think you want to talk about. We decided number one, we had a limited amount of time to train them and we wanted to give them as much training as we can and part of the training that we kinda thought we wanted to give was for them to see how things are done outside of China. If they come over here and they are treated exactly the same as they are treated at home they are never going to learn that there's another way to do it. (EMEMC)

... they had a problem in that they're not used to working as hard as we expect them to work. We picked them up at 8:00 in the morning and kept them going until 6:00 at night and they weren't used to that. They're used to having a couple of hours for lunch, tea breaks in the middle of the afternoon. You have to have tea before you start work. We didn't have tea... . The first training group we would have lunch for half an hour and then expect them to get right back into training. Well, they are not the least bashful about putting their head down and snoring, it didn't bother them at all... . It turns out just to get them to come back to work after lunch was impossible anyhow so we ended up having a longer lunch period and taking that time out of our training program. (EMEMC)

The $\mathrm{BDC}$ respondent reported,

They are used to just coming in and working ten hours, supposedly ten hours a day in China ... the working hours, the actual time that they put probably 6 hours or less. Our pace is much faster. There is no time to sit and nap during the working hours, whereas in China it is very common to go in, and the first thing is to drink tea and talk and read the papers and before 11:30, everyone is gathering up their things and ready to leave to go home for lunch. Here we don't have 
a nap break as such. We were trying to be accomodating when they were here and most of us take only one-half hour for lunch, but we gave them an hour and they left early. They came in around 8:30 A.M. or 9:00 A.M. ... . So this is a very short time in comparison to our hours, and yet you could feel that they cannot concentrate that long. They would feel fidgety. They would get up, they would yawn. After lunch they would yawn so I could see if they were used to taking a nap for thirty years, and then all of a sudden, no naps that would become a hard thing to break. That is understandable. However during the day, you could still feel that they are not used to working and constantly moving and constantly concentrating. I think that it's their attitude towards work. It is a cultural thing in the ways of the new communist China, not under the old Chinese, you know, the work ethics. Traditionally, the Chinese work very hard but these people when they come, they don't show that. (BDC)

There's No Teamwork In China. Contrary to what some of the respondents thought they would find in collectivist China they found a lack of coordination and cooperation among the Chinese. A Chinese-American respondent explained that the Chinese were really very individualistic in that their only loyalty was to the family, otherwise they wanted to do everything their own way. He said,

I can say they're not good team workers. I believe this goes back to the nature of being a Chinese I guess. The entrepreneur individualistic Chinese way. That is why China is not unified as strong in that sense. It is a basic problem. They can't be strong as a group. Each ... everyone has got their idea running different directions.

China still has strong family ties ... . But if you allow the individuals openness and freedom to choose, the chances are they would choose not to be part of the group. My personal experience and belief, this is the root of the problem, the basic problem in China, I believe ... . I see individuals try to promote themselves... . There would never be General Motors or Mitsubishi in China because each has to have his own 
company. They just cannot possibly grow to be that gigantic and powerful. They would have to pool their resources together ... . They work against each other. Different ministries, different airlines in China. I can give you hard facts. If they can be half as strong and nationalistic as Japanese, China would be strong. They are not dumb. They are working hard, why is it? They don't get together. They don't pool their resources to work as a group, they don't cooperate. You see these engineers over here each one trying to do their own things and hiding things from one another. 'I don't want them to know what I do at night.' That type of attitude.

Another respondent said he didn't see anything in China that he would describe as teamwork but he was open to there being a system that he did not readily perceive:

I haven't observed anything that I would say was teamwork... . If I'd noticed anything it would be an absence of teamwork. That doesn't mean it isn't there I just haven't seen anything that I would classify as teamwork... . Let me give you an example. Teamwork is everybody knowing what everybody else is going to do before they do it. You're aware of everybody else's actions ... and you count on each other to do their jobs. In China people seem to run around, at least in the factory the appearance was that they ran around without any real plan. Without any real knowledge of what they were doing. I don't know if that's the fact, the truth, but how I perceived the situation. (EMEMC)

Chinese Have No Concern for Quality. "Quality control doesn't exist.

It's getting better. The concept of conforming to a specification - they just don't do it ... you don't see any quality control or quality assurance as we think of it." (EMEMC)

This respondent's comment is representative of what the other respondent's said about quality control in China. The SMC respondent spent about seven years in China trying to upgrade the quality of shoe 
manufacturing in order to buy shoes from China. He left before accomplishing his goal. He said, "They had no knowledge of the outside world and how commerce works, or how business works in the outside world... they had no understanding of supply and demand at all. To reject a shoe because it was royal blue instead of dark royal blue which is unheard of - they just thought we were nuts."

Other respondents had more success in improving quality standards and quality control systems in the Chinese plants they worked with. But in all cases reaching the expected standards took many years. And for some, after several years the standards necessary for world markets still had not been reached. The respondents attribute this lack of concern for quality to the practical concern with quantity rather than quality. Chinese plants could sell everything they made as fast as they made it in the local market, therefore there was no incentive for improvement. When the Chinese first invited foreign companies into China they didn't understand the great concern with precise standards. With the desire to compete in world markets and export for badly needed foreign exchange the respondents felt the Chinese were beginning to realize the need for quality control measures and improvement. One respondent said,

If you try to tell them, 'You could do a better job' - this is very difficult to convince them. If they are already do something it's proof that it's good ... . They have a computer or some circuit board which is huge size, you tell them some IC can replace the whole board. Maybe they won't do it if they are happy with this board already. But one day they will find out that this board is a burden when they can't sell it. Nobody wants such a big thing. So its only export pressure that will make them redesign it to make it smaller not some sense of making it better ... . But if this thing is already sellable, why would they want to make it better? It's just like they are 
designing the same old car for the last 30 or 40 years. They don't need to improve it. (CC)

The EMEMC respondent said that responding to customers' needs and improving quality relates to a lack of exposure to market economies and again to the lack of responsibility and the fear of getting into trouble:

There's no one who really feels the responsibility for - if it's my responsibility for seeing that this casting gets out the door and into the customer's hands - obviously the idea of customers is something new to them. They're just getting used to the concept of the plant has a responsibility to produce things for the customer instead of producing for the government.

The concept that we would like to see them do, what's certainly more popular in the west today - instead of lots of inspectors running around you design your system so that you and I as individual workers are responsible for the quality. We won't wait to see if we can get it past the inspector at the end. We become our own quality inspectors. And you do away with your so called quality control people when every individual worker is responsible for the quality of what he is doing. This is a concept that is more common in the west today but something that's a long way form happening in China. In China you still have to depend on final inspection. If it's wrong you have to send it back and that's a waste of time, money and everything. It shouldn't be wrong when it gets there.

It requires an individual to take responsibility for his actions. To believe, to know that he's being backed up ... . If I complain about not having two batteries in there maybe I will get into trouble. The guy who complains has got to know that he's doing the right job to come back to the other guy to learn to put two batteries in there. So he has to feel that he has responsibility for his actions and that doesn't exist.

Many differences in cultural values clearly can be attributed to the problems identified by the respondents. The next chapter discusses the 
problems and issues in terms of Hofstede's Value Dimensions and Hall's High-Low Context Communication. 


\section{CHAPTER V}

\section{ANALYSIS AND DISCUSSION}

Cultural differences between the respondents and their Chinese trainees can largely account for the problems the respondents experienced. Cultural differences in individualism-collectivism, power distance (PD), uncertainty avoidance (UA), language and other value differences relating to time, activity and others can be seen throughout the respondents' experiences. As mentioned in the earlier section on values, any situation can be seen as an extremely complex web of interacting and sometimes competing values, beliefs and expectations. The following analysis identifies the primary values and assumptions, beliefs and expectations that may be operating for both the Americans and the Chinese in the situations described by the respondents. In addition, explanations are provided for how these cultural factors influence the perceptions and behavior of both the Americans and the Chinese.

Within each major category a sample of the respondents' most salient problems are examined and analyzed for value differences, Hofstede's Value Dimensions and Hall's High-Low Context Communication Schema. This sample of problems was selected for analysis for four reasons: First, the problem was reported by many respondents or was mentioned several times by individual respondents. Second, the respondents had strong emotional associations with the problem or situation which indicated the importance 
they attributed to the problem. Third, problems were chosen where the cultural differences could easily be seen operating in the situation. Fourth, problems were chosen where there appeared to be a contradiction between behavior and cultural values.

Many of the problems the respondents identified are consistent with the training problems Hofstede predicted when a trainer from an individualist, low PD, weak UA culture trains students from a collectivist, high PD, strong UA culture.

\section{ANALYSIS OF CULTURAL DIFFERENCES}

\section{Power and Authority}

It's Hard to Tell Who's in Charge. The tensions between individualism and collectivism can be seen in almost every problem in every subcategory, from Bureaucratic Maze through Connections. In many situations the respondents are struggling with individualist expectations that there be a clear singular authority. They expect an individual decision maker who has the power to get things done. They believe they have the right to gain access to the decision maker and believe they can affect the decisions made (Hofstede, 1983; Morgan, 1986; Stewart \& Bennett, 1991). When the respondent is aware that decisions in China are made by the very top leaders through a process of consensus building, the inability to gain access or to know who the players are is still frustrating.

Even when the decision-makers are known, the strict Chinese prohibition against favoring outgroup members (Bond, 1991; Bond \& Hwang, 1986; Yum, 1988) combined with the high UA tendency to avoid risk 
(Hofstede, 1984; Lieberthal \& Oksenberg, 1986; Seligman, 1989) leads to very few individuals willing to "stick their necks out" for the Americans. The very real negative repercussions of "making the wrong decision" or getting too close to foreigners effectively prevents the Chinese from challenging this cultural rule (Seligman, 1989).

The Hong Kong Chinese of course have an advantage, being Chinese and having first hand insights to the culture. They are perceived as members of the ingroup, "Chinese," and are therefore privy to more information than the Americans. In addition, the Hong Kong Chinese, also being from a high context culture, will be aware of the contextual information available in a situation that the Americans would not (Hall, 1976). They may also be drawing upon nonverbal information when they talk about finding out who the leaders are in a group of Chinese trainees. A Chinese friend of mine working as an interpreter in the U.S. confirms the Hong Kong respondents' comments about being told who the real leader is in a group of PRC Chinese. She said that the visiting Chinese delegation will tell her who the leader is but will not tell the Americans. In fact, she says, they work at hiding who the leader is by the leader remaining silent or by sending a woman in a leadership position - something they believe would not be expected by the Americans.

Suggestions. The experience of my friend, the Chinese interpreter, suggests the value of having a Chinese interpreter on staff for any interaction with one's Chinese business partners. A knowledgable Chinese "go-between" or interpreter who understands the culture and who would be privy to information unavailable to a Westerner could provide the Western business person with a way to understand the situation and evaluate 
information received from Chinese partners. My interpreter friend also suggests that Americans can figure out who the leader is by careful observation of nonverbal behavior among the Chinese delegation. Watch the Chinese talk among themselves and notice who gets the undivided attention of the other members of the group when speaking, who is never interrupted while speaking and who is watched by the others for his or her reaction to events. This will be the leader.

Macleod (1988) suggests Westerners cope with the Chinese decisionmaking process by understanding the process, being very clear on what one's own bottom line is and having infinite patience. In his experience in China he found that seemingly stalemated unreconcilable negotiations could sometimes work themselves out through persistence and patient rehashing of the situation. Having the time and patience to continue talking when differences appear unsolvable is often not an option for American businesses people under the pressure of deadlines. But Macleod believes altering one's timeline and expectations leads to more success in China.

Pye's (1982) advice is similar to Macleod's in that he stresses patience and expectations of delays. He says the Chinese, knowing that Americans tend to be impatient, will use stalling tactics and delays to wrest concessions from the Americans. In addition to practicing patience and expecting delays and long periods of no movement, Pye suggests controlling exaggerated expectations and discounting Chinese rhetoric about the future; expect the Chinese to use shaming as a tactic; don't dwell on thinking the delays are caused by one's own mistakes; and understand Chinese culture.

Chinese Display No Individual Initiative. The respondents' strong commitment to freedom, to being able to choose from many options and to 
making their own decisions (Samovar, Porter \& Jain, 1981; Bellah, Madsen, Sullivan, Swidler \& Tipton, 1985) was frequently challenged in their relationships with the Chinese. They had strong reactions to the restrictions on individual initiative and freedom of choice. The key phrase "they are so used to being told what to do" reflects the American abhorrence to being commanded (Samovar, et al., 1985). The American inference here is that the Chinese really would like to make their own decisions, have preferences they would like to express, and are being suppressed by an authoritarian leader and system. The hierarchy of relationships with their prescribed roles and behaviors, the emphasis on conformity, and high risk-avoidance prevents individual Chinese from initiating problem solving or innovation (Bond, 1991; Hofstede, 1984). The Americans find it hard to believe that people may be comfortable not having to make decisions and not having to choose from myriad options. As reported by Bond (1991) and noted by Baird, Lyles \& Wharton (1990), the average Chinese may find it a burden to make decisions and would prefer to leave them to the people who know how: the leaders, fathers, and teachers.

In my experience in graduate school I met several Chinese students from the People's Republic of China. Some of them responded with enthusiasm to the new-found freedom, being out from under the watchful eye of the family or work unit and free to make their own decisions. Others were bewildered with the many decisions that had to be made and the numerous options from which to choose. Never having had to make many decisions, these students didn't know how to go about it (Bond, 1991). In conversations with them they would express a desire for someone else to make the decision, to tell them what to do. Sudden "freedom" can mean 
greater responsibility and feel like a burden to those who haven't been prepared.

Relationship is the Key in Chinese Culture. Decision-making. As noted above, the respondents generally experienced the Chinese trainees as being reluctant to express an opinion and make decisions. The EMEMC respondent's experience was presented as representative of this problem (see pp. 134-135). But there was one example in the data in Power and Authority where groups of Chinese trainees behaved quite differently. The TEMC respondent said the Chinese trainees in his program had no hesitation in expressing very different and conflicting opinions and desires. As a result, when the TEMC Chinese trainees were together as a group they had difficulty coming to a consensus and making a decision (see p. 135).

The contrast in behaviors of the two groups can be related to the importance of relationship in China and the fact that the TEMC respondent used very Western criteria for selecting trainees for this program (see Selection of Trainees p. 171). The EMEMC trainees all came from the same factory in China. They had been working together for over twenty years in the same work unit. They were brought to the U.S. as a group, lived as a group and trained as a group. They had their established leaders and hierarchy of relationships (Bond \& Hwang, 1986; Yum, 1988).

On the other hand the trainees for the TEMC all worked in different units throughout China. These people were selected individually and brought together as a group only for training in the U. S. company. They were selected for their independence and affinity for other Western attitudes and behaviors. Their only loyalty to one another was the fact they were Chinese and worked under the same ministry. Without established 
relationships these Chinese were much more independent of one another. The rules that guide behavior among members of the ingroup didn't strictly apply, so individual goals became more important. As Bond (1991) notes, "In this vacuum there are no constraints beyond self-interest to bind people together" (p. 57).

The apparent difficulty they had making a decision as a group without a leader also concurs with the respondents' observations about the lack of cooperation and teamwork among the Chinese which was presented in Work Habits (see p. 188). The respondents' reports support the experience of Lindsay \& Dempsey (1985) in their training in China where the need for an identified leader to guide group decision process was very apparent. Their Chinese students were unable to proceed in discussion or decisionmaking until a leader had been chosen to make the final decision.

Conflict. The MBCC respondent, who constructed a metal building in southern China, related another example of the importance of relationship in Chinese culture; it is also possibly an example of passive-aggressive expression of hostility (Bond, 1991). Once the Chinese leaders left the construction site, the hotel staff had no reason to attend to the needs of the Americans so they made no effort to cook good food for them. There was no relationship that needed nourishing, therefore the Americans were simply ignored.

In accordance with the Chinese attitude toward conflict and appropriate expressions of hostility (Bond \& Hwang, 1986; Ma, 1992), the Chinese cooks may have been expressing their anger toward the Americans by serving them bad food. The Chinese could have been indirectly retaliating for something the Americans did earlier that caused a Chinese 
person to lose face. Or they may simply have been expressing their dislike of foreigners.

Company Loyalty. Many of the problems the respondents encountered had to do with guanxi. The respondents were generally out of the loop and rarely benefited from the system. Perhaps after several years of establishing relationships and doing favors a foreign business person would develop his or her own guanxi.

A common reaction to situations involving guanxi, which kept them in the dark or without a way to influence the situation, was frustration and anger. According to Hwang (1983) China is a barter system where resources are scarce and under the control of a few top leaders who are able to distribute these resources to their benefit by offering them as favors. It is a system where survival depends upon membership in an ingroup. The ingroup takes care of their own. In a situation with few material resources, favors such as jobs, promotions and information are valuable commodities that can be used in trade. Also, in a system where the political winds are volatile, having people beholden to you becomes a survival mechanism. In the American system - based on notions of equality of opportunity and individual self-fulfillment - the appearance, if not always the practice, of nepotism is avoided (Stewart \& Bennett, 1991). There was much tension between the Chinese system of guanxi and the individualist respondents, who were used to taking care of themselves and relying upon themselves for getting what they need. To most Americans the guanxi system is simply unfair. Ideally the person most qualified in terms of skill and experience should be given the job. Favors are exchanged in American 
business but they are constrained by law and regulations and guided by the notion that each person must prove himself or herself worthy.

The mobility of Americans and fluidity of relationships means that an American will belong to many different groups over a lifetime (Stewart \& Bennett, 1991). When Americans change jobs they also change loyalties from the old to the new company. They remain loyal to that company until a better opportunity comes along in a different company and they move. For the Chinese, whose network of relationships extend back through ancestors and into a broad extended family, shifting loyalties does not make sense even if they could do so. If a joint venture is new and unproved, the Chinese managers' guanxi will be necessary to get the company established and become successful. Perhaps over time, the company can be depended upon to provide some of the workers' needs; then loyalty can be extended. The importance of relationship can easily be seen operating in the problem the HMMC respondent had with the Chinese managers of his joint venture and his concern with company loyalty and identity (see p. 123 \& p. 144). It is possible that the respondent could have avoided the conflict that developed between the Chinese managers and avoided the subsequent considerable loss of time if he had been aware of the importance of guanxi in Chinese society. Had the respondent known to consider the characteristics and relationships that are important for doing business within the Chinese system he may have hired someone more suited the first time around.

In the first place his hiring practices were quite unorthodox for China at that time. While advertising and interviewing were beginning to happen it was still unusual to advertise for positions. Foreign business people had 
been negotiating for quite some time to be able to hire workers independent of the lists provided by government ministries (Mann, 1989). This respondent's actions reflect the general Western belief that he could hire more appropriate people, based on ability, if he were free to advertise and interview for open positions. He specifically looked for a person who had the characteristics that would be appropriate for an American manager. It is possible that it is precisely these characteristics (aggressive, entrepreneurial) that would make it difficult for a Chinese to work well within the Chinese system. In addition, he hired a person who was not an engineer and who was not associated in any way with any of the other Chinese managers who had been working at the plant for many years. This general manager's guanxi was of unknown value. When the respondent hired a new general manager this person was accepted by the other managers because he was an engineer and he was a member of the manufacturing association to which all the other Chinese managers belonged. Also the second general manager was older than the first and slightly older than the other Chinese managers in the joint venture. The veneration of age automatically gave the second general manager more authority in the eyes of the other Chinese managers. This respondent's experience points out that to ignore relationship and guanxi in China can be an expensive mistake.

At the same time this respondent is wrestling with knowing whether the Chinese counterparts are sincere in wanting to create a successful joint venture with the American company or just see this as an opportunity to gain money, equipment and training from an American company. $\mathrm{He}$ needs to see some level of loyalty and identification with the joint venture 
to feel that the Chinese are working with the interest of the company in mind and not just for what they can personally gain.

In general the respondents are asking the Chinese to give up guanxi and start using a system of hiring and promotion based on ability and merit. Given that until now quality has not been a serious concern in China, it will take some time before ability and merit can be integrated into this system. It is unlikely that guanxi will totally disappear; instead some combination of guanxi and the Western approach will probably evolve.

Chinese Allow No Access to Information. Frustration resulting from a lack of access to information pervades the respondents' experiences and appears to increase their anxiety about uncertainty. Americans are used to having easy access to much information. Whether or not the information really provides a basis for accurate prediction, having the information, the facts, provides a sense of control (Stewart \& Bennett, 1991). In a large PD culture information is power (Hofstede, 1984) and this is clearly the case in China. Information is a resource that can be used to gain other resources through guanxi (Bond, 1991; Hwang, 1983). Therefore information as a commodity will not be as freely available as it is in the U. S. The sharing of information is also affected by the allegiance to ingroups. By virtue of being foreigners the Americans are members of an outgroup and not to be provided with information.

A good example of these conflicting cultural values can be seen in the MBCC respondent's story about being given conflicting information about what kind of weather to expect while constructing the warehouse (see p. 136). The American, who believes uncertainty and problems can be avoided by careful planning (Stewart \& Bennett, 1991), tried to gather information 
about the weather upon which to base his timing for the project. The Chinese were operating from a different set of assumptions: First, nature is unpredictable and there is not much you can do about it (Yang, 1986); and second, protecting relationships is most important (Bond, 1991). To nourish that relationship and maintain harmony, the Chinese will avoid talking about negative things, and tell the respondent what they think is in his best interest and would most please him. To the low-context American the pursuit of "truth" is most important and therefore telling white lies or bending the truth is a serious matter and can lead to a lack of trust (Bond, 1991).

Getting Things Done. For some of the respondents, classifying China as an authoritarian society meant a strong boss who tells workers what to do and the workers do it without hesitation. They were surprised to find that this wasn't the case in China. And it seems some had a hard time reconciling that in the democratic U.S. the boss had more power to demand workers perform their tasks in a particular way. Referring to the differences in power distance can help explain this phenomenon. As noted in the literature review (Bond \& Hwang, 1986; Bond, 1991; Yum, 1988), the Chinese emphasis on Confucian principles in the Wu Lunn leads them to prefer a benevolent, paternalistic, authoritarian style of leadership (Bond \& Hwang, 1986). This combined with proletarian communism and belief in equality in the distribution of resources leads to a situation where leaders must be concerned with feelings and maintaining harmony while being decisive (Baird, Lyles \& Wharton, 1990). They must respect the worker and provide strict, but benevolent guidance as a father would for a son. 
Other factors have also influenced the situation between workers and supervisors and managers. The iron rice bowl created a situation that protects workers from repercussions regardless of the quantity or quality of the work performed (Savada \& Dolan, 1988). With this safeguard, political study sessions and criticism-self-criticism sessions attempt to motivate slack workers to model themselves after heroic figures who put the motherland and the people above self (DeGlopper, 1988). The political changes, betrayals and suffering caused from the many purges and the cultural revolution has created a populace that looks after itself, draws no attention and gets by.

Legitimate power is bestowed on people in the U.S. based on accomplishment, skill or some other recognized criteria. By definition a "boss" has the right to tell employees what to do and how to do it. This power is kept in check through other cultural values such as fairness, democracy, and respect for individual self-fulfillment. In general, the American agrees to suspend his or her independence and follow a leader as long as the leader continues to earn allegiance. Also the American worker is willing to temporarily subsume his or her independence in the group and follow a leader in order to gain rewards or to accomplish personal goals. The relationship of boss to employee is only one, often isolated, relationship. This one relationship doesn't define the individual who can exercise his or her independence elsewhere or who may leave the job for another (Samovar, et al., 1981; Stewart \& Bennett, 1990).

With these values operating, the American worker believes the boss has the right to demand work be conducted in a particular way. At the same time the commitment to democratic values leads American workers to believe that the boss would be more effective, and the workers more 
responsive and motivated, if their opinions were consulted before decisions were made.

Communication is Only From the Top Down. The strength of the Confucian principle of hierarchical relationships can also be seen in the lack of lateral communication between workers and work units. The $W u$ Lunn dictates appropriate behavior depending upon one's status in the hierarchy, and one's allegiance is strictly to who is above him or her and is responsible to guide those below. Pye (1988) believes this often leads to those above tyrannizing those lower in the hierarchy. This social structure is overlayed on Chinese bureaucracy where there are many layers of organization each reporting to the one above but having no relationship to other ministrys or seemingly parallel work units. In Chinese manufacturing plants, different work units responsible for different parts of the same product may report to different managers with inconsistent priorities. This, combined with the very real negative consequences of stepping out of one's position and assuming authority one does not have by making a decision or trying something new, effectively prevents the Chinese worker from doing anything that has not been clearly defined as his or her job.

\section{Learning and Training Problems}

Language. It is not surprising that language was mentioned as the number one problem the respondents had in training Chinese. Language was mentioned as a problem or issue in most reports in the literature on training programs for Chinese (Dalton, 1990; Holton, 1990; Ondrik, 1984; Porter, 1990; Sensenbrenner, 1986). In general, the respondents found the Chinese students could read English well but had difficulty with speaking 
and listening. While English is now taught in Chinese schools, many older Chinese are self-taught. Given the emphasis on rote learning, objective tests, and the teacher-centered approach to teaching, students do not get much of an opportunity to speak English or hear English spoken by a native speaker (Porter, 1990; Wenzhong \& Grove, 1991).

Suggestions. Trainers of Chinese students need to be aware that most Chinese students will not have had much practice listening to and speaking English. They need to compensate for this by speaking more slowly, enunciating clearly, using basic terminology and providing many visual aids and written materials to which the students can refer.

Chinese is a very difficult language to learn as a second language; it is admirable that some respondents learned the language or at least tried to use it. The insistance by the TEMC that there would be no attempt to learn or use Chinese is a common attitude in Western businesses in China. But it would work to their benefit to have at least a few people on staff who speak Mandarin. Especially when a Western company has an office or plant located in China, the information that one could pick up around the Chinese staff would be invaluable. Using a consultant who is fluent in Mandarin is essential if a company is trying to market a product in China. A proposed Pepsi advertisement for the Chinese version of Reader's Digest shows how important it is to use a skilled translator when appealing to the Chinese market. Pepsi's slogan "Come Alive With Pepsi" was translated as "Pepsi Brings Your Ancestors Back From the Grave" (Simon, 1980).

If a Western company is going to invest considerable time, technology and money in a project in China, it doesn't make sense not to have a Chinese interpreter on staff. While these services can be expensive, prudent 
use of an interpreter could be invaluable. As reported by the respondents who developed close relationships with interpreters in China (see p. 150), a good interpreter who grew up in China can provide that contextual information to which a low-context American would not be privy. The willingness of Chinese delegations to speak more openly to another Chinese acting as interpreter for American business people would be another source of valuable information. If the issue of company loyalty is a concern, having a Chinese interpreter on staff whose loyalty is primarily to the company can assist in evaluating the information one is receiving from Chinese hosts and managers with the company's needs and goals in mind.

Finding Chinese interpreters who are versed in a particular technical terminology is a problem but not one that should prevent the use of an interpreter. Familiarizing the interpreter with the company's product and manufacturing process should be the first step in using an interpreters' services. Ideally an interpreter should be taken through the plant to observe the processes, be provided with a set of terms used most often, and review the contract, training materials or other relevant documents before the interpretation is needed.

Training and Learning Processes. Consistent with the emphasis on tradition, resistance to change, dependence on authority and rote learning in Chinese classrooms (Porter, 1990; Yang, 1986; Yum, 1988), the Chinese students took many notes and expected information provided by the trainers to be consistent over time. Consistent with a collectivist, strong UA, high PD culture, Chinese students expect the speaker to be the authority and information to be based in traditional principles that are accurate and constant (Hofstede, 1986). This expectation goes contrary to American 
notions that what people are interested in hearing from a speaker are the new developments in a particular field, what has been learned from past mistakes, and what has been disproved or brought into question by new research.

The EMEMC respondent's experience of being challenged by a Chinese person in his audience appears to contradict the cultural rule which prohibits students from challenging the teacher for fear of causing the loss of face. This cultural rule is very strong in Chinese culture but there are individual differences even in a homogeneous culture like China and individuals do break the rules. Another explanation for this behavior is that the Chinese person who challenged the speaker's information was familiar with Western culture. Knowing that questions and intellectual challenges are more acceptable in Western culture the Chinese person may have been doing what he or she thought was expected by the speaker.

Consistent with several of Hofstede's (1986) predicted problems in all three value dimensions, the respondents experienced the Chinese students as hesitant to ask questions, ask for help or admit mistakes. The cultural rules operating in these situations were these: Don't speak unless spoken to by the teacher or leader; don't lose face by showing ignorance; the teacher or expert should know what the student needs to know; and training should focus on "how to do"(Bond, 1991; Porter, 1990; Wenzhong \& Grove, 1991). American teaching methods stress general guidelines, principles and analysis (Bellah, et al., 1985; Bond, 1991). And it is often thought that providing too much explanation does not respect the students' ability and discourages creativity in solving a problem. American students are expected to ask questions if they don't understand and to ask for help if they have a 
problem they cannot solve themselves. Asking questions and asking for help is connected with taking responsibility. Therefore when Chinese do not ask questions or ask for help and as a result proceed without a clear understanding of what should be done, the American tends to interpret this behavior as being irresponsible. The Chinese student is operating from an assumption that the teacher/trainer should know that all the necessary information is not available and that the students do have questions to be addressed.

Suggestions. One approach to deal with a situation where Chinese students are not asking questions in the formal classroom is to take a break and invite the students to talk informally. The concern with challenging the teacher and losing face in front of other students does not operate in the informal setting. Students will gather around the trainer eager to hear the answers to the questions other students have.

Trainers must expect Chinese students to have questions they are not asking. Directly asking a specific student to ask a question or to respond to a question usually elicits a response. If English proficiency is an issue, even when asked directly to speak, the student may be inhibited from speaking. In this case have the students write down their questions anonymously.

Chinese Have Problems Going From Theory to Application. The respondents had problems with the Chinese coordinating a manufacturing process so that all parts fit to make a cohesive whole; being able to use manuals to set up and operate equipment and solve problems; and being able to go from theory to application. These problems are consistent with the Chinese relational-contextual style of cognitive processing and lack of creativity (Chiu, 1972; Kagan, Moss \& Sigel, 1963); the hierarchical 
relationships that restrict lines of communication (Bond \& Hwang, 1986; Pye, 1988); and the extreme specialization of work tasks in Chinese culture (Bond, 1991; Pye,1988). In addition, Pye (1988) suggests that the tension between complaining and criticizing inhibits Chinese from conducting any in-depth analysis of their lives and cultural history. He says complaining is permitted and much Chinese literature involves the expression of how bad, painful and sad some circumstances are. But, he says, criticizing by analyzing the conditions that allow or produce these circumstances is prohibited.

The isolation and specialization of roles and status prevents most Chinese from seeing the "big picture" of anything in Chinese culture. It is the job of the leaders to know what the big picture is and the job of the worker to perform his or her one task. It is also the job of the expert to solve the problems and to know what the average worker needs to know (Pye, 1988). This specialization extends to university training in that theory and application are separate areas of study. One person will learn theory and another person will learn application.

The relational-contextual style of cognitive processing causes considerable difficulty for Chinese students in American universities. I have been told by Chinese students in the U. S. that the two biggest problems they have in school are not being given enough information about how to complete an assignment, and conducting and writing analysis. They need and want more specific details on how to do an assignment, what the expectations are, and the criteria for evaluation.

Suggestions. To assist Chinese students in bridging theory and application, more explanation for the relationship between theory and 
practice should be provided. Clear, step-by-step directions for every procedure should then be taught while referring back to theory by explaining why a particular step or technique is necessary. In keeping with Chinese tradition of copying the masters, samples of analysis should be provided to show the students what an analytical paper looks like. Many universities provide writing labs and tutors for students. These tutors should be specially trained to help Chinese students learn the mechanics of writing analysis.

Problem Solving. Two issues related to problem solving are evident in several of the respondents stories: First, Chinese often will not see a situation as a problem when Americans will; and second, Chinese display little initiative and creativity in problem solving. Americans are oriented to activity, to doing things (Stewart \& Bennett, 1991). This orientation combined with their commitment to improvement and belief in one's ability to affect change led the respondents to identify situations as "problems needing solving" that the Chinese did not define as problems. In contrast, the Chinese are being and inner-development oriented and less likely to see a situation as requiring human intervention (Yang, 1986). This orientation, coupled with their reliance on experts to solve problems and lack of individual experience in initiating problem solving, contributes to a different definition of the situation.

The story by the $\mathrm{MBCC}$ respondent regarding the construction of the warehouse floor is a fascinating example of the different approaches to solving a problem (see p. 164-165). The high context Chinese concern with avoiding conflict, avoiding punishment or censure, saving face and preventing the disruption of harmony (Bond \& Hwang, 1986; Ting-Toomey, 
1985), as well as a distrust of technology motivated the worker constructing the floor. The construction worker wanted to prevent a problem from occurring and was unwilling to take even the remotest chance of being blamed for causing a problem with the floor. His solution was ingenious in turning the problem into a solution by having cracks throughout the floor as part of the design.

The Chinese displayed considerable ingenuity in adapting and modifying materials and processes to the Chinese situation but the respondents never experienced a Chinese person creating something entirely new. Their skill at modification and adaptation corresponds to Norman's (cited in Bond, 1991) description of Chinese education as "polishing the jade" by fine-tuning and adding to already existing knowledge.

The lack of experience with creativity, the concern with chaos, the extreme specialization of tasks and roles and the placing of authority in select leaders has contribute to a lack of creativity in Chinese culture. In addition, several of the conditions that have been identified as necessary for creative problem solving (see p. 33) do not exist in China. Without the safety and support from superiors and a protected environment, few Chinese will risk breaking away from the group to stand apart, for qian da chu tou niao ("the bird that leaves the bush first gets shot down"). Also, the Chinese relational-contextual cognitive style, which has been associated with socialization to obey strict parental authority, appears to inhibit creativity (Hoosain, 1986; Liu, 1986). Whether creativity can be introduced without resulting chaos is a serious question. Creativity by definition is revolutionary. Introducing more individual initiative and creativity would 
alter the traditional emphasis on the hierarchy of relationships and the $W u$ Lunn (Bond, 1991). Therefore it is understandable that creativity has been viewed with suspicion by the Chinese elders. The question today is whether they can modernize by acquiring Western technology and "know how" without developing more creativity in order to utilize that technology to its full capacity.

\section{Work Attitudes and Behaviors}

Motivation and Work Habits. Many issues in motivation have been touched on in the other categories, particularly the affect the iron rice bowl has had on worker attitudes and behaviors. True to their culture's values, the respondents felt that the lack of monetary and other merit rewards and the knowledge that one could not be fired resulted in a lack of motivation on the part of Chinese workers. The rewarding of good work with money, promotion, and other material gains is a cornerstone of the American economic system (Samovar, et al., 1981). The respondents reasoned that, without these incentives, why would the Chinese worker care about the quality, accuracy or timeliness of their work. In some respects the lack of quality and motivation appeared to prove their case - that these rewards were necessary in order to motivate workers.

The tendency for workers to leave whenever they wanted to smoke, nap or drink tea certainly indicated a casual attitude toward work - an attitude those raised within the "Puritan work ethic" would find difficult to accept. American business people place a high value on work and activity. It is an integral aspect of identity, self respect, and feeling one has been successful in life (Stewart \& Bennett, 1991). Americans work long hours and 
work hard. In China the respondents have encountered a culture where work does not have the same value and importance in one's life. Being rather than activity is of value (Yang, 1986). Being with family and friends, having time to relax and talk over tea, having time to read the newspaper are more important than keeping busy with some activity. In addition, the stress on conformity and the norm of equality in the distribution of wages makes it difficult to initiate wage differentials. Mann (1989) reports on an American attempt to change wage rewards that was rejected by the workers. The TEMC respondent's experience with his Chinese trainees indicates how ingrained this expectation is in the Chinese system. His trainees in the U.S. plant who didn't work overtime believed those Chinese workers who did work over time should share their over time pay. With the introduction of wage and merit rewards we may see a shift in these values in China such as is happening in Taiwan and Hong Kong.

Mann (1989) also reports on a different attempt by an American manager to motivate Chinese workers by offering more leisure time. The standard Chinese work week is six days with Sunday off. This manager attempted to cut his plant's work week to five days. He believed his Chinese workers would appreciate having more time to spend at home and therefore would be more motivated when they were at work Monday through Friday. He also figured out that he could save several hundred thousand dollars a year in lower operating costs by closing the plant for two days a week. His attempt failed for several reasons. He was attempting to change a firmly established routine that is accepted throughout China and was strongly resisted by the Chinese leaders. In addition, he failed to take into account that the Chinese workplace functions differently than an 
American workplace. The Chinese plant is a place for work, but it is also a place for socializing and simply spending time, since many Chinese apartments are very small and cramped.

Without wage and merit rewards, appeals to achievement and face were identified as motivators by a couple of the respondents. As noted by Bond (1991), achievement as a motivatior in Chinese society has become more important since the early twentieth century. The CC respondents appealed to the need to maintain face and to a desire for achievement in their Chinese trainees. They designed their training program to allow the trainee to return to their work unit with a concrete product.

The conflict the HMMC respondent had with the Chinese chief metallurgist is a good example of the importance of face and relationship in Chinese motivation (see p. 177). The chief metallurgist was motivated by a loss of face or the prevention of the loss of face. He became a major obstacle in the manufacturing process; this resulted in sub-quality steel being produced in the Chinese plant. His insistence on the correctness of his process could jeopardize the success of the joint venture.

The resistance of the chief metallurgist to conform to the American technique for producing steel was interpreted by the respondent as simply a technical disagreement. By overlooking the importance of relationship and face in Chinese culture the respondent had only one avenue for resolving this conflict. He continued to try to convince the chief metallurgist with more documentation and expert testimony that the American process was correct. I surmise that at some point early in the negotiating process the chief metallurgist lost face and, to regain face or at least not lose more face, it became imperative that he maintain his position. It would have been 
difficult for the American company to have identified all the important players in the Chinese plant since access to the plant and this kind of information is not easily available. But if this person had been given face early on in the negotiation by asking for his advice or including him in certain decisions, I believe his attitude toward the American process would have been positive. To resolve this stalemate now the respondent must find a way for the chief metallurgist to save face while complying with the American procedure.

Suggestions. More research needs to be done on Western businesses in China who have been able to institute different ways of motivating workers including wage differences, and wage and merit rewards to see if these incentives do increase motivation and quality. Other research on Chinese motivation needs to be conducted to understand the interrelationship between motivation, rewards, collectivism, and the place of work in Chinese society.

Responsibility. As seen in the other categories the issue of responsibility is related to many other problems and issues. The respondents' stories with respect to responsibility can be understood as a conflict between individualism and collectivism, the differences between high and low power distance, and the differences between strong and weak uncertainty avoidance. The individualist, moderately low PD, weak UA respondents believed that the individual worker is responsible for not only his or her work but also for the overall quality and success of the company. It is expected that problems and mistakes are corrected by the individual worker or brought to the attention of the supervisor or manager. The reasoning appears to be this: If you notice a problem you then become 
responsible for it even if you were not the cause. The issue may be where the "blame" is laid when something goes wrong. In the U.S. if a mistake is made it is the responsibility of the person who made it to notice it and correct it. If the person making the mistake is not aware of it but it is noticed by another the responsibility then shifts to that person for correcting the problem or bringing it to the attention of the appropriate person. If the mistake is not corrected but a worker is aware of it he or she is often held more responsible for the mistake going uncorrected than the person who caused it originally. Ultimately it is the manager's responsibility for creating an environment in which workers can safely bring problems and mistakes to the attention of other workers or the supervisor.

This system is possible in a moderately low PD, moderately weak UA culture where hierarchy is fluid, there is less concern with obedience, there is more independence and freedom, conflict is resolvable without major consequences, and consultation between subordinates and managers is commonplace (Hofstede, 1984).

In moderately high PD, strong UA China, people accept their place in the hierarchy and depend on authority to make decisions and plans. Obedience, conformity, a distrust of co-workers, a need for close supervision, avoidance of conflict and a prohibition to disagree with the boss all conspire to locate responsibility outside the individual worker. These characteristics of high PD cultures present in China have combined with the caution bred from political changes. The "lack of responsibility" experienced by the respondents is a survival response that makes sense given the cultural values and political realities of China. 
The question needs to be asked: How is responsibility expressed in a collectivist culture where the needs of the group are paramount? The respondents are expecting "responsibility" to look a certain way given their individualist perspective. But the exercise of responsibility in China's system may mean primarily avoiding getting into trouble that brings shame upon the family. Avoiding conflict, avoiding shame, avoiding loss of face, and maintaining security may be the ultimate expression of responsibility.

Suggestions. Perhaps the TEMC experience (see p. 150) indicates that it is possible to create an environment in training classrooms and Western businesses in China where the rule of "personal responsibility" is established by the manager. When the blame is placed on the individual for not correcting mistakes or not bringing problems to the attention of the supervisor rather than on making the mistake, perhaps this kind of "responsibility" can be established. On the other hand, Lindsay \& Dempsey (1985) attempted to establish small groups with their Chinese management students where they were to critique each other's work and "learn from their mistakes." This attempt did not work because the students' only experience with this kind of examination of mistakes had taken place in criticism/self-criticism sessions in their political study or work units. And this was the model they used and followed in their critique groups during this management training.

This experience points out that the Chinese have no models for improvement through analysis and critique that do not involve selfcriticism. One approach is to provide models, films and roleplays of these processes so that the Chinese can see how it is done and see the purpose and long term outcome of these procedures in Western business practices. 
These suggstions assume that training Chinese to "take responsibility," as it is defined in the West, and encouraging group critiques and role playing is the right thing to do. Wenzhong and Grove (1991) and Baird, Lyles and Wharton (1990) suggest that these training and learning approaches, so popular in the West, are not appropriate in training Chinese nor are they appreciated by Chinese students.

In all training of Chinese, Westerners must be weighing whether they are trying to change the Chinese by imposing Western values on them or providing them with tools that can be integrated into the Chinese social and value system. It may be impossible to transfer technology that is created and produced in one culture, (which reflects that culture's values in the way it is designed and operates) to another culture without impacting the value and social system of the new culture. To accomplish this integration without gross disregard for the receiving culture's values, Western trainers must be aware of how their technology and training methods reflect and assume particular values and beliefs. They must also understand the social structure and value system of the culture receiving this technology in order to understand the impact technology transfer may have in the receiving culture. And then they must work with this structure in designing their training programs and integrating new technology into China. To acquire this sensitivity to culture, Western trainers and business people should avail themselves of the intercultural communication training that is becoming increasingly available. 


\section{CONCLUSION}

In-depth interviews of nine respondents working for American companies training Chinese produced rich, substantive data and proved to be a useful method for this thesis. An analysis of the data produced three major problem categories: Power and Authority Training and Learning Problems, and Work Attitudes and Behaviors. Within each of these major categories several subcategories with specific problems or issues emerged from the data. The problems identified by the respondents, for example, ranged from a lack of access to information to a feeling that nobody takes responsibility for anything in China. For example, within Power and Authority the subcategory Bureaucratic Maze contained these problems: It's Hard to Tell Who's in Charge, which concerned the respondents' frustration with identifying the leaders and decision-makers in Chinese organizations; and No Explanations are Provided For Actions, which described the respondents lack of access to information regarding decisions and behaviors of the Chinese.

Hofstede's Value Dimensions and Hall's Low-High Context Communication Schema proved useful in analyzing the respondents' problems for cultural differences. The many characteristics and values associated with Hofstede's Dimensions and Hall's Schema effectively described both American and Chinese cultures and the problems that may arise when people from these two cultures interact in a training context. In the analysis of the data, many of the cultural differences which were identified in the respondents' experiences were associated with Hofstede's and Hall's value dimensions and other value differences. Hofstede 
predicted specific value differences when a teacher from an individualist, low PD, weak UA culture teaches students from a collectivist, high PD, strong UA culture, and several of his predicted differences were supported by the respondents' experiences.

By understanding the cultural differences that contributed to the respondents' problems, Western trainers can become more interculturally sensitive and more effective. Knowing what the Chinese expect and positively respond to, Western trainers can choose to change their behaviors and assumptions and and still accomplish their goals. They may avoid these problems and enhance the effectiveness of their training of Chinese.

\section{LIMITATIONS OF THIS STUDY}

For this study, in-depth interviewing was an effective method which resulted in rich, detailed experiences of the respondents. A tape recorder was used for all but the first two interviews. In these two interviews extensive notes were taken and one respondent was interviewed twice. This second interview was conducted with a tape recorder. In spite of the careful notes I took during the first two interviews and the addition of field notes, without a tape recorder data was invariably lost. Especially of concern are the subtle nonverbal nuances that can provide information about the feelings and intent behind a statement. The use of a tape recorder for all interviews would rectify this problem. Waiting until the following day to review some of the interviews and record field notes may also have resulted in a loss of data. Reviewing the interviews and recording field notes 
immediately after each interview when impressions and memory are fresh would prevent this loss of data.

In the other eight interviews only one session was conducted with each respondent. Subsequent interviews could have yielded greater depth and detail as the respondent remembered more and became more relaxed with talking to me. In listening to the tapes, I recognized opportunities where a follow-up question or more probing could have led to richer data. Subsequent interviews would have helped to fill in these gaps and allow for deeper probing.

The study may also be limited by the number of respondents and by the location. All respondents but one lived and worked in the Pacific Northwest. Respondents from other parts of the United States may have different experiences peculiar to their geography. Increasing the number of respondents might have gained greater support for the problem categories that emerged from the study as well as expanded them.

There was no attempt to control for the type of business the respondents conducted in China or to the location of their enterprises in China. Different industries doing business in different locations in China may experience different problems. Other factors that may influence the kind and severity of certain problems include the intercultural experience and training of the respondents; knowledge of China; time spent in China; Chinese language ability; and other attitudinal and personality characteristics. 


\section{SUGGESTIONS FOR FURTHER RESEARCH}

This study suggests several avenues for further research. A follow up with the respondents in this study five years later would result in a deeper understanding of the long range affects of the training programs and how the respondents resolved the problems that emerged in the first study. A complement to the current study would be to follow up with the Chinese who were involved in the training programs to gain their perspective of the programs and problems. Another approach that could yield a greater understanding of the Chinese perception of a problem would be to take one of the critical incidents reported by the respondents in this study and ask the Chinese involved to relate their side of the story.

A more in-depth study of one company's training program, from the needs assessment to classroom instruction and teacher-student dynamics through on-the-job practice could provide insights that the current study was unable to gain. An in-depth study of a large training program for Chinese that has clearly been successful (in terms of reaching quality and production standards and goals and appropriate use of technology) in transferring technology, software and skills needs to be conducted to understand why it was successful and whether the critical elements can be duplicated in other training programs. Most of the training programs represented in the current study were not designed by trained instructional designers or educators nor were the trainings conducted by trained trainers. The addition of these professionals may impact the type and depth of the problems that might arise in training Chinese. An examination of the influence of educationally and culturally sensitive training needs to be 
conducted to see whether careful design and presentation can affect the quality and effectiveness of training Chinese.

We also need to examine why quality control has been successfully implemented in some Chinese plants and has been a failure in others. In terms of intercultural communication, we need to ask what role cultural differences play in these situations and how intercultural training of American managers and American trainers might contribute to these successes.

As mentioned in a few places in the study, more research needs to be conducted on current Chinese cultural values in the PRC. Gaining permission and cooperation to conduct research in China is still difficult. But showing the Chinese that the intent of research is to provide better services to the Chinese may help the process.

More research needs to be done on Chinese cognitive processes and difficulties when Chinese trainees are confronted with teaching methods and materials based on the descriptive-analytical style common in American universities and training programs. Are there ways American teachers and university professors can change their approach to help the Chinese student make the transition or adapt more easily to doing analysis? As a result of learning a different cognitive style, do Chinese students lose the relational-contextual style or do they become more cognitively complex and add another style? Does this ability translate, as Wapner (1976) suggests, into a greater repertoire of cognitive styles that can be called upon in different cultural contexts? An in-depth look at Chinese students in American universities and the academic problems they encounter would provide some insights to these issues. 
This study suggests that using Hofstede's and Hall's theories to analyze case studies for cultural differences may assist Western business people doing business in China in understanding the problems they encounter. By understanding the cultural differences operating between American trainers and Chinese students, Western trainers of Chinese might avoid many of the problems predicted by Hofstede and reported by these respondents. In addition, this thesis contributes to understanding the assumptions American and Chinese education are based upon and how our training principles and design are influenced by our cultural values. With this understanding perhaps designers and trainers will become more sensitive to the needs of Chinese trainees and create more effective training programs for Chinese students. 


\section{REFERENCES}

Ackermann, J. M. (1976). Skill training for foreign assignment: The reluctant U. S. case. In L. Samovar \& R. Porter (Eds.), Intercultural communication: A reader (2nd ed.) (pp. 298-306). Belmont, CA: Wadsworth.

Adler, N. J. (1986). International dimensions of organizational behavior. Belmont: CA: Wadsworth, PWS-Kent Publishing.

Adler, N. J., \& Kiggundu, M. (1983). Awareness at the crossroad: Designing translator-based training programs. In D. Landis \& R. W. Brislin (Eds.), Handbook of intercultural training vol II: Issues in training methodology (pp. 124-151). New York: Pergamon Press.

Anonymous (1986, April). What China wants now from foreigners. International Management (UK), 41(4), 54-55.

Applegate, J. L., \& Sypher, H. E. (1988). A constructivist theory of communication and culture. In Y. Y. Kim \& W. B. Gudykunst (Eds.), Theories in intercultural communication (pp. 41-65). Beverly Hills, CA: Sage Publications.

Argyle, M., Henderson, M., Bond, M. H., Iizuka, Y., \& Contarello, A. (1986). Cross-cultural variations in relationship rules. International Journal of Psychology, 21, 287-315.

Baird, I. S., Lyles, M. A., \& Wharton, R. (1990, Special Issue). Attitudinal differences between American and Chinese managers regarding joint venture management. Management International Review, 30, 53-68.

Baldinger, P. (1990, May-June). Project notebook: An SGS tour of quality control in China. The China Business Review, 17(3), 14-15.

Barna, L. M. (1982). Stumbling blocks in intercultural communication. In L. A. Samovar \& R. E. Porter (Eds.), Intercultural communication: A reader (3rd. ed.) (pp. 323-329). Belmont, CA: Wadsworth Publishing Company. 
Barnes, R. L. (1985, October). Across cultures: The Peace Corps training model. Training and Development Journal, 46-58.

Becker, C. B. (1992). Reasons for the lack of argumentation and debate in the Far East. In L. A. Samovar \& R .E. Porter (Eds.), Intercultural communication: A reader (6th ed.) (pp. 234-251). Belmont, CA: Wadsworth Publishing Co.

Becker, H. S., \& Geer, B (1957). Participant observation and interviewing: A comparison. Human Organization, 16(3), 28-32.

Bell, R. R. (1981). Worlds of friendship. Beverly Hills, CA: Sage Publications.

Bellah, R. N., Madsen, R., Sullivan, W. M., Swidler, A., \& Tipton, S. M (1985). Habits of the heart: Individualism and commitment in American life. Berkeley: University of California Press.

Bennett, J. M. (1986). Modes of cross-cultural training: Conceptualizing cross-cultural training as education. International Journal of Intercultural Relations, 10 117-134.

Bennett, M. J. (1986). Towards ethnorelativism: A developmental model of intercultural sensitivity. In R. M. Paige (Ed.), Cross Cultural

Orientation: New Conceptualizations and Applications (pp. 27-69). Lanham, MD: University Press of America.

Berger, P. L., \& Luckman, T. (1967). The social construction of reality: A treatise in the sociology of knowledge. Garden City, NY: Doubleday.

Bing, J. A. (1984, March-April). Project management in China. The China Business Review 11(2), 20-23.

Bing, J. A. (1988, September-October). Project management report. The China Business Review, 15, 30-33.

Blau, P., \& Schwartz, J. (1984). Cross-cutting social circles. New York: Academic Press.

Bond, M. H. (Ed.). (1986). The psychology of the Chinese people. Hong Kong: Oxford University Press. 
Bond, M. H. (1990, March). Enhancing cross-cultural competence in Hong Kong organizations! Oriental teambuilding in the Orient? Unpublished manuscript, Chinese University of Hong Kong.

Bond, M. H. (1991). Beyond the Chinese face: Insights from psychology. Hong Kong: Oxford University Press.

Bond, M. H., \& Hwang, K. K. (1986). The social psychology of Chinese people. In M. H. Bond (Ed.), The psychology of the Chinese people. Hong Kong: Oxford University Press.

Bond, M. H., Wan, K. C., Leung, K., \& Giacalone, R. A. (1985, March). How are responses to verbal insult related to cultural collectivism and power distance? Iournal of Cross-Cultural Psychology 16(1), 111-127.

Bourgeois, L. J., \& Boltvinik, M. (1981). OD in cross-cultural settings: Latin America. California Management Review, 23 (3), 75-81.

Brislin, R. W. (1981). Cross-cultural encounters: Face to face interactions. New York: Pergamon Press.

Burns, S. K. (1984, October). When training is the law. Training and Development Journal, 29-31.

Chang, H. C., \& Holt, G. R. (1991, Summer). More than relationship: Chinese interaction and the principle of Kuan-Hsi. Communication Quarterly, 39(3), 251-271.

Chickering, A. W. (1976). Commentary: The double bind of field dependence/independence in program alternatives for educational development. In S. Messick (Ed.), Individuality in learning: Implications of cognitive styles and creativity for human development (pp. 79-90). San Francisco: Jossey-Bass.

Chiu, L. H. (1972). A cross-cultural comparison of cognitive styles in Chinese and American children. International Journal of Psychology 7. 235-242.

Chong, L. E., Cragin, J. P., \& Scherling, S. A. (1983, April) Manager workrelated values in a Chinese corporation. Paper presented to the annual meeting of the Academy of International Business, San Francisco, U. S. A. 
Chu, G., Hung, F., Schramm, W., Uhalley, S., Jr., \& Yu, F. T. C. (1976, September). Communication and development in China. Communication Monographs, 1 .

Chua, E. G., \& Gudykunst, W. B. (1987). Conflict resolution styles in lowand high-context cultures. Communication Research Reports, $\underline{4}(1)$, 32-37.

Cohen, R. A. (1969, October). Conceptual styles, cultural conflict, and nonverbal tests of intelligence. American Anthropologist, 71(5), 826856.

Cole, M., \& Bruner, J. S. (1971). Cultural differences and inferences about psychological processes. American Psychology 26, 867-876.

Cole, M., Gay, J., Glick, J. A., \& Sharp, D. W. (1971). The cultural context of learning and thinking: An exploration in experimental anthropology. London: Methuen.

Coleman, J. S. (1958). Relational analysis: The study of social organization with survey methods. Human Organization, 17(4), 28-36.

Condon, J. C., \& Yousef, F. (1975). An introduction to intercultural communication. Indianapolis, IN: Bobbs-Merrill.

Dalton, G. R. (1990, September). Training China's business elite. The China Business Review, 17(5), 46-48.

De Mente, B. L. (1989). Chinese etiquette \& ethics in business.

Lincolnwood, IL: NTC Business Books.

DeGlopper, D. R. (1988). The social system. In R. L. Worden, A. M. Savada, \& R. E. Dolan (Eds.), China, a country study (DA pam 550-60) (pp. 99150). Washington, D C: U. S. Government Printing Office.

Deng, X. (1984). Build socialism with Chinese characteristics. Beijing: Foreign Language Press.

Deutscher, I. (1973). What we say/what we do: Sentiments and acts. Glenview, IL: Scott Foresman. 
Dinges, N. G., \& Maynard, W. S. (1983). Intercultural aspects of organizational effectiveness. In D. Landis \& R. W. Brislin (Eds.), Handbook of intercultural training vol II: Issues in training methodology (pp. 50-82). New York: Pergamon Press.

Eckhardt, W., \& White, R. K. (1967, September). A test of the mirror-image hypothesis: Kennedy and Krushchev. Iournal of Conflict Resolution, 11, 325-332.

Ehrenhaus, P. (1983). Culture and the attribution process: Barriers to effective communication. In W. B. Gudykunst (Ed.). Intercultural communication theory: Current perspectives (pp. 259-270). Newberry Park, CA: Sage Publications.

Fairbank, J. K. (1967). The nature of Chinese society. In F. Schurmann \& O. Schell (Eds.), The China reader: Imperial China (pp. 36-66). New York: Vintage Books.

Fallding, H. (1965, April). A proposal for the empirical study of values. American Sociological Review 30, 223-233.

Fisher, G. (1980). International negotiation: A cross-cultural perspective. Yarmouth, ME: Intercultural Press, Inc.

Frake, C. O. (1977, June). Plying frames can be dangerous: Some reflections on methodology in cognitive anthropology. Quarterly Newsletter of the Institute for Comparative Human Development, 1 , 6-7.

Frost, P. J., Moore, L. F., Louis, M. R., Lundberg, C. C., \& Martin, J. (1985). Organizational culture. Beverly Hills, CA: Sage Publications.

Glaser, B., \& Strauss, A. (1967). The discovery of grounded theory: Strategies for qualitative research. New York: Aldine De Gruyter.

Goffman, E. (1967). Interaction ritual: Essays on face-to-face behavior. Garden City, NY: Doubleday.

Gorden, R. L. (1975). Interviewing: Strategy, techniques and tactics. Homewood, Ill: Dorsey Press.

Green, K. (1990, May-June). The uphill climb toward quality. The China Business Review, 17(3), 10-13. 
Green, L. (1979). Rural high school students' perceptions of the basic values and educational philosophies of significant secondary school role models. Personnel and Guidance Journal, 57, 392-397.

Grieve, T. D., \& Davis, J. K. (1971). The relationship of cognitive style and method of instruction to performance in ninth grade geography. Lournal of Educational Research, 65, 136-141.

Gudykunst, W. B. (1983). Similarities and differences in perceptions of initial intracultural and intercultural encounters: An exploratory investigation. Southern Speech Communication Journal, 49, 49-65.

Gudykunst, W. B. (1988). Uncertainty and anxiety. In Y. Y. Kim \& W. B. Gudykunst (Eds.), Theories in intercultural communication (pp. 123156). Newbury Park, CA: Sage Publications.

Gudykunst, W. B., \& Nishida, T. (1986, Summer). Attributional confidence in low- and high-context cultures. Human Communication Research $12(4), 525-549$.

Gudykunst, W. B., \& Ting-Toomey, S. (1988). Culture and interpersonal communication. Newbury Park, CA: Sage Publications.

Hall, E. T. (1959). The silent language. New York: Doubleday.

Hall, E. T. (1976). Beyond culture. Garden City, NY: Anchor Books.

Harris, P. R., \& Moran, R. T. (1987). Managing cultural differences. Houston: Gulf.

Hawes, F. (1980). The culture factor in the transfer of technology to developing countries. The Bridge, 17-19, 40-41.

Hawes, L. (1977, Summer). Toward a hermeneutic phenomenology of communication. Communication Quarterly, 25(3), 30-41.

Hawkins, J. (1981). Chinese education. In B. Ignas (Ed.), Comparative education systems (pp. 91-134). Itaska, IL: F. E. Peacock Publishers, Inc.

Hayes, J., \& Allinson, C. H. (1988, July). Cultural differences in the learning style of managers. Management International Review, 28, 75. 
Hildebrandt, H. W., \& Liu, J. (1988, November-December). Career and education patterns of Chinese managers. The China Business Review, 15(6), 36-38.

Ho, D. Y. (1976). On the concept of face. American Journal of Sociology $\underline{81}(4), 867-884$.

Hocker, J. L., \& Wilmot, W. W. (1985). Interpersonal conflict (2nd ed.). Dubuque, IA: William C. Brown.

Hofstede, G. (1980). Culture's consequences: International differences in work-related values. Beverly Hills, CA: Sage Publications.

Hofstede, G. (1983). Dimensions of national cultures in fifty countries and three regions. In J. Deregowski, S. Dzuirawiec, \& R. Annis (Eds.), Explications in cross-cultural psychology. Lisse, The Netherlands: Swets \& Zeitlinger.

Hofstede, G. (1984). Culture's consequences: International differences in work-related values (abridged ed.). Beverly Hills, CA: Sage Publications.

Hofstede, G. (1986). Cultural differences in teaching and learning. International Journal of Intercultural Relations, 10, 301-320.

Holton, R. H. (1990, Special Issue). Human resource managment (sic) in the People's Republic of China. Management International Review $\underline{30}$ 121-136.

Honey, P., \& Mumford, A. (1983). Using your learning styles. Maidenhead: Honey.

Hooper, B. (1985). Youth in China. New York: Penguin Books.

Hoosain, R. (1986). Perceptual processes of the Chinese. In M. Bond (Ed.), The psychology of the Chinese people. Hong Kong: Oxford University Press.

Hsieh, Y. W. (1977). Filial piety and Chinese society. In C. A. Moore (Ed.), The Chinese mind. Honolulu: The University Press of Hawaii.

Hsu, F. L. K. (1987). Americans \& Chinese: Passage to difference. Honolulu: University of Hawaii Press. 
$\mathrm{Hu}, \mathrm{H} . \mathrm{C}$. (1944). The Chinese concept of face. American Anthropologist, $\underline{46}, 45-64$.

Hwang, K. K. (1983). Face and favour: Chinese power games. Unpublished manuscript .

Kagan, J., \& Moss, H. A., \& Sigel, I. E. (1963). The psychological significance of styles of conceptualization. In J. F. Wright \& J. Kagan (Eds.), Basic cognitive processes in children, 28, 73-111.

Keck, B. (1985, May-June). China's managers look west. The China Business Review, 12(3), 36-39.

Kelley, G. A. (1963). A theory of personality: The psychology of personal constructs. New York: W. W. Norton \& Co.

Kelley, D. B. (1984, September-October). A project manager's notebook. The China Business Review, 11(5). 10-12.

Kim, Y. Y. (1988). On theorizing intercultural communication. In Y. Y. Kim \& W. B. Gudykunst (Eds.), Theories in intercultural communication (pp, 11-21). Beverly Hills, CA: Sage Publications.

Kim, Y. Y., \& Rubin, B. D. (1988). Intercultural transformation: A systems theory. In Y. Y. Kim \& W. B. Gudykunst (Eds.), Theories in intercultural communication (pp, 299-321). Newbury Park, CA: Sage Publications.

King, A. Y. C. (1985). The individual and group in Confucianism: A relational perspective. In D. Monroe (Ed.), Individualism and holism: Studies in Confucian and Taoist values (pp. 57-70). Ann Arbor, MI: University of Michigan.

Kluckhohn, F. R., \& Strodbeck, F. L. (1961). Variations in value orientations. New York: Row, Peterson.

Knapp, M., Ellis, D., \& Williams, B. (1980). Perceptions of communication behavior associated with relationship terms. Communication Monographs, 47, 262-278.

Kotarba, J. A. (1980). Discovering amorphous social experience: The case of chronic pain. In W. B. Shaffir, R. A. Stebbins, and A. Turowetz (Eds.), Fieldwork Experience: Qualitative Approaches to Social Research. New York: St. Martin's Press. 
Kroeber, A. J., \& Kluckhohn, C. (1952). Culture: A critical review of concepts and definitions. Cambridge, MA: Harvard University Press.

Lazarfeld, P., \& Merton, R. (1954). Friendship as a social process: A substantive and methodological analysis. In M. Berger (Ed.), Freedom and Control in Modern Society. New York: Van Nostrand.

Lee, R. W. (1985, May-June). Training ground for a new breed of professionals. The China Business Review, 12(3), 39-42.

Lesser, G. S., Fifer, G., \& Clark, D. H. (1965). Mental abilities of children from different social class and cultural groups. Monograph of the Society for Research in Child Development $\underline{30}$ (4).

Lieberman, D. A. (1991). Ethnocognitivism and problem solving. In L. A. Samovar and R. E. Porter (Eds.), Intercultural communication: A reader (6th ed.) (pp. 229-243). Belmont, CA: Wadsworth.

Lieberthal, K., \& Oksenberg, M. (1986, November). Understanding China's burearcracy. The China Business Review, 13(6), 24-31.

Lin, Y. N. (1978). A study of the value orientations of junior high school students in the Republic of China. Guidance Journal, 1. Changhua, Taiwan.

Lindsay, C. P., \& Dempsey, B. L. (1983). Ten painfully learned lessons about working in China: The insights of two American behavioral scientists. Lournal of Applied Behavioral Science, 19(3), 265-276.

Lindsay, C. P., \& Dempsey, B. L. (1985, February). Experiences in training Chinese business people to use U. S. management techniques. Journal of Applied Behavioral Science, 21(1), 65-78.

Littlejohn, S. W. (1983). Theories of human communication. Belmont, CA: Wadsworth.

Liu, I. M. (1986). Chinese cognition. In M. H. Bond (Ed.), The psychology of the Chinese people (pp. 73-105). Hong Kong: Oxford University Press.

Liu, I. M., \& Hsu, M. (1974) Measuring creative thinking in Taiwan by the Torrance test. Testing and Guidance, 2 , 108-109.

Lofland, J., \& Lofland, L. H. (1984). Analyzing social settings: A guide to qualitative observation and analysis. Belmont, CA: Wadsworth. 
Lu, Hsun (1934). Selected Works of Lu Hsun (H. Yang \& G. Yang, Trans.). Beijing: Foreign Language Press.

Ma, R. (1992, Summer). The role of unofficial intermediaries in interpersonal conflicts in the Chinese culture. Communication Quarterly, $\underline{40}(3), 269-278$.

Macleod, R. (1988). China Inc: How to do business with the Chinese. Toronto, Canada: Bantam Books.

Mahler, I., Greenberg, L., \& Hayashi, H. (1981). A comparative study of rules of justice: Japanese versus Americans. Psychologia, 24, 1-8.

Mann, J. (1989). Beijing Jeep: The short, unhappy romance of American business in China. New York: Simon and Schuster.

Martin, J. N. (Ed.) (1986). Theories and methods in cross-cultural orientation [Special issue]. International Journal of Intercultural Relations, 10(2).

McCaffrey, J. A., \& Hafner, C. R. (1985, October). When two cultures collide: Doing business overseas. Training and Development Journal, 26-31.

Messick, S. (1976). Personality consistencies in cognition and creativity. In S. Messick (Ed.), Individuality in learning: Implications of cognitive styles and creativity for human development (pp. 4-22). San Francisco: Jossey-Bass.

Miller, V. A. (1979). The guidebook for international trainers in business and industry. New York: Van Nostrand Reinhold.

Morgan, G. (1986). Images of organization. Beverly Hills: Sage Publications.

Morgan, G., \& Smircich, L (1980). The case for qualitative research. Academy of Management Review, 5(4), 491-500.

Nakamura, H. (1964). Ways of thinking of Eastern Peoples: India, China, Tibet, and Japan. Honolulu: University of Hawaii Press.

Nelson, K. (1992, January-February). Project notebook: A high-tech success. The China Business Review, 19(1), 36-38. 
Nelson, J. A., \& Reeder, J. A. (1985). Labor relations in China. California Management Review, 27, 13-32.

Nordlie, P. G. (1968, June). The role of values in psychological operations. HSR Conference on Psychological Operations and Communications with Foreign Nationals (Research Report 68/9-CR). McLean, VA: Human Sciences Research, Inc.

Okabe, R. (1983). Cultural assumptions of East and West: Japan and the United States. In W. Gudykunst (Ed.), Intercultural communication theory. Beverly Hills, CA: Sage Publications.

Ondrik, R. S. (1984, July-August). Training Chinese oilfield workers. The China Business Review, 11(4), 7-11.

Pedersen, P. B. (1983). Asian personality theory. In R. J. Corsini \& A. J. Marsella (Eds.), Personality Theories, research and assessment. Itasca, Ill: R. E. Peacock.

Pelz, D. C. (1976). Environments for creative performance within universities. In S. Messick (Ed.), Individuality in learning: Implications of cognitive styles and creativity for human development (pp. 229-247). San Francisco: Jossey-Bass.

Pettigrew, A. M. (1979). On studying organizational cultures. Administrative Science Quarterly, 24(4), 570-581.

Pollock, S. M., \& Chen, K. (1986, March-April). Strive to conquer the black stink: Decision analysis in the People's Republic of China. Interfaces, 16(2), 31-37.

Porter, E. A. (1990). Foreign teachers in China: Old problems for a new generation, 1979-1989. New York: Greenwood Press.

Porter, R. E., \& Samovar, L. A. (1988). Approaching intercultural communication. In L. A. Samovar \& R. E. Porter (Eds.), Intercultural communication: A reader (5th ed.) (pp. 15-30). Belmont, CA: Wadsworth.

Powell, B. (1989, July 3). We simply can't go rushing back in. Newsweek, p. 30.

Prosser, M. H. (1978). The culture dialogue: An introduction to intercultural communication. Boston, MA: Houghton Mifflin. 
Pusch, M. D, Patico, A., Renwick, G W., \& Saltzman, C. (1981). Aspects of intercultural educational activity. In G. Althen (Ed.), Learning across cultures: Intercultural communication and international educational exchange (pp, 72-103). National Association for Foreign Student Affairs.

Pye, L. W. (1982). Chinese commercial negotiating style. Cambridge, MA: Oelgeschlager, Gunn \& Hain.

Pye, L. W. (1988). The Mandarin and the cadre: China's political cultures (Michigan Monographs in Chinese Studies vol. 59). Ann Arbor: MI: University of Michigan, Center for Chinese Studies.

Redding, G., \& Wong, G. Y. Y. (1986). The psychology of Chinese organizational behaviour. In M. H. Bond (Ed.), The psychology of the Chinese people (pp. 267-295). Hong Kong: Oxford University Press.

Redding, S. G. (1980). Management education for orientals. In B. Garratt and J. Stopford (Eds.), Breaking down barriers: Practice and priorities for international management education ( $\mathrm{pp}, 193-214)$. Farnborough Hants: Westmead.

Rogers, E., \& Bhowmik, D. (1970). Homophily-heterophily: Relational concepts for communication research. Public Opinion Quarterly 34 536-551.

Samovar, L., \& Porter, R., \& Jain, N. (1981). Understanding intercultural communication. Belmont, CA: Wadsworth.

Savada, A. M., \& Dolan, R. E. (1988). Education and culture. In R. L. Worden, A. M. Savada, \& R. E. Dolan (Eds.), China, a country study (DA Pam 550-60). Washington, DC: U. S. Government Printing Office.

Schnapper, M. (1979). Multinational training for multinational corporations. In M. K. Asante, E. Newmark, \& C. A. Blake (Eds.), Handbook of intercultural communication (pp. 447-474). Beverly Hills: CA: Sage Publications.

Scott, W. A. (1965). Values and organizations: A study of fraternities and sororities. Chicago: Rand McNally.

Scoval, T. (1983). English teaching in China: A historical perspective. Language Learning and Communication, 2, 105-109. 
Scribner, S. \& Cole, M. (1981) The psychology of literacy. Cambridge, MA: Harvard University Press.

Seelye, N., \& Wasilewski, J. (1979). Historical development of multicultural education. In M. D. Pusch (Ed.), Multicultural education. Yarmouth, Maine: The Intercultural Press.

Seligman, S. D. (1986, November-December). Translating your tradmark into Chinese. The China Business Review, 13(6), 14-16.

Seligman, S. D. (1989). Dealing with the Chinese: A practical guide to business etiquette in the People's Republic Today. New York: Warner Books.

Sensenbrenner, J. S. (1986). The training component. The China Business Review, $\underline{13}(6), 8-12$.

Sensenbrenner, J. S. (1988, July-August). Project notebook: Babcock and Wilcox Beijing Company Ltd. The China Business Review, 14, 10-12.

Shiminoff, S. B. (1980). Communication rules: Theory and research. Beverly Hills, CA: Sage Publications.

Simard, L. (1981). Cross-cultural interaction. Journal of Social Psychology $\underline{113}, 171-192$.

Simon, P. (1980). The tongue tied American. New York: Continuum.

Sitaram, K. S., \& Haapanen, L. W. (1979). The role of values in intercultural communication. In M. K. Asante, E. Newmark, and C. A. Blake (Eds.), Handbook of Intercultural Communication (pp. 147-160). Beverly Hills, CA: Sage Publications.

Sitaram, K. S., \& Cogdell, R. T. (1976). Foundations of intercultural communication. Columbus, $\mathrm{OH}$ : Charles E. Merrill.

Speidel, W. M (1985, May-June). An experiment in international relations. The China Business Review, 12(3), 42-43.

Spence, J. D. (1990). The search for modern China. New York: W. W. Norton \& Co..

Spencer, D. L. (1970). Technology gap in perspective. New York: Spartan Books. 
Stephan, W. G., \& Stephan, C. W. (1985). Intergroup anxiety. Journal of Social Issues, $\underline{41}(3), 157-176$.

Stewart, E. C. (1978). Intercultural awareness for business [videotape]. Author.

Stewart, E. C., \& Bennett, M. J. (1991). American cultural patterns: A crosscultural perspective (rev. ed.). Yarmouth, ME: Intercultural Press, Inc.

Sue, D. W., \& Kirk, B. A. (1972). Psychological characteristics of ChineseAmerican students. Journal of Counseling Psychology 19, 471-478.

Sullivan, R. W. (1990, November-December). Letter from the president. The China Business Review, 17(6), 30-31.

Swanland, C. (1979, March). 'Personalized' training materials and instruction for the foreign technical trainee. Training and Development Journal, 57-58.

Tarwater, J. W. (1966). Chinese and American students' interpersonal values: A cross-cultural comparison. Iournal of College Student Personnel, 7 , 351-354.

Taylor, S. J., \& Bogdan, R. (1984). Introduction to qualitative research methods: The search for meanings. New York: John Wiley \& Sons.

The Chinese Culture Connection (1987, June). Chinese values and the search for culture-free dimensions of culture. Journal of CrossCultural Psychology 18(2), 143-164.

Ting-Toomey, S. (1985). Toward a theory of conflict and culture. In W. Gudykunst, L. Stewart, \& S. Ting-Toomey (Eds.), Communication, culture, and organizational processes (pp. 71-86). Beverly Hills, CA: Sage.

Ting-Toomey, S. (1986). Conflict styles in black and white subjective cultures. In Y. Kim (Ed.), Current research in interethnic communication. Beverly Hills, CA: Sage Publications. 
Triandis, H. C. (1986). Collectivism vs. individualism: A reconceptualization of a basic concept in cross-cultural psychology. In C. Bagley \& G. Verma (Eds.), Personality, cognition, and values: Cross-cultural perspectives of childhood and adolescence. London: Macmillan.

Triandis, H. C. (1973). Culture training, cognitive complexity, and interpersonal attitudes. In D. Hoopes (Ed.), Readings in intercultural communication: Vol. II (pp. 55-67). Pittsburgh, PA: Regional Council for International Education.

U. S. - China Business Council (1990, November-December). Two years of trouble. The China Business Review 17(6), 32-37.

Useem, J., Useem, R., \& Donoghue, J. (1963, Fall). Men in the middle of the third culture: The roles of American and non-western people in cross-cultural administration. Human Organization, 2(3), 169-179.

Van Mannen, J., \& Schein, E. (1979). Toward a theory of organizational socialization. In B. M. Staw (Ed.), Research in organizational behavior (Vol. 1). New York: JAI.

Vernon, P. E. (1982). The abilities and achievements of Orientals in North America. New York: Academic Press.

Von Glinow, M. A., \& Teagarden, M. B. (1988, Summer). The transfer of human resource management technology in Sino-U. S. cooperative ventures: Problems and solutions. Human Resource Management, 27(2), 201-229.

Waddle, M. L. (1988). Industry. In R. L. Worden, A. M. Savada, and R. E. Dolan (Eds.), China, a country study (DA pam 550-60). Washington, DC: U. S. Government Printing Office.

Walker, N. R. (1979, March). Management training through Chinese eyes. Training and Development Journal, $\underline{33}(3), 26-29$.

Wang, K. (1981). English and other foreign language teaching in the People's Republic of China. College English, 43, 653-662.

Wapner, S. (1976). Commentary: Process and context in the conception of cognitive style. In S. Messick (Ed.), Individuality in learning: Implications of cognitive styles and creativity for human development (pp. 73-78). San Francisco: Jossey-Bass. 
Warner, M. (1986). Managing human resources in China: An empirical study. Organization Studies, $\underline{7}(4), 353-366$.

Wen, C. -i. (1988). The kuan-hsi of the Chinese [in Chinese]. In K. S. Yang (Ed.), The thinking and behavior of Chinese (pp. 30-44). Taipei: Yuan-liou Publishing Company.

Wenzhong, H., \& Grove, C. L. (1991). Encountering the Chinese: A guide for Americans. Yarmouth, ME: Intercultural Press.

Wexley, K. N., \& Latham, G. P. (1981). Developing and training human resources in organizations. Glenview, Illinois: Scott, Foresman and Co.

Whorf, B. L. (1956). Language, thought, and reality. New York: John Wiley \& Sons.

Williams, R. M., Jr. (1970). American society. New York: Alfred A. Knopf.

Witkin, H. A. (1976). Cognitive style in academic performance and in teacher-student relations. In S. Messick (Ed.), Individuality in learning: Implications of cognitive styles and creativity for human development (pp. 38-72). San Francisco: Jossey-Bass.

Yang, K. S. (1981). Social orientation and individual modernity among Chinese students in Taiwan. Lournal of Social Psychology, 113 159170.

Yang, K. S. (1986). Chinese personality and its change. In M. H. Bond (Ed.), The psychology of the Chinese people (pp. 106-170). Hong Kong: Oxford University Press.

Yang, K. S., \& Chang, F. L. (1975). Chinese value orientations and their change: The case of university students (In Chinese.). Unpublished manuscript, National Taiwan University.

Yang, K. S., Tsai, S. G., \& Hwang, M. L. (1963). Rorschach responses of normal Chinese adults: III. Number of responses and number of refusals (In Chinese). Psychological Testing (Taipei), 10, 127-136.

Yum, J. O. (1988, December). The impact of confucianism on interpersonal relationships and communication patterns in East Asia. Communication Monographs, 55, 374-388. 
Zikopoulos, M. (Ed.). (1990). Open doors 1990-1991: Report on international educational exchange. New York: Institute of International Education. 
APPENDIX A

LETTER TO PROSPECTIVE RESPONDENT 
October 16,1989

Mr./Ms. Prospective Respondent

XYZ Company

Portland, Oregon 97210

Dear Mr./Ms. Respondent,

My friend $X X X X X X X$, manager of corporate production planning at $X Y Z$ Company, gave me your name as one who may be interested in my research. I am a graduate student at Portland State University working on my master's thesis in intercultural communication. I am most interested in the problems American trainers have encountered when teaching Chinese to use American technology or management practices.

I would like to interview you about your experience training Chinese for $X Y Z$ Company. The interviews have been taking up to two hours; the interview can be broken up into shorter sessions to fit your schedule. I will call you at XYZ Company within a week to see if you are interested in discussing your experience and to set up a time for the interview.

Thank you for your time and interest.

Yours truly, 
APPENDIX B

INTERVIEW SCHEDULE PHASE I 
1. I understand that your company does business with China and that you have been involved in a training program training Chinese. What exactly is your business with China?

Probes: How did you first get involved in China?

How long have you been involved with China?

What is/was your role?

What is the current situation?

What are your future plans?

2. Tell me about the training program.

Probes: What was your agreement with China?

What was the purpose of the training?

Who was/is involved? Who were the students? Who were the trainers?

Where was the training conducted?

What was taught in the training and how was it done?

What materials were used? Who designed the training materials?

Were translators or interpreters used?

Was the training successful? Why?

What has happened since the training?

3. Tell me about the problems, difficulties or conflicts you had in negotiating, designing and conducting the training program.

Probes: What happened that was confusing or surprising to you?

Describe what happened in the classroom; on-the-job, or in meetings. What did you do? What did the Chinese students, interpreters, leaders, do? 
What was successful? Why?

What didn't work? Why?

Who was particularly helpful; difficult to deal with?

What was the biggest problem you had in this whole project?

What would you do differently? Why? 
APPENDIXC

INTERVIEW SCHEDULE PHASE II 
1. I understand that your company does business with China and that you have been involved in a training program training Chinese. What exactly is your business with China?

Probes: How did you first get involved in China?

How long have you been involved with China?

What is/was your role?

What is the current situation?

What are your future plans?

2. Before getting involved in this venture what was your experience with China or Chinese culture?

Probes: Have you ever been to China?

Where did you go?

What was your experience?

3. Tell me about the training program.

Probes: What was your agreement with China?

What was the purpose of the training?

Who was/is involved?

Who were the students?

Who were the trainers?

Where was the training conducted?

What was taught in the training and how was it done?

What materials were used?

Who designed the training materials?

Were translators or interpreters used? Why?

4. Was the training successful? Why?

Probes: What has happened since the training? 
What would you do differently?

5. Tell me about the problems, difficulties or conflicts you had in negotiating, designing and conducting the training program.

Probes: What happened that was confusing or surprising to you?

Describe what happened in the classroom; on-the-job, or in meetings. What did you do? What did the Chinese students, interpreters, leaders, do?

What didn't work? Why?

Who was particularly helpful; difficult to deal with?

What was the biggest problem you had in this whole project?

What would you do differently? Why?

6. What problems did the Chinese students have during the training?

Probes: What do you think accounts for these problems?

7. How did you deal with the language differences?

Probes: Was this a problem? Why?

8. What opportunities did you have in the training for group work, or team work?

Probes: How did the Chinese students work together and or with the American workers?

Was this a problem?

What is your idea of teamwork? Did you see this happening with the Chinese?

9. What opportunities did your training program have for the Chinese trainees to create or produce something new, individually; in a group?

Probes: Was this a problem? 
Did you perceive creativity to be a problem?

10. Would you describe the exercises in the training that required the Chinese trainees to solve problems or make decisions?

Probes: What happened? Was this a problem?

What solutions, new ways of seeing a problem, did the students come up with?

11. What opportunities did the training program have for the Chinese students to implement ideas or design a process for putting an idea into practice?

Probes: How did the trainees perform? What problems did they have?

Were the students able to come up with different ways of doing this?

Was this a problem?

12. Did you see evidence for the ability to see how one part fits into or affects a whole process? What was this evidence?

Probes: Do you consider this a problem?

13. Compared to the quality control you have in you company how would you characterize the quality control in the Chinese companies you are working with?

Probes: Do you consider this to be a problem?

14. Some managers and trainers I have interviewed have found a reluctance for personal accountability among the Chinese they have worked with. To what extent have you experienced this?

Probes: Is this a problem? Why?

15. How did you evaluate the performance of the Chinese trainees? 
Probes: How did the trainees respond to this form of evaluation? What follow-up evaluation have you done?

16. Is there anything you would like to add to our discussion?

17. What advice would you give to someone who is going to do something similar to what you did?

Probes: How could someone else avoid the problems you experienced? 


\section{APPENDIX D}

INFORMED CONSENT FORM 
I, agree to serve as a respondent in the research project entitled "Cross-Cultural Training of Chinese Managers and Chinese Workers by U. S. Companies: A Comparative Cultural Analysis of the Problems Faced by U. S. Trainers" conducted by Linda Vick under the supervision of Milton Bennett, Ph.D.

I understand that the study involves verbally responding to questions asked by Linda Vick.

It has been explained to me that the purpose of the study is to identify problems U.S. trainers have encountered when training Chinese from the People's Republic of China. The problems will then be analyzed from the perspective of Chinese values and American values to gain an under-standing of the cultural differences involved in the U. S. training context.

I may not receive any direct benefit from participation in this study, but my participation may help to increase knowledge and intercultural understanding which may benefit others in the future.

Linda Vick has offered to answer any questions I may have about the study and what is expected of me in the study. I have been assured that all information I give will be kept confidential and that my identity will be protected in any discussion of results or in any written research summary.

I understand that I am free to withdraw from participation in this study at any time without jeopardizing my relationship with Linda Vick, persons who may have referred me to this study or Portland State University.

I have read and understand the foregoing information.

Date

Signature

If you experience problems that are the result of your participation in this study, please contact the secretary of the Human Subjects Research and Review Committee, Office of Grants and Contracts, 303 Cramer Hall, Portland State University, 725-3417. 